\title{
EFFECT OF A CIDR INSERT AND FLUNIXIN MEGLUMINE ADMINISTERED AT THE TIME OF EMBRYO TRANSFER ON PREGNANCY RATE AND RESYNCHRONIZATION OF ESTRUS IN BEEF CATTLE
}

by

\section{SCOTT HUDSON PURCELL}

Thesis submitted to the Faculty of the Virginia Polytechnic Institute and State University in partial fulfillment of the requirements for the degree of

\section{MASTER OF SCIENCE}

in

Animal Science

(Physiology of Reproduction)

\section{APPROVED}

Dr. W. E. Beal, Chairman

Dr. J. B. Hall

Dr. M. A. McCann

Dr. S. R. Smith

June, 2004

Blacksburg, VA

Key Words: Embryo Transfer, CIDR, Flunixin Meglumine, Beef Cattle Copyright 2004, Scott H. Purcell 


\title{
EFFECT OF A CIDR INSERT AND FLUNIXIN MEGLUMINE ADMINISTERED AT THE TIME OF EMBRYO TRANSFER ON PREGNANCY RATE AND RESYNCHRONIZATION OF ESTRUS IN BEEF CATTLE.
}

by

\author{
Scott Hudson Purcell
}

\begin{abstract}
The objectives of this study were to evaluate the effects of flunixin meglumine (FM), an inhibitor of $\mathrm{PGF}_{2 \alpha}$ synthesis, administered at the time of embryo transfer (ET) and insertion of an intravaginal progesterone-releasing device (CIDR) at the time of ET on pregnancy rates $(P R)$ and the resynchronization of estrus. Beef cows $(n=796)$ and heifers $(n=108)$ at three locations were assigned randomly within age to one of four groups in a $2 \times 2$ factorial arrangement of treatments with injection of FM (500 mg i.m.; Phoenix Scientific, St. Joseph, MO) 2 to $12 \mathrm{~min}$ prior to ET and insertion of a CIDR (1.38 g progesterone; Pfizer, New York, NY) for $13 \mathrm{~d}$ immediately following ET as main effects. Fresh or frozen embryos (Stage $=4$ or 5 ; Grade $=1$ or 2 ) were randomly assigned to be transferred to recipients on d 6 to 9 of the estrous cycle. At Location 2 a subset of fresh embryos were split and transferred as fresh half embryos $(n=192)$. Recipients at Location 2 only $(n=493)$ were observed for signs of return to estrus beginning $9 \mathrm{~d}$ after ET. Recipients that returned to estrus at Location 2 were either bred by AI $12 \mathrm{~h}$ after estrus or received an embryo $7 \mathrm{~d}$ after estrus. Pregnancy was diagnosed by ultrasonography. Pregnancy rates were analyzed using the LOGISTIC procedure of SAS. Pregnancy rates of split embryo recipients were analyzed separately using the same statistical procedure. Variation in the timing of the return to estrus was determined by an F-test for heterogeneity of variances. Following the initial ET, pregnancy rates of recipients receiving whole embryos were not affected by CIDR administration $(P>0.05$; $65 \%$ with CIDR, 70\% without CIDR), however, there was a significant FM x location interaction on PR (Location 1, 89 vs. 57\%; Location 2, 69 vs. 64\%; Location 3, 64 vs. $67 \%$ for FM vs. no FM, respectively). There was a significant CIDR x FM interaction on PR of recipients receiving split embryos. Pregnancy rates of split embryo recipients
\end{abstract}


receiving CIDR treatment (54\%) or FM treatment alone (41\%) were less than controls (64\%). However, recipients receiving both CIDR and FM had PR similar to controls $(60 \%)$. The timing of the return to estrus was more synchronous $(P<0.01)$ for recipients fitted with a CIDR, but PR of recipients bred following a return to estrus did not differ in cows receiving or not receiving a $\mathrm{CIDR}(P>0.13 ; 68$ and $62 \%$, respectively). Effects of FM on PR were location dependent and CIDR insertion at ET improved synchrony of the return to estrus. 


\section{Acknowledgements}

These last two years at Virginia Tech have been a lot of fun, but not easy. I would like to specifically thank the following people for helping me out along the way.

Dr. Bill Beal, for being not only a great advisor but a friend as well. You've taught me a lot in the last two years. The long hours we put in inside the classroom and out were more than worth it and I've sincerely enjoyed all of it.

Mr. Lee Johnson, for answering innumerable questions and somehow always knowing the answer, from the best fishing streams and hikes to computer programs and biochemistry. I appreciate all the help.

Mr. Henry Dickerson, for teaching me a lot while working at Kentland and for being an enjoyable person to be around and work with. Thanks for all your help.

Ms. Mary Jane Thompson, I don't think I'll ever meet another secretary who does everything from grading tests to helping ultrasound cows. Thanks for everything.

Mr. Larry Kuehn, for always having an open door and taking the time to help me out with the statistics of my project.

My housemates, Mr. Ryan Horsley and Mr. Cory Smith, It's been great living with you this last year. Ryan, thanks for always being willing to help out with anything, at all hours of the day and night. I'm glad we've become friends during graduate school together. Cory, thanks for being a great friend since middle school. Thanks for sticking around those extra two years at Virginia Tech. I hope both of you make it out to Colorado sometime.

Animal and Dairy Science graduate students, Thanks for helping each other out with projects and homework and for going to downtown and having bbq's to take a break from the work.

My family, for being supportive and interested in my studies and for coming up to visit when I didn't have the time to make it home. Thanks for everything you've done for me. I'll miss you all in Colorado.

Pfizer Animal Health, for providing the CIDRs and Lutalyse used in this experiment.

Phoenix Scientific, for providing the flunixin meglumine used in this experiment.

Dr. Kirk Gray and staff at Cross Country Genetics North, Inc., for performing all of the embryo transfers in this experiment.

Alyward Ranch, Gardiner Angus Ranch, and Larson Ranch, for their willingness to participate in this experiment. 


\section{Table of Contents}

Chapter 1 Introduction ......................................................................................................1

Chapter 2 Review of literature .....................................................................................................3

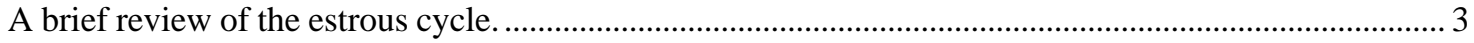

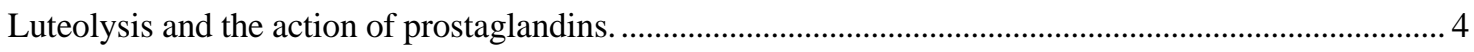

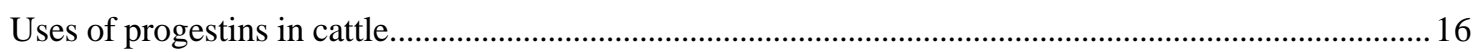

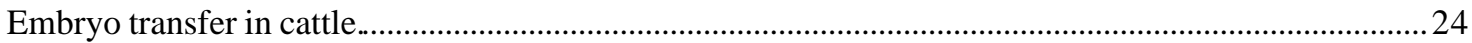

Chapter 3 Rationale and Experimental Objectives...............................................................30

Chapter 4 Materials and Methods ...............................................................................................31

Chapter 5 Results..............................................................................................................................39

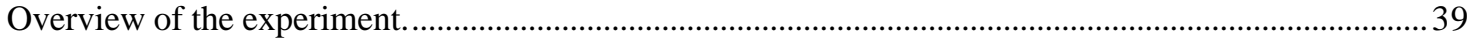

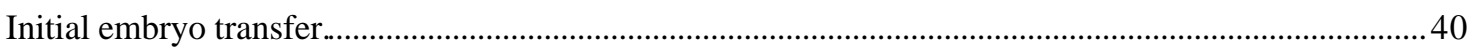

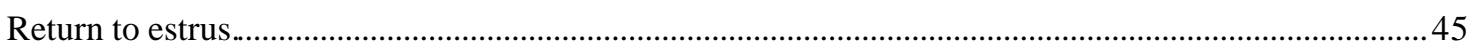

Chapter 6 Discussion ........................................................................................................................49

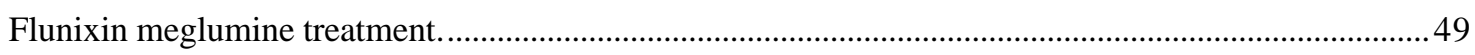

CIDR treatment.

Treatment x Location interaction. ........................................................................................................5

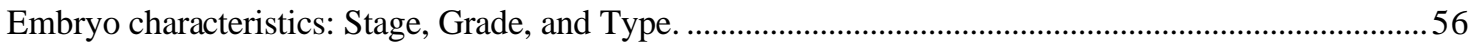

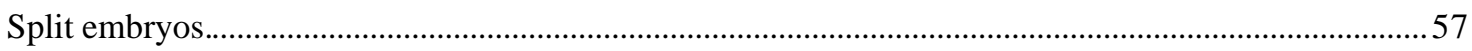

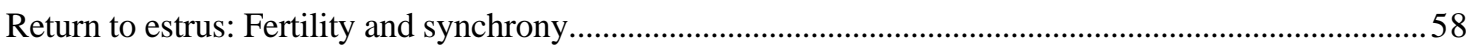

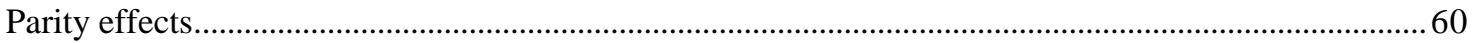

Chapter 7 Implications ................................................................................................................61

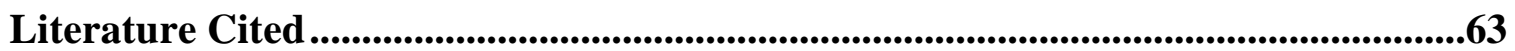

Appendices...........................................................................................................................................72

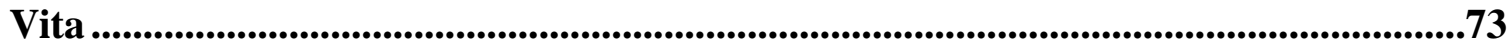




\section{List of Figures}

Figure 2.1 . Prostaglandin synthesis pathways. ....................................................................................... 11

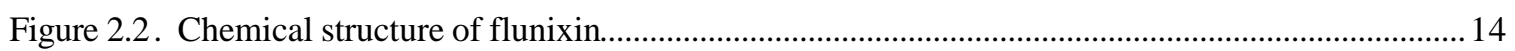

Figure 2.3. Pregnancy rates after transfer of Grade 1, 2, or 3 embryos in cows treated with flunixin

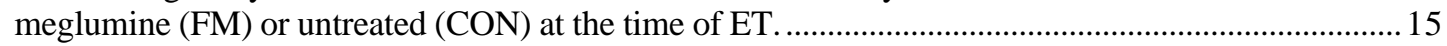

Figure 4.1. Diagrammatic represent ation of experimental design: Initial ET. ....................................................

Figure 4.2. Number of animals assigned to each $2 \times 2$ factorial treatment group.......................................... 36

Figure 4.3. Diagrammatic representation of experimental design: Resynchronization of estrus for AI or ET

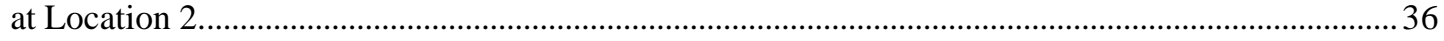

Figure 5.1a. Mean pregnancy rate \pm SEM of embryo recipients by FM treatment at each location. ............ 42

Figure 5.1b. Mean pregnancy rate \pm SEM of embryo recipients by CIDR treatment at each location........ 43

Figure 5.2. Mean pregnancy rate \pm SEM of embryo recipients by treatment for split embryos at Location 2 . (n)

Figure 5.3. Time of the return to estrus of those animals that did not become pregnant to the initial ET. ..46

Figure 5.4. Mean pregnancy rate \pm SEM by CIDR treatment and embryo grade for those animals bred by

ET after a return to estrus................................................................................................................... 48 


\section{List of Tables}

Table 2.1 Effect of synchrony between the donor and recipient on pregnancy rates of recipients following ET

Table 4.1. Standardized classification of bovine embryos based on stage of development. International

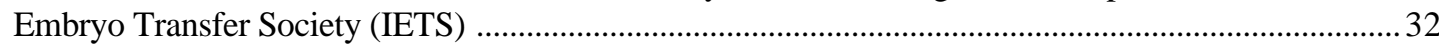

Table 4.2. Standardized classification of bovine embryos based on quality. International Embryo Transfer

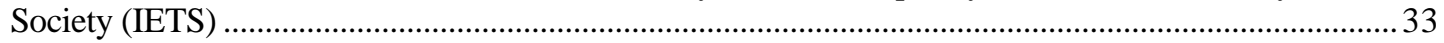

Table 5.1. Pregnancy rate in recipients that varied in synchrony between the stage of the estrous cycle of the recipient and the stage of embryo development............................................................................... 40

Table 5.2. Mean pregnancy rate of embryo recipients that received embryos with different embryo quality

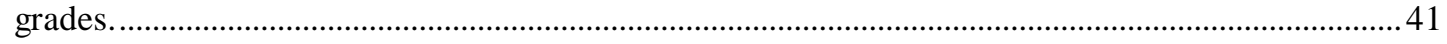

Table 5.3. Mean pregnancy rate of embryo recipients that received a fresh or frozen embryo..................... 41

Table 5.4. Mean pregnancy rate of embryo recipients by treatment administered.........................................42

Table 5.5. Mean pregnancy rate of embryo recipients receiving split Stage 4 or 5 embryos......................... 44

Table 5.6. Mean pregnancy rate of embryo recipients receiving split embryos by parity.............................. 44

Table 5.7. Mean pregnancy rate of parous (P) and non-parous (NP) animals bred by AI following a return

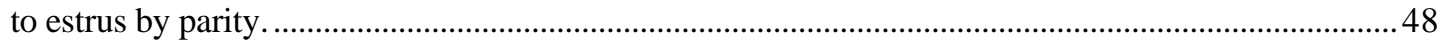




\section{Chapter 1 Introduction}

Embryo mortality (EM) contributes more to pregnancy failure in cattle than does fertilization failure. The majority of EM occurs early in pregnancy $(<\mathrm{d} 25)$, especially during a "critical period" when major physiological changes take place in the pregnant animal. During the "critical period" (d 15 to 17) maternal recognition of pregnancy (MRP) must occur to ensure the prevention of luteolysis and the maintenance of the corpus luteum (CL). Maternal recognition of pregnancy is a complex set of events and failure of any component, either through an intrinsic disruption or through an external stressor, may cause pregnancy failure.

This period of high EM is also the time period that embryo transfer (ET) is performed in cattle. The transfer of embryos in cattle occurs on approximately $\mathrm{d} 7$ of the estrous cycle. An embryo collected from a genetically superior donor animal on $\mathrm{d} 7$ is transferred to a recipient whose estrous cycle is in close synchrony with the donor animal. The procedures involved during the transfer of an embryo include transrectal palpation of the uterus in order to place the embryo deep into the uterine horn ipsilateral to the CL. This uterine manipulation may cause the release of prostaglandin $\mathrm{F}_{2 \alpha}\left(\mathrm{PGF}_{2 \alpha}\right)$ from the uterus. Prostaglandin $\mathrm{F}_{2 \alpha}$ has been implicated in pregnancy loss. Prostaglandin $\mathrm{F}_{2 \alpha}$ release may cause luteolysis or act through a direct effect on the developing embryo. Prevention of $\mathrm{PGF}_{2 \alpha}$ release by administration of compounds that prevent its synthesis is currently being investigated as a method of improving pregnancy rates in embryo recipients.

Not all embryo recipients will become pregnant to ET under the best of circumstances, and those that do not will exhibit estrus again 18 to $24 \mathrm{~d}$ after their previous estrus. Estrus must be observed over a period of time due to biological variation in animals. In addition estrus can be missed due to human error. Resynchronization protocols have aimed to decrease the variation in the return to estrus through the use of progestins. In order to decrease the time interval between services, resynchronization protocols are applied to all animals after breeding, when they are of an unknown pregnancy status. Therefore, effective resynchronization protocols must not only result in the majority of animals being in estrus in a short time period, but must not have a detrimental effect on established pregnancies. 
This thesis will describe literature related to $\mathrm{PGF}_{2 \alpha}$ induced $\mathrm{EM}$ and methods to prevent its occurrence. Literature related to progestin based resynchronization protocols will also be discussed. Finally, an experiment will be described that was designed to test the hypothesis that administration of a $\mathrm{PGF}_{2 \alpha}$ inhibitor and a progesterone-containing intravaginal insert at the time of ET would improve pregnancy rates of embryo recipients and resynchronize the return estrus of recipients that did not conceive to the initial ET. 


\section{Chapter 2 Review of literature}

A brief review of the estrous cycle.

Polyestrus animals, such as the cow, exhibit regular estrous cycles throughout the year. In the cow, estrous cycles average $21 \mathrm{~d}$ in length. During each estrous cycle there is a long progesterone $\left(\mathrm{P}_{4}\right)$ dominated luteal phase and a shorter estrogen $\left(\mathrm{E}_{2}\right)$ dominated follicular phase (Senger, 1999). There are two or three waves of follicular growth during an estrous cycle. Emergence of follicular waves are caused by surges of follicle stimulating hormone (FSH) released from the anterior pituitary (Adams, 1999). Follicles in each wave go through recruitment, selection, dominance, and atresia with the dominant follicle of the last wave escaping atresia and becoming the ovulatory follicle (Senger, 1999). As FSH levels decline, a dominant follicle becomes dependent on luteinizing hormone (LH) from the anterior pituitary through the development of LH receptors (Adams, 1999).

After ovulation, the granulosa and thecal cells of the dominant follicle undergo morphological changes and become the CL, which secretes $\mathrm{P}_{4}$. Progesterone production and the size of the CL both increase until the mid-luteal phase of the estrous cycle, at which time both CL size and $\mathrm{P}_{4}$ production plateau (McCracken et al., 1999). Progesterone downregulates $\mathrm{E}_{2}$ receptors and restricts $\mathrm{LH}$ and FSH secretion to lowfrequency pulses during the luteal phase through a negative feedback on gonadotropin releasing hormone $(\mathrm{GnRH})$ in the hypothalamus (Niswender et al., 2000). If the oocyte released from the dominant follicle is not fertilized, luteolysis is initiated by endometrial PGF $_{2 \alpha}$ released between d 15 and 17 of the cycle (Arosh et al., 2002).

Oxytocin (OT) from the CL and posterior pituitary and $\mathrm{PGF}_{2 \alpha}$ from the uterus are involved in a positive-feedback loop to cause luteolysis (McCracken et al., 1999). As a result of luteolysis, decreased $\mathrm{P}_{4}$ removes the negative feedback on GnRH to cause increased frequency and amplitude of LH and FSH release (Adams, 1999). The increased gonadotropin secretion allows increased $\mathrm{E}_{2}$ from the dominant follicle to act on the surge center of the hypothalamus causing the release of $\mathrm{GnRH}$, which is followed by an LH surge that induces ovulation and begins a new cycle (Niswender et al., 2000; Thatcher et al., 2001b). This series of events allows a female another opportunity to conceive again in a relatively short amount of time if pregnancy did not occur 
(McCracken et al., 1999). If fertilization has occurred, the luteolytic signal is blocked and the CL continues to secrete $\mathrm{P}_{4}$ to maintain the pregnancy.

Luteolysis and the action of prostaglandins.

Prostaglandin $\mathrm{F}_{2 \alpha}$ is the luteolytic substance produced by the uterus in cattle (McCracken et al., 1973). Many hormones are involved in luteolysis, which requires communication between the uterus, hypothalamus, pituitary, and ovary. Luteolysis is characterized by an initial decline in $\mathrm{P}_{4}$ known as functional luteolysis, followed by regression of the CL, or structural luteolysis (McCracken et al., 1999). McCracken et al. (1999) proved that uterine $\mathrm{PGF}_{2 \alpha}$ has a unilateral effect on the CL. Removal of the uterine horn ipsilateral to the CL increased the lifespan of the CL, while removal of the uterine horn contralateral to the CL had no effect on estrous cycle length.

The release of OT is involved in $\mathrm{PGF}_{2 \alpha}$ secretion from the uterus by a positivefeedback loop. Progesterone inhibits OT action during the early-luteal phase of the estrous cycle by inhibiting $\mathrm{E}_{2}$-induced OT receptor (OTR) formation and by a direct effect on OTR gene transcription. This period, known as $\mathrm{P}_{4}$ priming, has been implicated in aiding $\mathrm{PGF}_{2 \alpha}$ production by causing increased lipid accumulation and increased prostaglandin synthase activity (McCracken et al., 1999). Toward the end of the luteal phase of the estrous cycle, (d 12) $\mathrm{P}_{4}$ downregulates its own receptors. This allows $\mathrm{E}_{2}$ to stimulate the hypothalamic OT pulse generator to secrete high-frequency OT pulses that upregulate endometrial OTR and cause the release of low levels of $\mathrm{PGF}_{2 \alpha}$ from the uterus. These low levels of $\mathrm{PGF}_{2 \alpha}$ stimulate the high affinity $\mathrm{PGF}_{2 \alpha}$ receptors in the $\mathrm{CL}$ and cause luteal OT release (McCracken et al., 1999). The period of $\mathrm{P}_{4}$ priming is critical for $\mathrm{PGF}_{2 \alpha}$ release. Ovariectomized cows that did not receive $\mathrm{P}_{4}$ for $12 \mathrm{~d}$ did not exhibit an increase in OTR or a luteolytic response to OT injection as measured by the $\mathrm{PGF}_{2 \alpha}$ metabolite, 13, 14-dihydro-15-keto prostaglandin $\mathrm{F}_{2 \alpha}$ (PGFM; Lamming and Mann, 1995). Luteal OT amplifies the release of uterine $\mathrm{PGF}_{2 \alpha}$ to activate the low-affinity $\mathrm{PGF}_{2 \alpha}$ receptor in the $\mathrm{CL}$, which inhibits $\mathrm{P}_{4}$ production. In summary, the neural signal (OT) is converted by the uterus into uterine $\mathrm{PGF}_{2 \alpha}$ pulses that cause luteolysis

(McCracken et al., 1999). 
Prostaglandins are rapidly metabolized in the cow, sow, and ewe (Greenspan and Gardner, 2001). In the cow, $65 \%$ of $\mathrm{PGF}_{2 \alpha}$ is metabolized in one pass through the pulmonary system, therefore a countercurrent exchange mechanism between the uterine vein and ovarian artery exists to insure adequate $\mathrm{PGF}_{2 \alpha}$ released from the uterus reaches the ovary to cause luteolysis (McCracken et al., 1999). The ovarian artery is intertwined in close proximity to the utero-ovarian vein, allowing low molecular weight substances, such as $\mathrm{PGF}_{2 \alpha}$, to diffuse from the uterine vein to the ovarian artery and thereby escape metabolism in the systemic circulation (Senger, 1999). McCracken et al. (1971) were the first to demonstrate the countercurrent exchange mechanism by infusing $\left[{ }^{3} \mathrm{H}\right] \mathrm{PGF}_{2 \alpha}$ into the uterine vein and measuring its level in the ovarian artery in sheep. Later the same authors observed that even low levels $\left(\sim 1 \%\left[{ }^{3} \mathrm{H}\right] \mathrm{PGF}_{2 \alpha}\right)$ infused into the uterine vein could bypass the systemic circulation and reach the ovary directly (McCracken et al., 1972). This countercurrent exchange mechanism, first described in sheep was also demonstrated to be present in the cow (Hixon and Hansel, 1974).

Prostaglandin $\mathrm{F}_{2 \alpha}$ acts as a luteolysin through $\mathrm{G}$-protein receptors coupled to phospholipase C (PLC) which generate the second messengers inositol triphosphate $\left(\mathrm{IP}_{3}\right)$ and diacyl glycerol (DAG; Arosh et al., 2004a). Diayl glycerol and $\mathrm{IP}_{3}$ cause the activation of protein kinase $\mathrm{C}(\mathrm{PKC})$ and the release of intracellular calcium $\left(\mathrm{Ca}^{++}\right)$, respectively. Protein kinase $\mathrm{C}$ and $\mathrm{Ca}^{++}$have been implicated in the luteolytic action of $\mathrm{PGF}_{2 \alpha}$ (McCracken et al., 1999; Niswender et al., 2000). The cellular mechanism of how $\mathrm{PGF}_{2 \alpha}$ causes luteolysis in cattle is not completely understood. Theories include: decreased blood flow to the CL; mediation through leukotrienes or endothelin-1; and inhibition of steriodogenic acute regulatory protein (StAR; McCracken et al., 1999; Niswender et al., 2000). The inhibition of StAR is the most commonly accepted theory.

The rate-limiting step in $\mathrm{P}_{4}$ production is the transport of cholesterol by StAR to the inner mitochondrial membrane where it is cleaved to pregnenolone by the side chain cleavage enzyme ( $P$-450scc; Clark et al., 1994). Transport of cholesterol appears to be the primary point of negative regulation of $\mathrm{P}_{4}$ by $\mathrm{PGF}_{2 \alpha}$ (Niswender et al., 2000). Morphological changes in the CL during luteolysis are not evident until 24 to $36 \mathrm{~h}$ after exposure to $\mathrm{PGF}_{2 \alpha}$ (Niswender et al., 2000). Structural luteolysis in the cow is possibly 
mediated through a variety of factors such as apoptosis, disruption of gap junctions, immune cells, monocyte chemoattractant protein-1, metalloproteinases, and tumor necrosis factor- $\alpha$ (McCracken et al., 1999).

Establishment of pregnancy.

Pregnancy recognition depends on the inhibition of luteolysis and the maintenance of the CL past the point of normal luteal regression (Binelli et al., 2001). In cattle the CL must be maintained throughout gestation (Niswender et al., 2000). Progesterone from the CL induces myometrial quiescence through decreased uptake of extracellular $\mathrm{Ca}^{++}$and suppresses the maternal immune response to fetal antigens (McCracken et al., 1999; Niswender et al., 2000). A biochemical communication between the bovine conceptus and the maternal unit is also required for MRP (Niswender et al., 2000). A live embryo in the uterine horn ipsilateral to the CL, capable of secreting conceptus proteins during the time of luteolysis is necessary for MRP (Schrick et al., 1999).

Interferon- $\tau($ IFN $\sim \tau)$ was demonstrated to be the antiluteolytic substance produced by the mononuclear cells of the trophoblast of the developing bovine embryo (Thatcher et al., 1997). In cows with a healthy conceptus, secretion of IFN $\tau$ is increased around the time of luteolysis (d 17 to 18 after estrus) in cattle (Bartol et al., 1985). Progesterone and IFN $\sim$ have been reported to be dependent on each other to maintain pregnancy (Mann et al., 1999). In a study by Mann et al. (1999), cows with higher plasma $\mathrm{P}_{4}$ on $\mathrm{d} 15$ to 17 after breeding had larger conceptuses that produced more IFN $\tau$. The amplification and sustained secretion of IFN $\sim$ requires exposure to the uterine environment (Thatcher et al., 1997).

There are various theories as to the cellular mechanism of decreased $\mathrm{PGF}_{2 \alpha}$ secretion through the action of IFN $\sim \tau$. First, IFN $\tau$ could alter gene expression to inhibit expression of molecules involved in $\mathrm{PGF}_{2 \alpha}$ biosynthesis. Interferon $\tau$ inhibits production of COX-2, an enzyme involved in the biosynthesis of prostaglandins (Thatcher et al., 2001a). A second possible mechanism is through the synthesis of molecules such as kinases, phosphatases, and lipases, which could directly inhibit $\mathrm{PGF}_{2 \alpha}$ biosynthesis (Thatcher et al., 1997). Additionally, IFN $\tau$ has suppressed the 
transcription of genes that encode for $\mathrm{E}_{2}$ and OT receptors, necessary components of luteolysis (Thatcher et al., 1997; Spencer and Bazer, 2002).

During early pregnancy substances other than IFN $\tau$ may aid in promoting maintenance of the $\mathrm{CL}$. Prostaglandin $\mathrm{E}_{2}\left(\mathrm{PGE}_{2}\right)$, produced by the uterine endometrium is a stimulator of cAMP and a potent vasodilator. Both properties are opposite the effects of $\mathrm{PGF}_{2 \alpha}$. (McCracken et al., 1999). It has been proposed that IFN $\tau$ may cause production $\mathrm{PGE}_{2}$ instead of $\mathrm{PGF}_{2 \alpha}$ in response to OT in bovine endometrial cells (Asselin et al., 1997). In cows and sheep $\mathrm{PGE}_{2}$ caused increased $\mathrm{P}_{4}$ secretion by luteal cells in vitro (Niswender et al., 2000).

Failure to establish pregnancy and embryo mortality.

Fertilization rates are high (80 to 95\%) in cattle, suggesting that EM is the major source of reproductive loss (Sreenan and Diskin, 1983). Recent estimates of EM in cattle are at 20 to 40\% (Zavy and Geisert, 1994; Lopez-Gatius et al., 1996; Hanzen et. al., 1999). There are a variety of potential causes of EM including: chromosomal abnormalities; failure of MRP; environmental stresses such as heat and toxins; and infectious diseases (Hansen, 2002). Early embryonic losses ( $<\mathrm{d} 20$ after mating) may account for as much as $80 \%$ of all EM (Sreenan and Diskin, 1983). Others have estimated that $40 \%$ of all EM occurred before or at the time of MRP (between d 8 and 17; Thatcher et al., 1994).

As described above, the maintenance of the CL, and its production of $\mathrm{P}_{4}$ are essential for maintenance of pregnancy. Anything that induces the release of $\mathrm{PGF}_{2 \alpha}$ could cause luteolysis and loss of pregnancy. The systemic effects of infectious diseases have caused the release of prostaglandins, and in turn caused luteolysis and abortion (Vanroose et al., 2000). In dairy cattle, OT may be administered to improve milk letdown. Studies have indicated that OT administration can result in elevated $\mathrm{PGF}_{2 \alpha}$ and the occurrence of short estrous cycles (Farin and Estill, 1993; Lemaster et al., 1999).

Uterine manipulation can cause the release of $\mathrm{PGF}_{2 \alpha}$ from the uterus. This effect is known as the Ferguson Reflex (Ferguson, J.W.K., 1941). In multiparous Brahman cows, uterine manipulation $35 \mathrm{~d}$ after calving for 2 min caused an increase in PGFM. Primiparous cows however, did not exhibit an increase in PGFM in response to uterine manipulation (Wann and Randel, 1990). The release of $\mathrm{PGF}_{2 \alpha}$ in association with uterine 
manipulation could potentially be detrimental during artificial insemination (AI) or the transfer of an embryo. During the AI procedure, the uterus is manipulated in order to pass the insemination rod through the cervix and into the uterine body. In a study by Schallenberger et al. (1989), four out of eight heifers had increased plasma $\mathrm{PGF}_{2 \alpha}$ within 10 min after AI. During ET, the uterus is handled in order to correctly place the embryo deep in the uterine horn ipsilateral to the CL. In difficult transfers, or transfers by an inexperienced technicians, the uterus may be manipulated to a greater extent. Schrick et al. (2003) presented data that indicated a significant decrease in pregnancy rate following ET as transfer difficulty increased. The authors speculated that this could have been due to $\mathrm{PGF}_{2 \alpha}$ release. However, Odensvik et al. (1993) reported no significant increase in PGFM as measured every $10 \mathrm{~min}$ from $50 \mathrm{~min}$ before ET to $5 \mathrm{~h}$ after ET. Another possible cause of $\mathrm{PGF}_{2 \alpha}$ release during ET is the placement of the catheter through the cervix into the uterus, which could cause irritation of the reproductive tract and subsequent inflammation (Odensvik et al., 1993).

Prostaglandin $\mathrm{F}_{2 \alpha}$ may have a direct effect on the embryo in reducing pregnancy rates. In vitro treatment of eight-cell rat embryos with $\mathrm{PGF}_{2 \alpha}$ prevented development to morula stage, and in-vitro treatment of eight-cell rabbit embryos with $\mathrm{PGF}_{2 \alpha}$ prevented development to the expanded- or hatched-blastocyst stage (Maurer and Beier, 1976; Breuel et al., 1993). Schrick et al. (2003) conducted two experiments to study the effect of $\mathrm{PGF}_{2 \alpha}$ on the development of bovine embryos. In the first experiment, pre-compacted in-vitro-produced 16- to 32- cell stage embryos were cultured for $4 \mathrm{~d}$ with $0,1,10$, or100 $\mathrm{ng} / \mathrm{mL} \mathrm{PGF}_{2 \alpha}$ or $5 \mathrm{ng} / \mathrm{mL} \mathrm{PGE}_{2}$. Compaction in bovine embryos refers to the formation of cell-cell adhesions that allow blastomeres to differentiate into the trophectoderm and the inner cell mass. It normally occurs at the 16- to 32- cell stage of embryo development. Prostaglandin $\mathrm{E}_{2}$ was used as a positive control and to ensure any effects were specifically due to $\mathrm{PGF}_{2 \alpha}$. Blastocyst development was reduced in pre-compacted embryos cultured with $\mathrm{PGF}_{2 \alpha}$. There was no difference in blastocyst development between embryos in the control and $\mathrm{PGE}_{2}$ treatments. In a second experiment, in-vivoderived morula-stage embryos were cultured with $0,0.1,1$, or10 ng/mL $\mathrm{PGF}_{2 \alpha}$ for $24 \mathrm{~h}$ and evaluated for development. Development of morula-stage embryos to the blastocyst 
stage was not affected by $\mathrm{PGF}_{2 \alpha}$, however, hatching rates of $\mathrm{PGF}_{2 \alpha}$-treated embryos were significantly less than controls.

During the hatching process, the volume of blastocoel fluid is increased through an osmotic gradient created by $\mathrm{Na}^{+}$transport to the interior of the embryo facilitated through a $\mathrm{Na}^{+}-\mathrm{K}^{+}$ATPase in the trophectoderm cells of the embryo (MacPhee et al., 2000). The decreased hatching rates could be related to altered $\mathrm{Na}^{+}$transport.

Prostaglandin $\mathrm{F}_{2 \alpha}$ has been reported to cause altered $\mathrm{Na}^{+}$transport across the trophectoderm, whereas a prostaglandin inhibitor increased the catalytic activity of $\mathrm{Na}^{+}-$ $\mathrm{K}^{+}$-ATPase (Kim and Yeoun, 1983; Lee et al., 2004).

Seals et al. (1998) conducted an experiment to determine the effects of $\mathrm{PGF}_{2 \alpha}$ on pregnancy rates in $\mathrm{P}_{4}$ supplemented cows with or without luteal tissue. Ninety-one beef cows were randomly assigned to receive saline $(\mathrm{CON}), 15 \mathrm{mg} \mathrm{PGF}_{2 \alpha}(\mathrm{PGF})$, or $15 \mathrm{mg}$ $\mathrm{PGF}_{2 \alpha}+$ lutectomy $(\mathrm{P}+\mathrm{L})$ during one of three periods of embryonic development; $\mathrm{d} 5$ to 8, d 10 to 13 , or d 15 to 18 after mating in a $3 \times 3$ factorial arrangement of treatments. All cows were fed $4 \mathrm{mg} / \mathrm{d}$ melengesterol acetate (MGA) beginning $2 \mathrm{~d}$ before treatments until d 30 after mating. When fed at a rate of $4 \mathrm{mg} / \mathrm{head} / \mathrm{d}$ MGA can inhibit estrus and maintain pregnancy. Plasma PGFM concentrations during all treatment periods were elevated in $\mathrm{PGF}$ and $\mathrm{P}+\mathrm{L}$ treatments compared to controls. Pregnancy rates of cows were reduced by $48 \%$ in PGF (5-8) compared to CON. However, pregnancy rates tended to increase in the PGF group across treatment periods. Lutectomy tended to improve pregnancy rates of cows in $\mathrm{P}+\mathrm{L}$ group (5-8) compared to PGF (5-8).

These data suggest that the embryo developing from a morula to an expanded blastocyst ( $\mathrm{d} 5$ to 8 ) is most susceptible to the direct negative effects of exogenous $\mathrm{PGF}_{2 \alpha}$. In addition, removal of luteal tissue decreased the negative effect of $\mathrm{PGF}_{2 \alpha}$ and may have acted through a disruption of the luteal OT-uterine $\mathrm{PGF}_{2 \alpha}$ positive feedback loop (Seals et al., 1998). Antiluteolytic strategies.

Any improvement in pregnancy rates or decrease in EM will lead to a greater numbers of calves produced. Due to the large degree of EM that occurs prior to and at the period of MRP, much research has been concentrated on strategies applied during that time to improve pregnancy rates. 
Binelli et al. (2001) identified six antiluteolytic strategies for improving pregnancy rates: increase the size of the pre-ovulatory follicle to generate a larger CL; increase the growth rate of the CL; increase luteal phase $\mathrm{P}_{4}$; decrease the effect of a dominant follicle on the critical period; increase the antiluteolytic stimulation by the conceptus unit; and decrease the luteolytic response of the maternal unit. This thesis will focus on two of these strategies; decreasing the luteolytic response of the maternal unit, and increasing the luteal phase $\mathrm{P}_{4}$.

Mechanism of prostaglandin synthesis.

To understand how uterine $\mathrm{PGF}_{2 \alpha}$ release can be prevented it is first necessary to understand prostaglandin synthesis. The site of prostaglandin synthesis in the uterus is the endometrium (McCracken et al., 1999). Prostaglandins belong to a class of compounds known as eicosanoids, which are derived from polyunsaturated fatty acids with 18-, 20-, or 22-carbon skeletons. Other examples of eicosanoids include prostacylins, thromboxanes, leukotrienes, and epoxyeicosatrienoic acids. The biosynthesis of prostaglandins takes place in three steps (Figure 2.1): first, hydrolysis of archidonic acid by phospholipases; second, the oxidation and reduction of archidonic acid to prostaglandin $\mathrm{H}_{2}$ by endoperoxide synthases, and last the conversion of $\mathrm{PGH}_{2}$ to biologically active end products by specific synthases (Smith et al., 2000; Arosh et al., 2002).

The precursor to all prostaglandins is the 20-carbon lipid arachidonic acid (cis5,8,11,14-eicosatetraenoic acid; Greenspan and Gardner, 2001; Arosh et al., 2004b). Arachidonic acid is stored in membrane phospholipids (Greenspan and Gardner, 2001; Arosh et al., 2004b). Late in the estrous cycle, the increased OT from the CL and posterior pituitary binds to OTR in the luminal epithelium of the endometrium, activating phospholipase $\mathrm{C}$ which metabolizes phosphatidylinositol bisphosphate (PI) into inositol triphosphate $\left(\mathrm{IP}_{3}\right)$ and diacylglycerol (DAG; Goff, 2004). These messengers enhance phospholipase $\mathrm{A}_{2}\left(\mathrm{PLA}_{2}\right)$ activity (Thatcher et al., 1997). Esterified arachidonic acid is released from the phospholipid bilayer by hydrolytic cleavage by $\mathrm{PLA}_{2}$ 


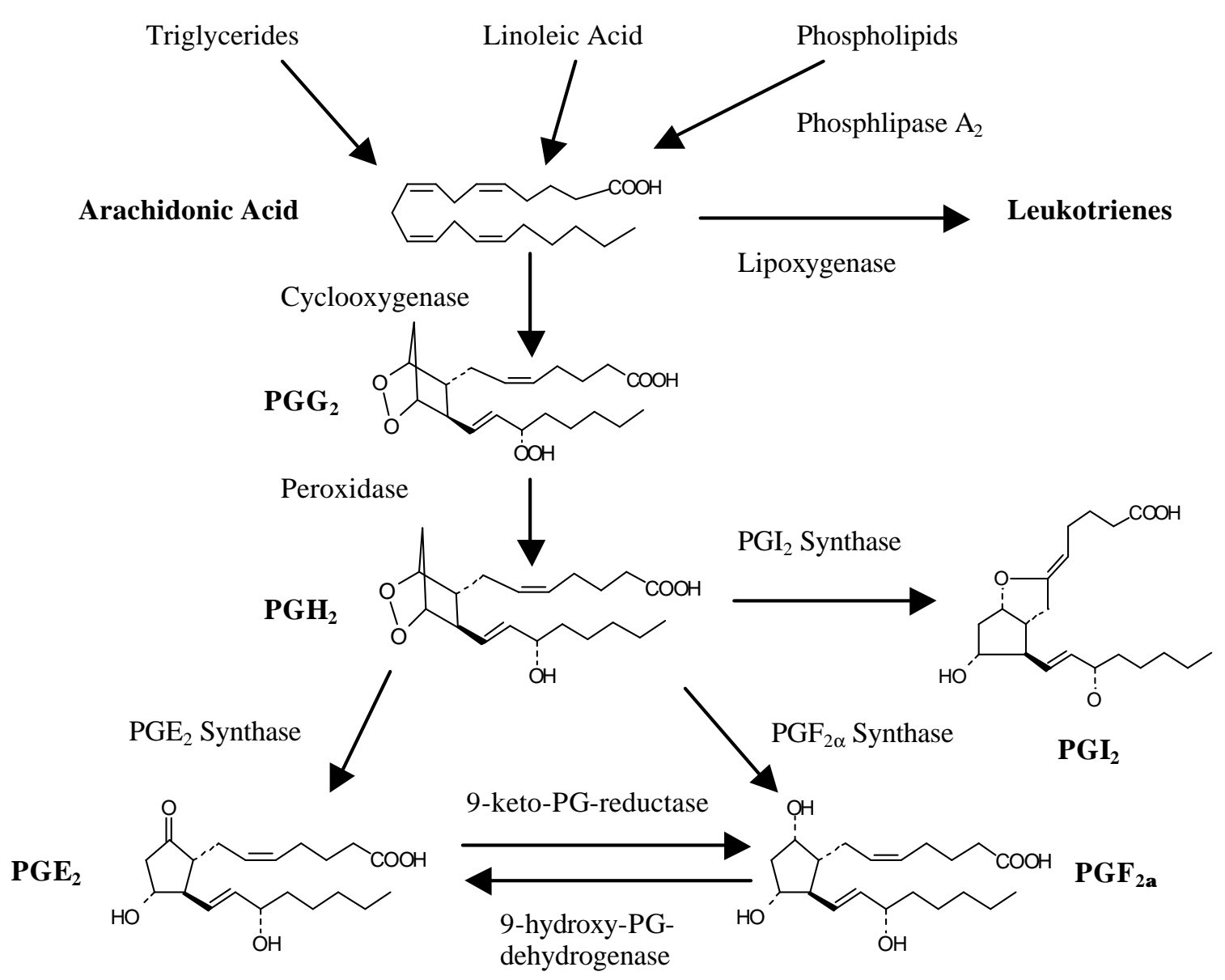

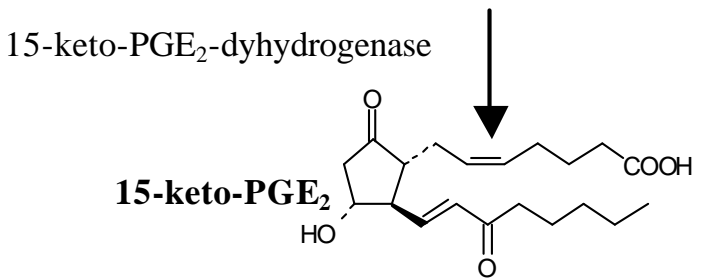

$13,14-\mathrm{PGE}_{2}$-reductase

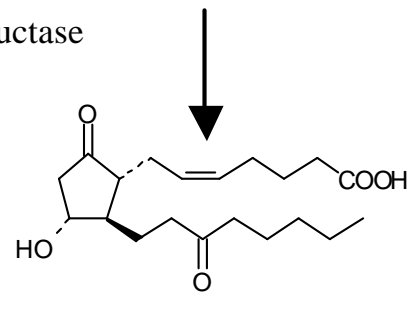

13,14-dihydro-15-keto-PGE
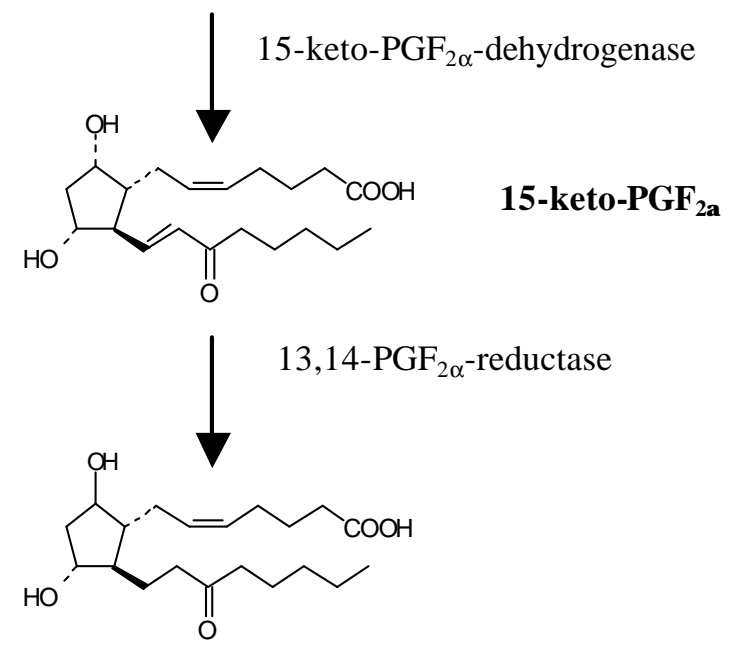

13,14-dihydro-15-keto-PGF ${ }_{2 \alpha}$

Figure 2.1. Prostaglandin synthesis pathways.

Arachidonic acid is liberated from the phospholipids and converted to $\mathrm{PGH}_{2}$ by endoperoxide synthases (COX-1 and COX-2). Specific synthases form other prostaglandins (adapted from Seals, 2000). 
Following its release, arachidonic acid enters either the linear pathway, leading to the formation of leukotrienes, or the cyclic pathway, leading to the formation of prostaglandins and thromboxanes. Newly-formed prostaglandins are predominately charged anions which diffuse poorly across plasma membranes, therefore they are transported by prostaglandin transporter (PGT) to their site of action (Arosh et al., 2004b).

\section{Prevention of PGF synthesis.}

The two rate-limiting factors in $\mathrm{PGF}_{2 \alpha}$ secretion are the availability of arachidonic acid and the availability of endoperoxide synthases (Thatcher et al., 1997; Figure 2.1). These synthases, also known as cyclooxygenases, are found in two isoforms, the constitutive COX-1 and the inducible COX-2 (Vane and Botting, 1998). Arosh et al. (2004b) studied the expression of both COX-1 and COX-2 mRNA in large and small luteal cells during the life span of the bovine CL. They reported that COX-2 mRNA was present on $\mathrm{d} 7$ to 17 while COX-1 mRNA was expressed at low levels during the entire life of the CL. During the bovine estrous cycle expression of endometrial COX-2 mRNA was significantly greater between d 13 to 21 compared to $d 1$ to 12 (Arosh et al., 2002). These studies indicate that COX-2 expression is increased later in the estrous cycle, near the time of luteolysis when $\mathrm{PGF}_{2 \alpha}$ secretion from the uterine endometrium is increased. During pregnancy, COX-2 mRNA expression was significantly greater in the bovine uterine and fetal membrane during early $(<50 \mathrm{~d})$ pregnancy and late pregnancy $(>250 \mathrm{~d})$ than mid-pregnancy, while COX-1 mRNA was expressed at low levels throughout gestation (Arosh et al., 2004a).

Certain compounds have the ability to inhibit the action of cyclooxygenases. Some polyunsaturated fatty acids inhibit prostaglandin synthesis by inhibiting cyclooxygenase activity and by competing with arachidonic acid for processing by those enzymes. Thatcher et al. (1994) reported that linoleic acid inhibited endometrial prostaglandin synthesis by inhibition of COX-2 activity in vitro. Additionally, linoleic acid was in greater concentrations in the uterine endometrium than arachidonic acid in $\mathrm{d}$ 17 pregnant cows compared to non-pregnant cows. Lactating dairy cows that received abomasal infusions of yellow grease (high linoleic acid content) released less PGF $_{2 \alpha}$ in response to an OT challenge on d 15 of the estrous cycle (Oldick et al., 1997). 
Eicosapentaenoic acid (EPA) and docosahexaneoic acid (DPA) are two other fatty acids that inhibit prostaglandin release. Eicosapentaenoic acid and DPA are processed into the less biologically active prostanoids of the 3 series by $\mathrm{PLA}_{2}$ and cyclooxygenase enzymes in the prostaglandin biosynthetic pathway (Thatcher et al., 2001a).

Eicosapentaenoic acid and DPA inhibited $\mathrm{PGF}_{2 \alpha}$ secretion by bovine endometrial cells in vitro (Mattos et al., 2001). High concentrations of EPA and DPA are found in menhaden fishmeal (Binelli et al., 2001; Mattos et al., 2002). Mattos et al. (2002) fed lactating dairy cows diets containing $0,2.6,5.2$, or $7.8 \%$ menhaden fishmeal for $50 \mathrm{~d}$. After 30 to $34 \mathrm{~d}$ on the diets estrus ( $\mathrm{d} 0$ ) was synchronized and on $\mathrm{d} 15$ of the subsequent estrous cycle $\mathrm{E}_{2}$ and OT were injected to induce $\mathrm{PGF}_{2 \alpha}$ release. Cows fed any diet containing fishmeal had reduced plasma PGFM concentrations after the $\mathrm{E}_{2}$-OT challenge than cows receiving no fishmeal (Mattos et al., 2002). Thatcher et al. (1997) also reported that lactating dairy cows fed menhaden fishmeal for $25 \mathrm{~d}$ released less PGFM in response to an $\mathrm{E}_{2}$ and OT injection on d 15 after estrus.

Another method of inhibiting prostaglandin release is through the use of nonsteroidal anti-inflammatory drugs (NSAIDs). Dr. Heinrich Dreser introduced the first NSAID, aspirin, in 1899 (Vane and Botting, 1998). The main actions of NSAIDs are antipyretic, anti-inflammatory and analgesic. These actions are mediated by the prevention of prostaglandin synthesis. This is accomplished through the inhibition of the cyclooxygenase enzymes (COX-1 and COX-2) involved in the formation of prostaglandins (Figure 2.1).

Flunixin meglumine (FM; Figure 2.2), is a NSAID approved for use in cattle and horses. Flunixin meglumine is a cyclooxygenase inhibitor. The manufacturer's recommendation for the use of FM is "for the control of pyrexia and inflammation in beef and non-lactating dairy cattle" (Phoenix Scientific, St. Joseph, MO). However, researchers have found other extra-label applications, specifically in the area of reproduction.

Odensvik et al. (1998) studied the effects of feeding FM granules $(2.2 \mathrm{mg} / \mathrm{kg}$ of body weight) on the length of the estrous cycle and maintenance of the CL. Heifers received FM orally twice, thrice, or four-times-daily for a $9 \mathrm{~d}$ period beginning on $\mathrm{d} 14$ or 15 of the estrous cycle. 


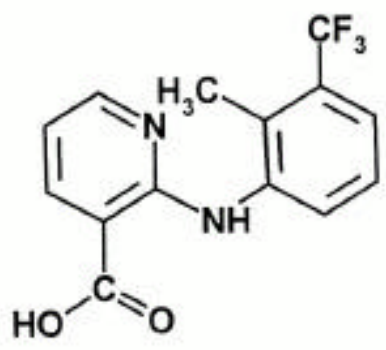

Figure 2.2. Chemical structure of flunixin

Average estrous cycle length was increased in heifers receiving FM thrice daily from 19.8 to $22.5 \mathrm{~d}$ and four-times-daily from 19.5 to $26 \mathrm{~d}$. Furthermore, luteolysis did not occur until after the treatment was terminated (d 23 or 24) in heifers receiving the four-times-daily dose. The same group studied the effects of FM on uterine involution and the postpartum period in primiparous cows. Postpartum cows were administered FM injections ( $2.2 \mathrm{mg} / \mathrm{kg}$ of body weight) twice- or four-times-daily for a 14-d period beginning at parturition. Those animals receiving four-times-daily FM injections had significantly decreased PGFM concentrations during the treatment period. However, there were no significant effects of FM administration on the time needed for cows to complete uterine involution (Odensvik and Fredricksson, 1993).

In an experiment by Lemaster et al. (1999) 42 non-lactating beef cows were synchronized and bred by AI on d 0. Cows received either $25 \mathrm{~mL}$ saline (CON), $100 \mathrm{IU}$ OT (OT), 100 IU OT + 1 g FM (OT + FM), or 100 IU OT + lutectomy (OT + LUT) on d 5 to 8 after AI. Seals et al. (1998) previously observed that the greatest amount of EM occurred during $\mathrm{PGF}_{2 \alpha}$ treatment on $\mathrm{d} 5$ to 8 after AI. All cows were fed MGA beginning $2 \mathrm{~d}$ before initiation of their treatments. Pregnancy rates at $\mathrm{d} 30$ were reduced in OT and OT + LUT groups compared to CON and the OT + FM group. This study indicated that in progestin supplemented cattle, OT administration decreased embryo survival with and without the presence of a luteal OT-uterine $\mathrm{PGF}_{2 \alpha}$ feedback loop. Additionally, FM increased embryo survival to levels observed in control cows, possibly through the inhibition of OT-induced $\mathrm{PGF}_{2 \alpha}$ release.

Flunixin meglumine injected at the time of ET may also improve pregnancy rates of embryo recipients. Uterine manipulation occurs during ET, which may cause the release of $\mathrm{PGF}_{2 \alpha}$ from the uterus and a subsequent loss of pregnancy (Fergusion, 1941; 
Odensvik et al., 1993; Schrick et al., 2003). In a study by Schrick et al. (2001) 737 beef cows were injected with $10 \mathrm{~mL}$ FM 2 to 5 min prior to transfer of fresh or frozen embryos. Pregnancy rates were greater in cows administered FM than in control cows (63.8 and $51.1 \%$, respectively).

There was an interaction between the effects FM treatment and embryo quality grade on recipient pregnancy rates. Pregnancy rate was significantly increased by FM treatment in recipients that received Grade 1 or 2 embryos, but not those receiving Grade 3 embryos (Schrick et al., 2001; Figure 2.3). The effect of FM treatment on pregnancy rate also depended on the developmental stage of the embryo. Flunixin meglumine treatment significantly improved pregnancy rates of recipients receiving Stage 4 embryos by $14.6 \%$ and tended to improve pregnancy rates of recipients receiving Stage 5 embryos by $11.4 \%$.

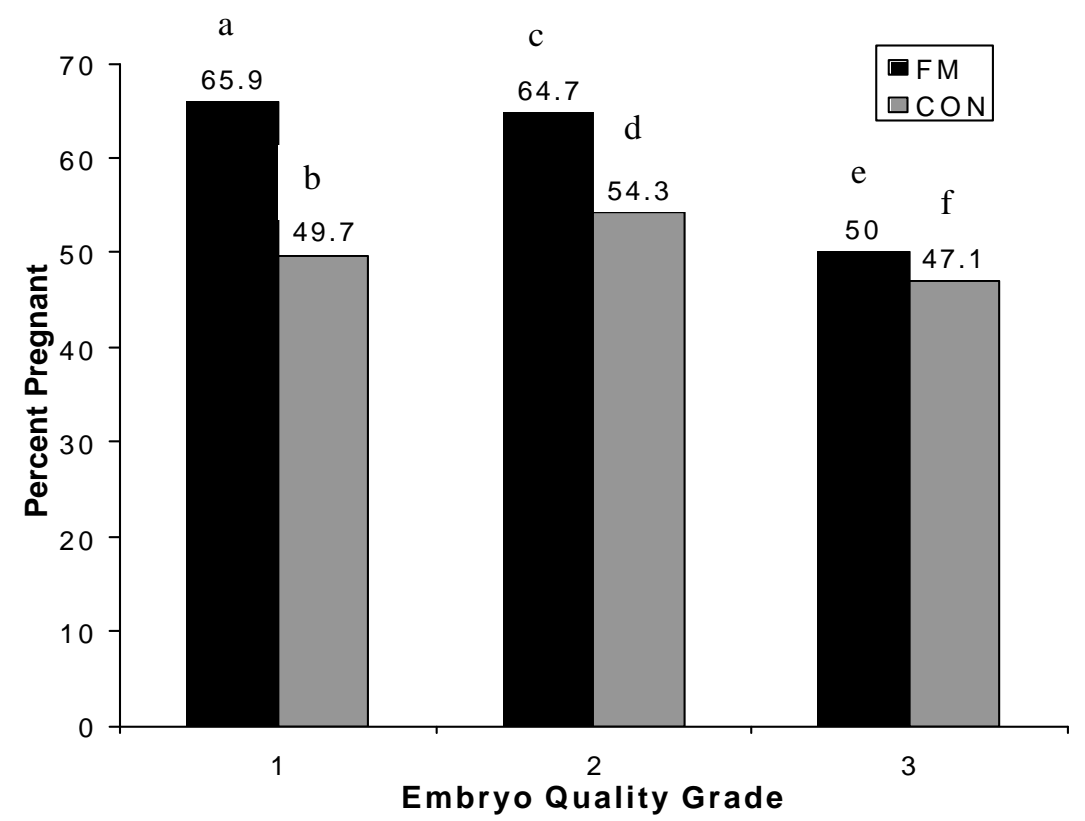

Figure 2.3. Pregnancy rates after transfer of Grade 1,2, or 3 embryos in cows treated with flunixin meglumine (FM) or untreated (CON) at the time of ET.

${ }^{\mathrm{a}, \mathrm{b}}$ Treatments are different when letters above the bars are different $(P=0.001){ }^{c, \mathrm{~d}}$ Treatments are different when letters above the bars are different $(P=0.09)$. ${ }^{\text {e,f }}$ Treatments are different when letters above the bars are different $(P=0.08$; adapted from Schrick et al., 2001). 
Summary of the effects of prostaglandins and prostaglandin inhibition.

In cattle, the CL must be maintained throughout the gestation period for pregnancy to be maintained (Niswender et al., 2000). For this to occur, luteolysis must be prevented. The luteolytic substance in cattle is $\mathrm{PGF}_{2 \alpha}$ from the uterus (McCracken et al., 1973). Prostaglandin $F_{2 \alpha}$ may cause pregnancy loss through the regression of the CL, or through a direct effect on the developing embryo. Other than release during natural cyclicity, $\mathrm{PGF}_{2 \alpha}$ release can be caused by disease, OT injection, or uterine manipulation (Ferguson, 1941; Lemaster et al., 1999; Vanroose et al., 2000). The time period of greatest sensitivity of the embryo to $\mathrm{PGF}_{2 \alpha}$ release appears to be on $\mathrm{d} 5$ to 8 after breeding, whereas the CL is most sensitive on $\mathrm{d} 15$ to 18 .

The prevention of prostaglandin release can be accomplished through the feeding of certain fatty acids, or through the administration of NSAIDs, such as flunixin meglumine. Flunixin meglumine prevents the synthesis of prostaglandins by inhibiting the cyclooxygenase enzymes involved in the formation of prostaglandins (Smith et al., 2000). In cattle, FM treatment has increased cycle length and decreased production of PGFM (Odensvik and Fredrickson, 1993; Odensvik et al., 1998). Furthermore, FM administration has prevented pregnancy loss caused by OT injection on $\mathrm{d} 5$ to 8 after breeding and has improved pregnancy rates of cows receiving embryos on $\mathrm{d} 7$ after estrus (Lemaster et al., 1999; Schrick et al., 2001).

Uses of progestins in cattle.

It has been established that $\mathrm{P}_{4}$ is necessary to maintain pregnancy in cattle. Embryo mortality could be caused by insufficient $\mathrm{P}_{4}$ release (Vanroose et al, 2000). Therefore, it has been suggested that $\mathrm{P}_{4}$ supplementation to cows during early pregnancy could increase the success of MRP and improve pregnancy rate (Thatcher et al., 1997). Lamming et al. (1989) observed a significant increase in milk $\mathrm{P}_{4}$ beginning on $\mathrm{d} 10$ to 16 post-mating in pregnant cows compared to non-pregnant cows. Similarly, milk $\mathrm{P}_{4}$ was significantly reduced in inseminated, non-pregnant cows on d 10 to 16 after mating compared to inseminated, pregnant cows (Lamming et al., 1989). Conceptuses recovered on $\mathrm{d} 14$ from cows injected with $100 \mathrm{mg} \mathrm{P}_{4}$ on $\mathrm{d} 1,2,3$, and 4 after mating were more advanced in development than those recorded from control cows (Garrett et al., 1988). 
In addition to a possible beneficial effect on embryo survival and development, exogenous $\mathrm{P}_{4}$ administration after breeding has been used for the resynchronization of estrus. Luteal phase concentrations of $\mathrm{P}_{4}$ inhibit gonadotropin release and inhibit ovulation of follicles. After AI or ET, the estrous cycles of those animals failing to conceive are synchronized, but not as precisely as following the original treatment to synchronize estrus (Van Cleef et al., 1996). Progesterone supplementation has been used to prevent the occurrence of an early estrus and provide a more synchronous return to estrus in those animals failing to conceive. In summary, progestins may be used after breeding to improve or aid in the MRP, or for resynchronization of the return to estrus. Methods of progestin administration.

Increased $\mathrm{P}_{4}$ can be accomplished either by the formation of an accessory CL, or by the administration of exogenous $\mathrm{P}_{4}$ (Thatcher et al., 1997). Progestins can be administered as a feed additive, ear implant, or an intravaginal $\mathrm{P}_{4}$-releasing insert. Alternatively, endogenous $\mathrm{P}_{4}$ can be elevated if an accessory $\mathrm{CL}$ is formed following administration of hormones such as human chorionic gonadotropin (hCG) or GnRH. These hormones cause the luteinization of follicles.

Melengestrol acetate is a synthetic progestin used as a feed additive, generally fed at a rate of $0.5 \mathrm{mg} / \mathrm{head} / \mathrm{d}$ in synchronization protocols. Norgestomet is a synthetic progestin used in ear implants. Implants can contain 3 to $10 \mathrm{mg}$ of norgestomet (Favero et al., 1993). The CIDR was developed as an intravaginal progesterone-releasing insert for the synchronization of estrus (MacMillan and Peterson, 1993). Originally the CIDR contained $1.9 \mathrm{~g} \mathrm{P}_{4}$, but $\mathrm{P}_{4}$ content of the CIDR was reduced to $1.38 \mathrm{~g}$ in the EAZIBREED $^{\mathrm{TM}}$ CIDR $^{\circledR}$ (Pfizer; New York, NY) available in the USA. The CIDR containing $1.38 \mathrm{~g} \mathrm{P}_{4}$ was determined to have the same rate of $\mathrm{P}_{4}$ release as the CIDR containing $1.9 \mathrm{~g}$ $\mathrm{P}_{4}$ (Rathbone et al., 2002).

\section{Actions of progestins on follicular dynamics and fertility.}

Before discussing trials involving the use of progestins for the purposes of resynchronization and improvement of MRP, it is first necessary to understand how progestins affect ovarian function. In cattle, there are two or three waves of follicular growth that occur on the ovary during an estrous cycle. During each wave a group of follicles is recruited, after which one is selected to continue growing while others 
undergo atresia. Each wave is preceded by a surge of FSH which causes growth of a cohort of small antral follicles (Adams, 1999). The first wave, and second wave in animals with three follicular waves, results in a large anovulatory dominant follicle that undergoes atresia, while the dominant follicle of the last wave of the cycle undergoes ovulation (Sirois and Fortune, 1990). The dominant follicle of each wave inhibits the growth of other follicles through hormones such as estradiol, inhibin, activin, follistatin and others (Savio et al., 1993a). Additionally, the dominant follicle becomes dependent on LH for growth instead of FSH. The subordinate follicles remain dependent on FSH and regress because FSH is reduced to basal levels after its initial surge. Exogenous $\mathrm{P}_{4}$ administration can have an effect on these follicular wave dynamics and on the fertility of the ovulatory follicle.

When administered to cows without a CL, exogenous $\mathrm{P}_{4}$ treatments in doses typically administered for estrus synchronization produce plasma $\mathrm{P}_{4}$ concentrations that are less ( 0.9 to $2 \mathrm{ng} / \mathrm{mL}$ ) than normal luteal phase levels (4 to $12 \mathrm{ng} / \mathrm{mL}$; Sirois and Fortune, 1990; Savio et al., 1993b). In the absence of a CL, these low $\mathrm{P}_{4}$ levels may cause increased LH pulse frequency and the development of a persistent dominant follicle (Savio et al., 1993b). Animals that received a CIDR for $14 \mathrm{~d}$ beginning on $\mathrm{d} 14$ of the estrous cycle had fewer follicular waves, but a larger dominant follicle that persisted longer than untreated animals. Estradiol concentrations were also greater in CIDRtreated animals than in untreated animals (Sirois and Fortune, 1990). In other studies exogenous progestins administered at low levels $(\leq 2 \mathrm{ng} / \mathrm{ml})$ soon after luteolysis increased LH pulse frequencey (Robinson et al., 1989; Sirois and Fortune, 1990). The increased pulse frequency of LH is thought to support the continuous growth of a persistent follicle, which maintains its dominance and prevents further follicular recruitment (Sirois and Fortune, 1990). Upon removal of the exogenous source of $\mathrm{P}_{4}$ the persistent dominant follicle ovulates.

Cattle that have developed a persistent follicle have been reported to have decreased fertility. Savio et al. (1993b) conducted an experiment to examine the fertility of heifers with a persistent follicle. A persistent follicle was created in heifers by injection of $\mathrm{PGF}_{2 \alpha}$ on $\mathrm{d} 7$ of the estrous cycle coincident with insertion of a CIDR for $9 \mathrm{~d}$. Control heifers only received the $\mathrm{PGF}_{2 \alpha}$ injection on $\mathrm{d} 7$. In those heifers treated to 
create a persistent follicle the mean diameter of the dominant follicle was $4.9 \mathrm{~mm}$ larger, plasma $\mathrm{P}_{4}$ was $0.6 \mathrm{ng} / \mathrm{mL}$ less, and plasma $\mathrm{E}_{2}$ was $8.2 \mathrm{pg} / \mathrm{mL}$ greater on the $\mathrm{d}$ of CIDR removal ( $d$ 16) than in control heifers on the $d$ of $P_{G F}$ injection $(d 7)$. Pregnancy rates of those heifers with persistent follicles $(37.1 \%)$ were reduced in comparison to those of control heifers $(64.8 \%)$.

Mihm et al. (1994) used a $3 \mathrm{mg}$ norgestomet implant to create follicles that persisted for different lengths of time in beef heifers. They observed that as the duration of dominance of a follicle increased from 4.1 to 8.6 to $12.1 \mathrm{~d}$ pregnancy rate of heifers decreased from 87.5 to 57.9 to 0\%. Similarly, Austin et al. (1999) reported that a duration of dominance $\leq 4 \mathrm{~d}$ resulted in acceptable fertility and precise onset of estrus, while extending the duration of dominance longer resulted in a decline in fertility.

The decreased fertility observed in animals with persistent follicles may be due to elevated $\mathrm{E}_{2}$ concentrations. Increased plasma $\mathrm{E}_{2}$ concentrations have been reported in animals with persistent follicles (Sirois and Fortune; 1990; Ahmad et al., 1995; Austin et al., 1999). Persistent follicles have more granulosa cells and a larger mass of theca cells than follicles recovered from control heifers. However, persistent follicles do not posses greater amounts of steroidogenic enzymes (Bigelow and Fortune, 1998). Abnormal oviductal or uterine environment caused by the elevated $\mathrm{E}_{2}$ observed in animals with persistent follicles may be the cause of decreased fertility (Savio et al., 1993b). Conversely, $E_{2}$ may have a direct negative effect on the embryo. Ahmad et al. (1995) recovered embryos $6 \mathrm{~d}$ after the fertilization of oocytes from persistent follicles. Plasma $\mathrm{E}_{2}$ during the last $6 \mathrm{~d}$ of the estrous cycle was $3.1 \mathrm{pg} / \mathrm{mL}$ greater in animals with persistent follicles, $E_{2}$ level and negatively correlated $(r=-0.64)$ with stage of embryo development. Fewer embryos were recovered from animals with persistent follicles and those that were recovered had a lower embryo quality score. Fourteen percent of the embryos recovered following the ovulation of persistent follicles were evaluated at "good or excellent" compared to $73 \%$ of the embryos recovered from heifers with growing follicles.

Another cause of decreased fertility observed in animals with persistent follicles could be premature oocyte maturation. Abnormal oocyte maturation may occur in persistent follicles being exposed to high frequency LH pulses for a prolonged period 
(Revah and Butler, 1996; Borchert et al., 1999). Follicles are in arrested development at prophase I of meiosis prior to the preovulatory LH surge. The LH surge causes resumption of meiosis, chromatin condensation, and the separation of the cumulus cells from the oocyte. The high frequency LH pulses which result in persistent follicles may mimic the action of the LH surge and induce premature maturation of oocytes. Oocytes recovered from persistent follicles were more advanced in development than those recovered from normal ovulatory follicles (Borchert et al., 1999). Revah and Butler (1996) observed that oocytes recovered from persistent follicles had expanded cumulus cells and condensed chromatin. This premature advancement in development may cause the decreased fertility or abnormal embryo development observed after the fertilization of persistent follicles.

Several studies previously cited indicate that progestins used at doses typically applied in synchronization protocols may result in the formation of a persistent dominant follicle if they extend the length of the estrous cycle or are initiated in the absence of a CL. However, the negative effects associated with progestin treatment are dependent on the length of progestin treatment and stage of follicular development at the initiation of treatment. Progestin treatments described in the studies discussed below began from $6 \mathrm{~h}$ before breeding to d 17 after breeding. Hence, they represent a wide range of biological conditions under which progestin administration could influence the maintenance of pregnancy or the fertility at the next estrus.

Progestins: Effects on pregnancy rates and use in resynchronization of estrus.

Induction of an accessory $\mathrm{CL}$ is one method of causing increased $\mathrm{P}_{4}$ secretion. Pregnancy rates following accessory CL formation before or shortly after breeding have been variable. Lewis et al. (1990) reviewed 13 studies involving cows and heifers treated with hCG at $6 \mathrm{~h}$ before AI to $6 \mathrm{~d}$ after AI. Pregnancy rates of hCG-treated animals ranged from $10 \%$ less to $25 \%$ greater than control animals. The same authors reviewed seven studies involving cows and heifers treated with $\mathrm{GnRH}$ at times ranging from $0 \mathrm{~h}$ after AI to $35 \mathrm{~d}$ after AI. Pregnancy rates in GnRH-treated animals in those studies varied from $18 \%$ less to $13 \%$ greater than in untreated control animals.

In a study by Santos et al. (2001), dairy cows were synchronized and bred by AI then injected with either saline or 3,300 IU hCG on d 5 after estrus. Accessory CLs were 
formed in $86.2 \%$ of hCG-treated cows. Plasma $\mathrm{P}_{4}$ concentrations on $\mathrm{d} 11$ to 16 after $\mathrm{AI}$ were increased by an average of $5 \mathrm{ng} / \mathrm{mL}$ and conception rates on $\mathrm{d} 28$ were increased from $38.7 \%$ in untreated cows to $45.8 \%$ in hCG-treated cows. Conversely, Walton et al. (1990) observed no significant increase in pregnancy rates of cows treated with $1500 \mathrm{IU}$ hCG 5 d after AI. Lewis et al. (1990) conducted a study in which cows and heifers were untreated or treated with $100 \mu \mathrm{g}$ GnRH immediately after AI, 3500 IU hCG on d 15 after $\mathrm{AI}$, or $\mathrm{GnRH}$ at $\mathrm{AI}$ and hCG $15 \mathrm{~d}$ after AI. Although hCG treatment significantly increased milk $\mathrm{P}_{4}$ concentrations, no significant differences were observed in pregnancy rates among treatment groups.

Attempts to improve pregnancy rates by insertion of an intravaginal progesteronereleasing device after breeding have yielded inconsistent results as well. Treatment of dairy cows with an intravaginal progesterone releasing device between $\mathrm{d} 5$ to 12 or d 10 to 17 after breeding significantly increased pregnancy rate compared to untreated control cows (60 and 30\%, respectively, Robinson et al., 1989). In a study by Van Cleef et al. (1996), previously synchronized and inseminated heifers were treated with either new CIDRs from d 1 to 8 after AI, a used CIDR from d 17 to 22 after AI, or were untreated. Conception rate to the initial AI was significantly reduced in heifers treated with a CIDR from $\mathrm{d} 1$ to $8(18.2 \%)$ than in heifers treated with a CIDR from d 17 to $22(46.4 \%)$. Conception rates were not different between control heifers (43.5\%) and heifers treated from 17 to 22. Seventy-five percent of the non-pregnant cows that received a CIDR from d 17 to 22 were in estrus 23 to $26 \mathrm{~d}$ following the initial AI. In contrast, only $49 \%$ of non-pregnant control heifers were in estrus during this time period. Conception rates after the resynchronized estrus were not different among treatments

Supplementation of $\mathrm{P}_{4}$ had no effect on pregnancy rates to the initial breeding or subsequent $\mathrm{AI}$ in lactating dairy cows treated with a progesterone releasing intravaginal device from d 5 to 13 or d 13 to 21 after the initial AI (Stevenson and Mee, 1991). In a study in New Zealand that involved multiple dairy herds insertion of a CIDR 4 to $9 \mathrm{~d}$ after insemination for a 6- or 12-d period increased pregnancy rates compared to control cows (74.6 and 66.1\%, respectively). However, insertion of a CIDR later after insemination (d 10 to 17 ) for a 4 - to 7 -d period had no effect on pregnancy rates. In the same study resynchronization data was recorded in those non-pregnant cows that 
received a CIDR from d 14 to 17 after insemination. After CIDR removal, 8.2\% more cows that had received a CIDR came into estrus and were bred on d 23 and 24 after the first insemination than cows that had not receive a CIDR. Pregnancy rates in the resynchronized cows were not affected by CIDR treatment (MacMillan and Peterson, 1993).

Stevenson et al. (2003) conducted a series of experiments to synchronize the return estrus in cattle. In the first experiment, previously synchronized and inseminated dairy and beef heifers were randomly assigned to receive either no treatment (CON), a CIDR on $\mathrm{d} 13$ post-insemination for a period of $7 \mathrm{~d}$ (CIDR), or the same CIDR treatment with injections of estradiol cypionate (ECP) at CIDR insertion and removal (CIDR + ECP). Heifers that returned to estrus were bred by AI 8 to $14 \mathrm{~h}$ after observed estrus. In a second experiment, the same treatment protocols were applied in beef heifers, however MGA was fed as the progestin instead of insertion of a CIDR. In both experiments the variability in the day of the return estrus was less in treated heifers than in control heifers. The conception rates to the first AI were unaffected by any treatment in either experiment. However, conception rates to the resynchronized estrus tended to be reduced by 26.7 and $24.8 \%$ in CIDR and CIDR + ECP groups and by 29.8 and $21.1 \%$ in MGA and MGA + ECP groups compared to control groups.

Other similar experiments involving the use of a CIDR during approximately the same time periods have been conducted. Chenault et al. (2003) assigned lactating dairy cows to receive a CIDR on $\mathrm{d} 14$ after AI for a $7 \mathrm{~d}$ period or to be untreated controls. Cows were observed for return to estrus and inseminated if estrus was detected. Synchronization of the return to estrus was significantly less variable in those animals that received a CIDR. During the a 3 d period after CIDR removal $34.1 \%$ of nonpregnant cows that had received a CIDR were observed in estrus, while only $19.3 \%$ of non-pregnant cows that had not received a CIDR were observed during the same time period. Pregnancy rate to the return estrus was not different between control cows and cows receiving a CIDR; however, pregnancy rate to the initial AI was slightly reduced in cows receiving a CIDR (32.7\%) than in control cows (36.7\%). El-Zarkouny et al. (2001) conducted a similar experiment in which previously synchronized and inseminated cows were resynchronized by insertion of a CIDR on d 13 after AI for a $7 \mathrm{~d}$ period. Although 
conception rate to the resynchronized estrus was reduced by $18 \%$, overall embryo survival on d 29 and d 57 after the experiment tended to be increased by insertion of a CIDR.

Treatment with an ear implant containing norgestomet has also been used in an attempt to improve pregnancy rates and increase the synchrony of return to estrus in embryo recipients and after AI. Pregnancy rates in beef cows supplemented with a $3 \mathrm{mg}$ norgestomet ear implant on the day of ET were not different between implanted cows and control cows (51.9 and 49.6\%, respectively; Smith et al., 1996). Favero et al. (1993) treated heifers with two $10 \mathrm{mg}$ norgestomet implants on d 9 after AI or one $3.6 \mathrm{mg}$ norgestomet implant on d 12 after AI. After the implants were removed on d 21, heifers were observed for estrus and bred by AI $12 \mathrm{~h}$ after estrus. Both treatments increased the number of non-pregnant heifers in estrus during a peak $3 \mathrm{~d}$ period when compared to untreated controls. The pregnancy rate after the initial AI was greater in heifers receiving an implant $(50.0 \%)$ than in control heifers $(21.4 \%)$. Conception rate to the resynchronized estrus tended to be $37 \%$ less than controls in heifers that received the 10 mg implant, while those receiving the $3.6 \mathrm{mg}$ implant had a $44 \%$ greater conception rate than controls. The same authors conducted a similar study using postpartum cows that were treated with a norgestomet implant on $\mathrm{d} 12$ after AI for a $9 \mathrm{~d}$ period or were untreated. After implant removal cows were bred by AI $12 \mathrm{~h}$ after the detection of estrus. Pregnancy rates to the initial AI and to AI after the repeat estrus were not affected by treatment. The number of non-pregnant cows in estrus during a peak $3 \mathrm{~d}$ period following implant removal was greater in cows that received an implant (81\%) compared to untreated controls (56\%; Favero et al., 1995).

There is a wide variety of resynchronization protocols that have been employed. Depending on the study, treatment of animals with progestins after breeding has been reported to improve, decrease, or have no affect on the pregnancy rates following the initial estrus and breeding. Similar variations in the effects of progestins on pregnancy rate have been observed following the resynchronized estrus. As discussed above, the fertility of the resynchronized estrus may be compromised if a persistent follicle was created due to progestin treatment. Regardless of its effects on fertility, progestin treatment after breeding appears to be able to successfully reduce the variation in the 
timing of the return to estrus in non-pregnant animals and thereby resynchronize the return estrus.

\section{Embryo transfer in cattle.}

The first successful transfer of a mammalian embryo occurred in rabbits in 1890 (Heape, 1891). There were no further reports of successful ET until the 1920's, and it was not until 1951 that the first calf was born as a result of ET (Willet et al., 1951). In North America, the commercial ET industry began in the 1970's due to the demand for "exotic" breeds of cattle that had been imported from Europe (Hasler, 2003). Initially, all collections and transfer were performed surgically through mid-ventral exposure of the uterus and ovaries. However, non-surgical embryo recovery and transfer techniques were developed in the mid-1970's (Hasler, 2003). Another advancement in ET technology that occurred in the mid-1970's was the ability to successfully cryopreserve bovine embryos (Wilmut and Rowson, 1973). The ability to freeze embryos for thawing and transfer at a later date eliminated the need for synchronous recipient animals at the time of embryo collection. These important scientific achievements made ET a practical tool for genetic improvement of cattle.

The transfer of bovine embryos today commonly involves estrus synchronization and superovulation of a donor animal, insemination of the donor animal, and collection of embryos from the donor approximately $7 \mathrm{~d}$ after estrus. The embryos are then transferred to recipients (fresh) or are frozen to be thawed and transferred at a later date. Almost all transfers today are performed non-surgically and most are performed on-farm, rather than in a central clinic (Hasler, 2003). Worldwide, close to 500,000 bovine embryos are produced and transferred each year.

Although it is relatively uncommon, the splitting of embryos has been applied with some success to the commercial ET industry. Split, or bisected embryos have the ability to develop into identical twins. Embryo bisection has also allowed for the removal of a sample of stem cells and determination of the sex of the embryo through polymerase chain reaction (PCR; Lopes et al., 2001). Furthermore, a greater number of pregnancies can be produced from one flush through embryo splitting.

The first split embryo twin calves were produced from a d 8 blastocyst-stage embyro (Ozil, 1983). Early methods of embryo bisection involved bisecting the embryo 
mass, extracting half of the embryo, and placing it in an empty surrogate zona pellucida. The remaining half of the embryo was surrounded by its original zona pellucida (Ozil, 1983). Warfield et al. (1987) demonstrated that embryos could be bisected and transferred without being placed in a zona pellucida with no negative effect on the resulting pregnancy rates. This simplified procedure is generally used in current ET programs.

Pregnancy rates of recipients receiving split embryos have been reported to be 50 to $60 \%$ (Lopes et al., 2001). Embryos chosen to be bisected are usually of a high quality grade; therefore, developmental stage of the embryo is the more variable factor that could affect pregnancy rates. Gray et al. (1991) analyzed pregnancy rates of bisected embryos and reported no differences in pregnancy rate when transferring split embryos of different developmental stages. As mentioned, the ability to produce identical twins is one advantage to split embryos. The number of pregnancies produced per split embryo pair is a method of analyzing the incidence of twins. However, when the two halves of a split embryo are transferred, only $27.5 \%$ produced twins while $44.8 \%$ of split embryo pairs produced a single pregnancy (Gray et al., 1991).

Factors affecting the success of embryo transfer.

Research topics in the area of ET have been widely varied. Studies have been conducted on methods of synchronization of donors and recipients, procedures for superovulation of donors, processes for in vitro production of embryos, methods of cryopreservation of embryos, and most recently, techniques for cloning or producing transgenic embryos (Hasler, 2003). Regardless of the focus of the research, there are certain inherent factors that affect the pregnancy rate of recipients receiving an embryo. Some of these factors are the developmental stage and quality grade of the embryo transferred, the type of transfer (fresh or frozen), the synchrony of the recipient animal with the donor animal, the lactational status or age of the embryo recipient, and the functionality of the CL at the time of transfer. Reliable characterization of how these factors affect pregnancy rates following ET requires a large number of animals. Therefore, most data examining these factors have come from analysis of large commercial ET operations or ET programs at large ranches. 
Embryos are assigned a developmental stage code and quality grade after collection. Developmental stages set forth by the International Embryo Transfer Society (IETS; Savoy, IL) are: 3 = early morula; 4 = morula; $5=$ early blastocyst; $6=$ blastocyst; $7=$ expanded blastocyst; and $8=$ hatched blastocyst. Quality grades are: $1=$ symmetrical and spherical embryo mass with individual blastomeres that are uniform in size, color, and density with at least $85 \%$ of the cellular material intact (excellent/good); $2=$ moderate irregularities in overall shape of embryonic mass or in size, color, and density with at least $50 \%$ of the cellular material intact (fair); $3=$ major irregularities in shape of the embryo mass, or size, color, and density of individual cells. At least $25 \%$ of the cellular material should be intact, viable embryo mass.

The developmental stage of the embryo does not appear to have an effect on the pregnancy rate of recipients in most studies. An analysis of 9022 transfers of fresh and frozen embryos in beef and dairy cattle reported no significant differences in pregnancy rate among recipients receiving embryos of various developmental stages ranging from Stage 4 to 8 (Hasler, 2001). Similarly, Spell et al. (2001) observed no significant differences in pregnancy rates of 448 beef cattle recipients receiving fresh or frozen embryos ranging from Stage 3 to 6. However, an earlier study did report a decrease in pregnancy rate of beef cattle recipients $(n=2286)$ that had received fresh Stage 3 or Stage 4 embryos when compared to pregnancy rates following transfer of Stage 5, 6, or 7 embryos (Wright, 1981). Few studies have included the transfer of Stage 7 or 8 embryos, which may result in reduced pregnancy rates of recipients, particularly if embryos are frozen and thawed.

The quality grade of the embryo usually has an effect on pregnancy rates of recipients. Two retrospective studies of large commercial ET programs $(n=11,307)$ in beef and dairy cattle reported an increase in recipient pregnancy rate after the transfer of fresh or frozen embryos as quality grade increased from Grade 3 (43.6 and 33\%) to Grade 2 (56.8 and 45\%) to Grade 1 (62.8 and 64\%; Wright, 1981; Hasler, 2001, respectively). A smaller study $(n=448)$ reported no significant differences in recipient pregnancy rates after the transfer of fresh or frozen Grade $1(74.1 \%)$ or $2(71.8 \%)$ embryos (Spell et al., 2001). In that study no Grade 3 embryos were transferred. 
Damage to embryos as a result of freezing can come from thermal shock, formation of ice crystals, increased solute concentration, or dehydration (Seidel, 1986). Therefore, pregnancy rates after the transfer of fresh embryos is expected to be greater than pregnancy rates resulting from the transfer of frozen embryos of the same quality. Following the transfer of beef cattle embryos $(n=448)$ pregnancy rates in recipient animals were greater in fresh compared to frozen embryos (82.8 and 69.0\%, respectively; Spell et al., 2001). Results of that study agree with a larger analysis $(n=14,320)$ involving dairy and beef cows where the pregnancy rates of recipient animals receiving fresh embryos $(68.3 \%)$ were almost $10 \%$ greater than that of recipients receiving frozen embryos (58.5\%; Hasler, 2001).

Ideally, embryos are collected from donor animals $7 \mathrm{~d}$ after estrus and transferred into synchronous recipients that were in estrus at the same time as the donor. However, this is not always possible and asynchrony between embryo recipient and donor can occur. Wright (1981) reported the effect of synchrony on the pregnancy rates of embryo recipients $(n=2282)$ receiving fresh embryos (Table 2.1). Recipients were in estrus from $36 \mathrm{~h}$ before the donor to $36 \mathrm{~h}$ after the donor and synchrony was recorded in $12 \mathrm{~h}$ increments. Pregnancy rates of recipients in estrus 36 or $24 \mathrm{~h}$ before the donor and 0,12 , and $24 \mathrm{~h}$ after the donor were not different from each other, but were less than pregnancy rates of recipients in estrus $12 \mathrm{~h}$ before the donor and greater than in recipients in estrus $36 \mathrm{~h}$ after the donor.

Table 2.1 Effect of synchrony between the donor and recipient on pregnancy rates of recipients following ET.

\begin{tabular}{ccc}
\hline \hline Synchrony $^{\mathrm{a}}$ & $\mathbf{n}$ & Pregnancy rate (\%) $^{\mathrm{c}}$ \\
\hline$-36 \mathrm{~h}$ & 27 & $59^{\mathrm{c}}$ \\
$-24 \mathrm{~h}$ & 98 & $61^{\mathrm{c}}$ \\
$-12 \mathrm{~h}$ & 374 & $68^{\mathrm{b}}$ \\
$0 \mathrm{~h}$ & 747 & $59^{\mathrm{c}}$ \\
$+12 \mathrm{~h}$ & 620 & $61^{\mathrm{c}}$ \\
$+24 \mathrm{~h}$ & 301 & $58^{\mathrm{c}}$ \\
$+36 \mathrm{~h}$ & 115 & $41^{\mathrm{d}}$ \\
\hline
\end{tabular}

${ }^{\mathrm{a}}$ Hours of first detected estrus of the recipient relative to the donor

${ }^{\mathrm{b}, \mathrm{c}, \mathrm{d}}$ Pregnancy rates with different superscripts differ $(P<0.01)$. Adapted from Wright, 1981. 
In a subsequent analysis of the effects of synchrony on recipient $(n=14,125)$ pregnancy rates, no differences were observed when fresh or frozen embryos were transferred to recipients that were in estrus $24 \mathrm{~h}$ before or after the donor (Hasler, 2001). Spell et al. (2001) observed similar results following the transfer of fresh or frozen embryos in beef cattle $(n=447)$. No significant differences were observed when embryos were transferred into recipients that were in estrus $24 \mathrm{~h}$ before the donor up to $24 \mathrm{~h}$ after the donor.

Lactational status of the recipient is another factor that could affect pregnancy rates following ET. The effects of lactation on fertility are more pronounced in dairy cows due to increased milk production, and therefore greater nutritional stress on the cow. There is a well documented decline in fertility with an associated increase in milk production in dairy cows bred by AI in the US (Hasler, 2001). In a study that involved the transfer of 9023 fresh or frozen embryos, donor type (dairy or beef) did not have an effect on recipient pregnancy rate. However, the pregnancy rate of dairy cow recipients was less than that of dairy heifers, or beef cows or heifers (Hasler, 2001). In a study that involved the transfer of embryos to beef animals only, lactational status had no effect on pregnancy rates (Wright, 1981).

Parity is closely related to lactational status. Most non-lactating animals tend to be non-parous heifers, while lactating animals tend to be primiparous or multiparous cows. Wright (1981) observed no difference in pregnancy rates of recipient beef animals $(n=2445)$ that had calved previously when compared to those that had never calved (59 and $58 \%$, respectively). Beef producers, however, may prefer cows over heifers due to reduced dystocia in cows (Wright, 1981).

A functional $\mathrm{CL}$ is a requirement for the maintenance of pregnancy in cattle (Niswender et al., 2000). Therefore, embryo transfer technicians routinely palpate the CL of the potential recipient animal before ET to assess the size and integrity of the CL (Spell et al., 2001). More objective methods of determining the functionality of the CL are ultrasonic evaluation of the $\mathrm{CL}$ and measurement of plasma $\mathrm{P}_{4}$ concentrations. Spell et al. (2001) evaluated the effect of luteal characteristics on pregnancy rate in a study that involved the transfer of fresh and frozen embryos to 526 recipient animals. The diameter of the CL and volume of luteal tissue at the time of ET were determined from video 
images of ovaries recorded via transrectal ultrasonography. A minimum CL diameter of $13 \mathrm{~mm}$ was set for embryo recipients. Blood samples were collected from the same animals and plasma $\mathrm{P}_{4}$ concentrations were determined. Additionally, a subjective CL quality score $(1=$ excellent/good; 2 = poor $)$ was assigned to each recipient at the time of ET based on rectal palpation. Pregnancy rates of recipients did not differ based on CL diameter, luteal volume, or plasma $\mathrm{P}_{4}$ concentrations. Pregnancy rates were slightly greater $(80 \%)$ in recipients assigned a CL quality grade of "poor" than recipients assigned a CL quality grade of "excellent/good" (70\%). The results from this study indicated that any recipient with a CL > 13mm is a suitable embryo recipient (Spell et al., 2001).

In summary, ET in cattle today involves the non-surgical transfer of fresh or frozen embryos from a genetically superior donor animal to recipient animals. Although not common, embryos can also be split and transferred fresh to produce identical twins. The studies discussed previously have indicated that certain factors can affect pregnancy rates of embryo recipients. The two factors that appear to have the most effect on pregnancy rate are the type of embryo transferred (fresh or frozen) and the quality grade of the embryo transferred. Other factors, such as embryo developmental stage, synchrony between the donor and recipient, parity, lactational status, and CL quality do not appear to have a significant effect on pregnancy rates of beef cattle recipients. 


\section{Chapter 3 Rationale and Experimental Objectives}

There are many factors that can affect the pregnancy rates of cattle following the transfer of an embryo. The process of transferring the embryo itself may be one of the factors that could have a negative effect on pregnancy rates of embryo recipients. This is because of the release of $\mathrm{PGF}_{2 \alpha}$ that can occur due to the uterine manipulation involved in the ET procedure. However, there has been little research into ways to improve pregnancy rates to $\mathrm{ET}$ through prevention of $\mathrm{PGF}_{2 \alpha}$ release.

Resynchronization of the return estrus in those animals that fail to conceive after the transfer of an embryo would reduce the time and labor needed to detect estrus. This has been accomplished with the use of progestins administered to cattle of unknown pregnancy status after an initial breeding. However, the fertility of the return estrus has been compromised by these treatments in some cases.

The objective of this experiment was twofold. First, to determine the effects of administration of a prostaglandin inhibitor at the time of ET on the pregnancy rates of embryo recipients. And second, to determine the effects of CIDR administration at the time of ET on the timing of the return to estrus in non-pregnant animals and fertility of those animals at the return estrus. The hypothesis was that by inhibiting the release of $\mathrm{PGF}_{2 \alpha}$ caused by uterine manipulation during ET, pregnancy rates of embryo recipients would be improved. Furthermore, it was hypothesized that CIDR insertion at the time of ET for a $13 \mathrm{~d}$ period would reduce the variation in the time of the return estrus in those animals not conceiving to the initial ET, without affecting the fertility of the return estrus. 


\section{Chapter 4 Materials and Methods}

\section{Experimental animals.}

The experiment involved the transfer of fresh or frozen bovine embryos to 940 embryo recipients and was conducted at three locations in Southwest Kansas (Location 1 $38^{\circ} 92^{\prime} \mathrm{N}, 97^{\circ} 37^{\prime} \mathrm{W}$; Location $237^{\circ} 11^{\prime} \mathrm{N}, 99^{\circ} 45^{\prime} \mathrm{W}$; Location $339^{\circ} 43^{\prime} \mathrm{N}, 97^{\circ} 00^{\prime} \mathrm{W}$ ) during the month of November, 2003. Recipients at Locations $1(n=141)$ and $3(n=83)$ were lactating Angus or Angus-cross cows ranging from 59 to 103 d postpartum. Recipients at Location 2 were either lactating Angus cows $(n=605)$ ranging from 31 to $111 \mathrm{~d}$ postpartum, or non-lactating virgin heifers $(\mathrm{n}=111)$. The average age of all animals was $5.5 \mathrm{yr}$, and ranged from 1 to $15 \mathrm{yr}$ of age. Based on differences in management of virgin heifers and cows, each recipient was assigned to a parity group. Non-parous animals were yearling and non-lactating virgin heifers. Parous animals were lactating or non-lactating cows that had calved previously. Both cows and heifers were fed diets containing alfalfa hay, native grass hay, wheat hay, and a wheat middlings-corn supplement. The diets were formulated to meet nutritional requirements based on age and lactation status (NRC, 2000).

Estrus synchronization, embryo transfer, and pregnancy diagnosis.

Estrus was synchronized in embryo transfer recipients with two i.m. injections of prostaglandin $\mathrm{F}_{2 \alpha}\left(25 \mathrm{mg} \mathrm{PGF}_{2 \alpha}\right.$, Lutalyse ${ }^{\circledR}$, Pfizer Inc., New York, NY) administered 14 $\mathrm{d}$ apart. Following the second injection of $\mathrm{PGF}_{2 \alpha}$ animals were observed for behavioral signs of estrus for $30 \mathrm{~min}$ four times daily. Six to $9 \mathrm{~d}$ following the detection of estrus (d 0 ), fresh or frozen-thawed embryos were transferred to synchronous recipients by the same technician at all locations.

All embryos used in this experiment were assigned a developmental stage and quality grade according to the standards of the International Embryo Transfer Society (IETS, Savoy, IL; Table 4.1 and Table 4.2). 
Table 4.1. Standardized classification of bovine embryos based on stage of development. International Embryo Transfer Society (IETS)

\begin{tabular}{|c|c|c|}
\hline Name & IETS $^{\text {a }}$ Stage & Description \\
\hline Ovum & 1 & Unfertilized. \\
\hline Early Morula & 2 & Fertilized ovum, but is less than 16 cells. \\
\hline $\begin{array}{c}\text { Compact } \\
\text { Morula }\end{array}$ & 4 & $\begin{array}{c}\text { Contains } 16 \text { or more cells that are distinct individuals and } \\
\text { have not coalesced. }\end{array}$ \\
\hline $\begin{array}{c}\text { Early Blastocyst } \\
\text { Blastocyst }\end{array}$ & 5 & $\begin{array}{c}\text { Embryo has formed a small blastocoele up to a blastocoele } \\
\text { that half-fills the embryonic mass. }\end{array}$ \\
\hline $\begin{array}{c}\text { Expanded } \\
\text { Blastocyst }\end{array}$ & 6 & $\begin{array}{c}\text { Blastocoele is highly prominent but not enough to fill the } \\
\text { zona pellucida and begin stretching the zona. }\end{array}$ \\
\hline $\begin{array}{c}\text { Hatched } \\
\text { Blastocyst }\end{array}$ & 8 & $\begin{array}{c}\text { Overall diameter of embryo increases, with a thinning of } \\
\text { the zona pellucida. }\end{array}$ \\
\hline $\begin{array}{c}\text { Hatched } \\
\text { Bxpanding }\end{array}$ & 9 & $\begin{array}{c}\text { Undergoing the process of hatching or may have } \\
\text { completely shed the zona pellucida. }\end{array}$ \\
\hline
\end{tabular}

Embryos were assigned to recipients based on the time of estrus in the recipient and developmental stage of the embryos transferred. Embryo developmental stages were assigned to an equivalent $d$ after estrus of the donor: Stage $4=\mathrm{d} 6.5$; Stage $5=\mathrm{d} 7$; and Stage $6=\mathrm{d} 7.5$. To the extent that it was feasible, embryos were assigned to recipients to maximize the synchrony between the stage of embryo development and the $d$ of the estrous cycle of the recipient. Synchrony of the recipient animal with the embryo it received was determined by the following formula: [days after estrus of the recipient day of embryo development]. Synchrony of the recipient with the embryo was recorded in $12 \mathrm{~h}$ increments. For example: A recipient in estrus $7.5 \mathrm{~d}$ before ET and receiving a Stage 5 (d 7) embryo would be assigned a synchrony of $+12 \mathrm{~h}$.

A quality grade was assigned to each embryo transferred by an experienced technician. The quality grade of the embryo is a subjective measure of developmental 
abnormalities intended to identify those embryos that are less likely to result in pregnancy.

Table 4.2. Standardized classification of bovine embryos based on quality. International Embryo Transfer Society (IETS)

\begin{tabular}{|c|c|c|}
\hline Grade & Quality & Description \\
\hline 1 & Excellent to Good & $\begin{array}{c}\text { Symmetrical and spherical mass with blastomeres that are } \\
\text { uniform in size, color, and density. At least 85\% of the } \\
\text { cellular material is in an intact, viable embryo mass. }\end{array}$ \\
\hline 2 & Fair & $\begin{array}{c}\text { Moderate irregularities in shape of the embryo mass, or size, } \\
\text { color, and density of individual cells. At least 50\% of the } \\
\text { cellular material should be intact, viable embryo mass. }\end{array}$ \\
\hline 3 & Poor & $\begin{array}{l}\text { Major irregularities in shape of the embryo mass, or size, } \\
\text { color, and density of individual cells. At least 25\% of the } \\
\text { cellular material should be intact, viable embryo mass. }\end{array}$ \\
\hline
\end{tabular}

Embryos transferred (Stage $=4,5$, or 6; Grade $=1,2$, or 3) were either fresh or frozen for direct transfer in $10 \%$ ethylene glycol as the cryoprotectant. Fresh embryos were obtained from donor cows in the morning and transferred the afternoon of the same day. At Location 2 a subset of the fresh embryos $(n=96$; Grade $=1$ or 2 ; Stage $=4$ or 5) collected were split by micromanipulation and 192 fresh, half-embryos were transferred.

The embryos transferred at all three locations were collected from a total of 102 donors bred to 1 of 30 sires. Donors at Locations 1 and 3 were Angus or Charolais cattle and donors at Location 2 were Angus cattle. Donor and sire were randomly assigned within the locations, however, embryos from three donors and three sires used at Location 1 were also used at Location 3.

A CL quality score based on rectal palpation was assigned to each embryo recipient immediately prior to ET by the technician transferring the embryos. The following criteria, as described by Spell et al. (2001), were used to assign a CL quality score: 1) the CL had a palpable diameter > $10 \mathrm{~mm}$ and firm or moderately firm 
consistency (excellent/good); or 2) the CL had a palpable diameter of $\leq 10 \mathrm{~mm}$, and/or the CL had a soft texture (poor).

At all locations pregnancy was diagnosed by transrectal ultrasonography (Aloka SSD 500, 7.5 MHz transducer, Wallington, CT) 30 to $60 \mathrm{~d}$ after initial embryo transfer. Experimental design and treatments.

Animals were randomly assigned to receive one of four treatments in a 2 x 2 factorial arrangement of treatments with flunixin meglumine injection (FM, $500 \mathrm{mg}$ i.m., Phoenix Scientific, St. Joseph, MO) 2 to 12 min prior to ET and insertion of an intravaginal progesterone-releasing device (CIDR, containing $1.38 \mathrm{~g} \mathrm{P}_{4}$, Pfizer Inc., New York, NY) immediately after ET as main effects (Figure 4.1). This created four treatment groups: 1) no treatment (Control; $\mathrm{n}=247), 2)$ CIDR insertion at ET (CIDR; $\mathrm{n}$ = 225), 3) FM injection immediately prior to ET (FM; $\mathrm{n}=242)$, and 4) CIDR insertion at ET and injection of FM immediately prior to ET (CIDR + FM; $n=226$; Figure 4.2).

The CIDRs were removed from cows in the CIDR and CIDR + FM groups $13 \mathrm{~d}$ after insertion (d 19 to 21 after initial detection of estrus). Beginning on d 18 or at the time of CIDR removal recipients at Location 2 only were observed for behavioral signs of estrus four times daily and the time of return to estrus was recorded. Those animals returning to estrus at Location 2 were either artificially inseminated approximately $12 \mathrm{~h}$ following estrus, or assigned to receive a second embryo 6 to $8 \mathrm{~d}$ following the observed estrus (Figure 4.3). Insemination was performed by three technicians with the semen from 1 of 13 sires. Embryos transferred at the return estrus (Grade =1, 2, or 3; Stage $=4$, 5 , or 6) were fresh and were transferred by the same technician. Pregnancy rates following $\mathrm{AI}$ or the second $\mathrm{ET}$ at Location 2 were diagnosed by transrectal ultrasonography 30 to $60 \mathrm{~d}$ after AI or ET. 
Control $(n=247)$

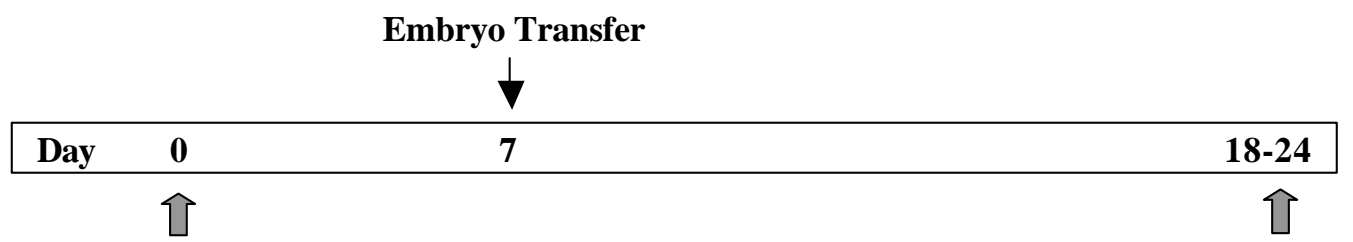

Estrus

Observe for

return to estrus

$\operatorname{CIDR}^{\mathrm{a}}(\mathrm{n}=225)$

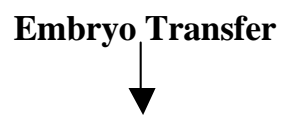

\section{3-d CIDR Insert}

\begin{tabular}{|llll|}
\hline Day & 0 & 7 & $20-24$ \\
\hline
\end{tabular}

Estrus

Observe for return to estrus

Flunixin Meglumine ${ }^{\mathbf{b}}(\mathrm{n}=242)$

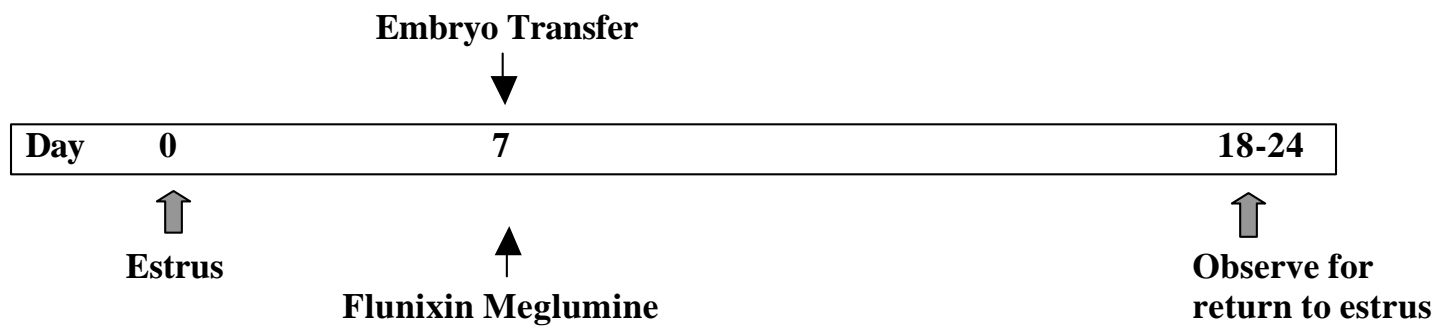

CIDR + Flunixin Meglumine $(\mathrm{n}=226)$

Embryo Transfer

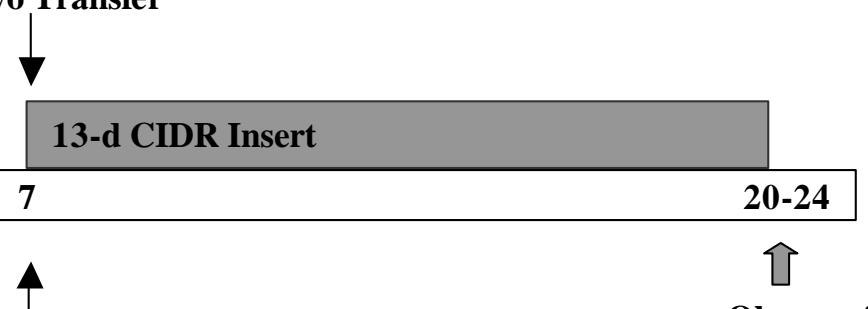

Estrus

Flunixin Meglumine

Observe for return to estrus

Figure 4.1. Diagrammatic representation of experimental design: Initial ET.

${ }^{\mathrm{a}} \mathrm{CIDR}$ containing $1.38 \mathrm{~g} \mathrm{P}_{4}$

${ }^{\mathrm{b}} 500 \mathrm{mg}$ flunixin meglumine injected i.m. 


\begin{tabular}{|lc|c|}
\hline & CIDR $^{\mathrm{a}}$ & No CIDR \\
Flunixin Meglumine $^{\mathrm{b}}$ & 226 & 242 \\
& & \\
\cline { 2 - 3 } No Flunixin Meglumine & 225 & 247 \\
& & \\
\hline
\end{tabular}

Figure 4.2. Number of animals as signed to each $2 \times 2$ factorial treatment group. ${ }^{\mathrm{a}}$ Insertion of a CIDR containing $1.38 \mathrm{~g}$ progesterone immediately following ET for a $13 \mathrm{~d}$ period.

${ }^{\mathrm{b}}$ Injection of $500 \mathrm{mg}$ Flunixin meglumine immediately prior to ET.

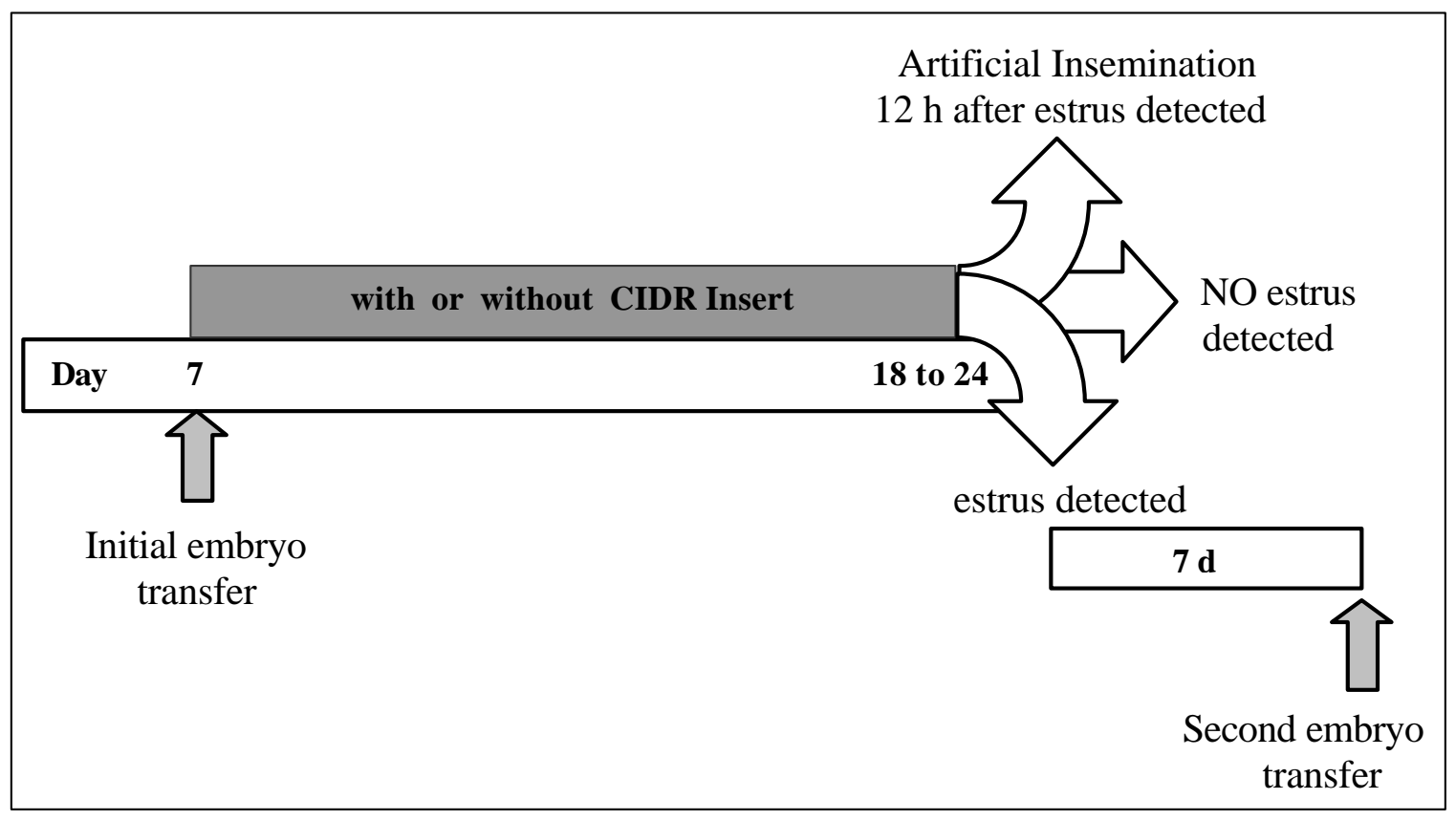

Figure 4.3. Diagrammatic representation of experimental design: Resynchronization of estrus for AI or ET at Location 2. 


\section{Statistical analysis.}

Pregnancy rates following the initial embryo transfer were analyzed as a linear logistic regression model for binary data using the LOGISTIC procedure of SAS (Statistical Analysis System v 8.2, Cary, NC). Logistic regression is a non-linear transformation of the linear regression model and is used to perform regression analysis on binary data. Linear regression cannot be used for binary data for the following reasons: 1) The predicted values of the response can become greater than one and less than zero, which is theoretically impossible with a binary response, 2) The assumption that variance of the dependent variable is constant across values of an independent variable is violated, and 3) The error term is not normally distributed. Chi-square analysis was not performed because there were more than two independent variables in the model. Additionally, the logistic procedure is more closely reflective of the true distribution of the data where chi-square is an approximation.

Location, breed of donor (nested within Location), parity of recipient (nested within Location), type of transfer (fresh or frozen), CL quality, synchrony of the embryo with the recipient, embryo stage, embryo grade, FM treatment, and CIDR treatment were included as main effects. Due to their low numbers, data from animals receiving either Stage $6(n=18)$ or Grade $3(n=18)$ embryos were excluded from the statistical analysis. Backward selection was used to remove independent variables that did not reduce the experimental error of the model. The significance level was set at $P=0.05$ for removal from the model. All treatment effects (CIDR and FM) and all main effects that had significant interactions with the treatments remained in the final model, regardless of significance. Pregnancy rates of recipients receiving split embryos at Location 2 were analyzed as a separate data set using the LOGISTIC procedure of SAS with the same main effects as described above for the initial ET. Backward selection was used with a significance level set at $P=0.05$ for removal of independent variables from the model. For all the data at the initial ET, raw means for each significant main effect with the associated standard error of the mean (SEM) are presented.

When possible, statistical comparisons between main effects were made using odds ratios with $95 \%$ confidence intervals (CI). Odds for this study are the probability of pregnancy occurring versus the probability of pregnancy not occurring (for a given level 
of an independent variable). The odds ratio is calculated as the ratio of the odds of pregnancy at one level of an independent variable to the odds of pregnancy at another level of an independent variable. For example, if the odds ratio for pregnancy occurring for Treatment A versus Treatment B was 1.5, then odds of pregnancy occurring for Treatment A is 1.5 times greater than the odds of pregnancy occurring for Treatment B. Pregnancy rates of cows bred by AI or ET following a return to estrus after the initial ET were analyzed using the LOGISTIC procedure of SAS (SAS Inst., Cary, NC). Method of breeding (AI or ET), CIDR treatment, and parity (nested within method of breeding) were included as main effects in the model. A separate analysis was performed for those animals rebred by AI that only included CIDR treatment and parity as main effects. Additionally, a separate analysis was performed for those animals rebred by ET that included CIDR treatment, embryo grade, and embryo stage as main effects. Parity was not included in the analysis of animals rebred by ET because no non-parous animal received an embryo following a return to estrus. Flunixin meglumine treatment was not included in the analysis of pregnancy rates following a return estrus due to its short halflife ( 3 to $5 \mathrm{~h}$ ) and the long interval (13 to $21 \mathrm{~d}$ ) between injection and a second breeding. Differences in the timing of the return to estrus in recipients that did not become pregnant to the initial embryo transfer were analyzed by the F-test for heterogeneity of variance (Steel and Torrie, 1960). 


\section{Chapter 5 Results}

Overview of the experiment.

Pregnancy rates of recipients were analyzed from the transfer of nine hundred four fresh $(n=454)$ or frozen $(n=450)$ bovine embryos were transferred to recipients at three locations. Embryo recipients received either: a FM injection prior to ET, a CIDR insert for $13 \mathrm{~d}$ beginning immediately after ET, injection of FM and insertion of a CIDR for $13 \mathrm{~d}$, or served as an untreated control. At Location 2 a subset of fresh embryos $(\mathrm{n}=$ 192) were split and then transferred. In addition, the time of the return estrus in those animals failing to conceive to the initial ET was recorded at Location 2. Those animals returning to estrus at Location 2 were rebred either by AI, or by a second ET.

In the statistical analysis of the initial ET, backward selection was used with a significance level of $P=0.05$ for removal of independent variables from the final model. A summary of the steps used in the backward elimination of independent variables can found in Appendix A. Mean pregnancy rates \pm SEM of the non-significant main effects are discussed here to provide an overall representation of the experiment. Presentation of raw means and standard errors is intended to serve as a reference point. Appropriate statistical inferences are presented as odds ratios generated by the LOGISTIC analysis.

The overall pregnancy rate of the experiment involving all transfers at all locations was $65.0 \pm 1.6 \%$. Of the 475 fresh embryos transferred, 192 were split embryos. The pregnancy rate of the split embryos was $54.1 \pm 3.6 \%$, while the pregnancy rate of whole fresh embryos was $70.8 \pm 2.8 \%$. Due to the unique biology and

characteristics of split embryos the pregnancy rates of recipients receiving split embryos were analyzed in a separate analysis.

Embryos assigned to a developmental stage of $4(n=463)$ and $5(n=249)$ were transferred at all locations. The mean pregnancy rates of Stage 4 and 5 embryos were $67.6 \pm 2.1 \%$ and $68.4 \pm 2.9 \%$, respectively. The synchrony of the recipient animal with the embryo was recorded in $12 \mathrm{~h}$ increments. The pregnancy rate for each period of synchrony is depicted in Table 5.1 
Table 5.1. Pregnancy rate in recipients that varied in synchrony between the stage of the estrous cycle of the recipient and the stage of embryo development.

\begin{tabular}{cccc}
\hline Synchrony $^{\mathbf{a}}(\mathbf{h})$ & No. of recipients & Pregnancy rate (\%) & SEM $^{\mathbf{b}}$ \\
\hline-24 & 17 & 76.5 & 11.5 \\
-12 & 125 & 73.6 & 4.0 \\
0 & 210 & 66.7 & 3.3 \\
+12 & 248 & 64.5 & 3.0 \\
+24 & 93 & 66.7 & 4.9 \\
+36 & 10 & 60.0 & 16.3 \\
\hline
\end{tabular}

${ }^{\mathrm{a}}$ Synchrony of the embryo with the recipient was determined by the following formula [days after estrus of the recipient - day of embryo development as determined by embryo developmental stage (see Table 3.2)]. Synchrony of the recipient with the embryo was recorded in $12 \mathrm{~h}$ increments.

${ }^{\mathrm{b}}$ Standard error of the mean

The quality of the CL in recipients was assessed by rectal palpation immediately prior to transfer of an embyro. The mean pregnancy rate of those recipients assigned a CL quality grade of $1(n=271)$ was $70.5 \pm 5.4 \%$ while the mean pregnancy rate of those recipients assigned a CL quality grade of $2(\mathrm{n}=441)$ was $65.8 \pm 5.9 \%$.

Parity was used as an independent variable and defined all animals one year of age as non-parous and all older animals, regardless of their lactation status as parous. Parity was nested within Location 2 as this was the only location with non-lactating cows and virgin heifers. The mean pregnancy rates of non-parous animals $(n=90)$ and parous animals $(n=622)$ were $58.1 \pm 5.1 \%$ and $69.2 \pm 1.8$, respectively. Breed of the donor animal was also an independent variable nested within location. All locations involved the transfer of embryos from Angus $(n=564)$ animals, however, at Locations 1 and 3 embryos were also transferred from Charolais donors $(n=148)$. The mean pregnancy rates of recipients that received embryos from Angus and Charolais donors were $66.0 \pm$ $2.0 \%$ and $73.6 \pm 3.6 \%$, respectively.

\section{Initial embryo transfer: Embryo characteristics.}

The final statistical model used after backward selection included location, type of transfer, embryo quality grade, FM treatment, CIDR treatment, and the location x FM treatment interaction. Split embryos were excluded and analyzed separately. Embryo quality grade had a significant effect on pregnancy rate of recipients (Table 5.2). 
Table 5.2. Mean pregnancy rate of embryo recipients that received embryos with different embryo quality grades.

\begin{tabular}{cccccccc}
\hline & & & & & \multicolumn{2}{c}{$95 \% \mathrm{Cl} \mathrm{Limits}^{\mathrm{c}}$} \\
\cline { 3 - 8 } Grade & No. of recipients Pregnancy rate (\%) & SEM $^{\mathbf{a}}$ & $\boldsymbol{P}_{\text {-value }}$ & odds ratio & lower & upper \\
\hline 1 & 296 & 71.6 & 2.6 & 0.02 & 1.5 & 1.1 & 2.1 \\
2 & 416 & 64.7 & 2.3 & 0.02 & 1.0 & - & - \\
\hline
\end{tabular}

${ }^{\mathrm{a}}$ Standard error of the mean

${ }^{\mathrm{b}}$ Odds ratio for the likelihood of the transfer of quality grade 1 embryos resulting in pregnancy vs. the transfer of quality grade 2 embryos resulting in a pregnancy

${ }^{c} 95 \%$ confidence interval for the pregnancy odds ratio $(\alpha=0.05)$ with upper and lower limits

Grade 1 embryos were 1.5 times more likely to result in pregnancy than Grade 2 embryos $(P<0.03 ; 95 \% \mathrm{CI} ; 1.1$ to 2.1$)$. There was also a difference $(P<0.05)$ in pregnancy rates between recipients that received a fresh or frozen embryo (Table 5.3). Embryos were frozen in $10 \%$ ethylene glycol as the cryoprotectant and were transferred directly after thawing. Fresh embryos were transferred on the same day as collected. A recipient receiving a fresh embryo was 1.4 times more likely to become pregnant than a recipient receiving a frozen embryo $(P<0.05 ; 95 \% \mathrm{CI}, 1.0$ to 2.0$)$.

Table 5.3. Mean pregnancy rate of embryo recipients that received a fresh or frozen embryo.

\begin{tabular}{|c|c|c|c|c|c|c|c|}
\hline \multirow[b]{2}{*}{ Transfer } & \multirow[b]{2}{*}{ No. of recipients } & \multirow[b]{2}{*}{ Pregnancy rate (\%) } & \multirow[b]{2}{*}{ SEM ${ }^{a}$} & \multirow[b]{2}{*}{$P$-value } & \multirow[b]{2}{*}{ odds ratio ${ }^{b}$} & \multicolumn{2}{|c|}{ 95\% Cl Limits ${ }^{c}$} \\
\hline & & & & & & lower & upper \\
\hline Fresh & 262 & 70.6 & 2.8 & 0.05 & 1.4 & 1.0 & 2.0 \\
\hline Frozen & 450 & 65.8 & 2.2 & 0.05 & 1.0 & - & - \\
\hline
\end{tabular}

${ }^{\mathrm{a}}$ Standard error of the mean

${ }^{b}$ Odds ratio for the likelihood of the transfer of fresh embryos resulting in pregnancy vs. the transfer of frozen embryos resulting in a pregnancy

${ }^{\mathrm{c}} 95 \%$ confidence interval for the pregnancy odds ratio $(\alpha=0.05)$ with upper and lower limits

\section{Initial embryo transfer: Treatment effects.}

This experiment was a 2 × 2 factorial arrangement of treatments evenly distributed at all locations. Mean pregnancy rates of ET recipients assigned to each of the four treatments are presented in Table 5.4. 
Table 5.4. Mean pregnancy rate of embryo recipients by treatment administered.

\begin{tabular}{cccc}
\hline \hline Treatment $^{\mathbf{b}}$ & No. of recipients & Pregnancy rate (\%) & SEM $^{\mathbf{a}}$ \\
\hline Control & 194 & 65.0 & 3.4 \\
CIDR & 168 & 60.7 & 3.8 \\
FM & 181 & 74.7 & 3.2 \\
CIDR + FM & 169 & 69.8 & 3.5 \\
\hline
\end{tabular}

${ }^{\mathrm{a}}$ Standard error of the mean

${ }^{\mathrm{b}}$ Recipients were assigned to one of four treatments:

Control recipients received no treatment,

CIDR-treated recipients were administered a CIDR containing $1.38 \mathrm{~g} \mathrm{P}_{4}$ at the time of ET for a $13 \mathrm{~d}$ period. FM-treated recipients were administered $500 \mathrm{mg}$ flunixin meglumine (FM) at the time of ET,

CIDR + FM-treated recipients were administered both a CIDR and FM at the time of ET.

Flunixin meglumine treatment improved pregnancy rate $(P<0.01)$. Those animals that received an injection of FM were 1.9 times more likely to become pregnant than those animals that did not receive an injection of FM (95\% CI, 1.2 to 3.0). However, there was a FM x Location interaction $(P<0.01)$. The effect of FM treatment on pregnancy rates of embryo recipients at each location are shown in Figure 5.1a. There was a 32\% increase in pregnancy rate when FM was used at Location 1. Conversely, the pregnancy rate was only $5 \%$ greater than that of controls at Location 2 and was $3 \%$ less than the pregnancy rate of untreated controls at Location 3. This variation in the effect of FM on pregnancy rate at the three locations was responsible for the FM x location interaction.

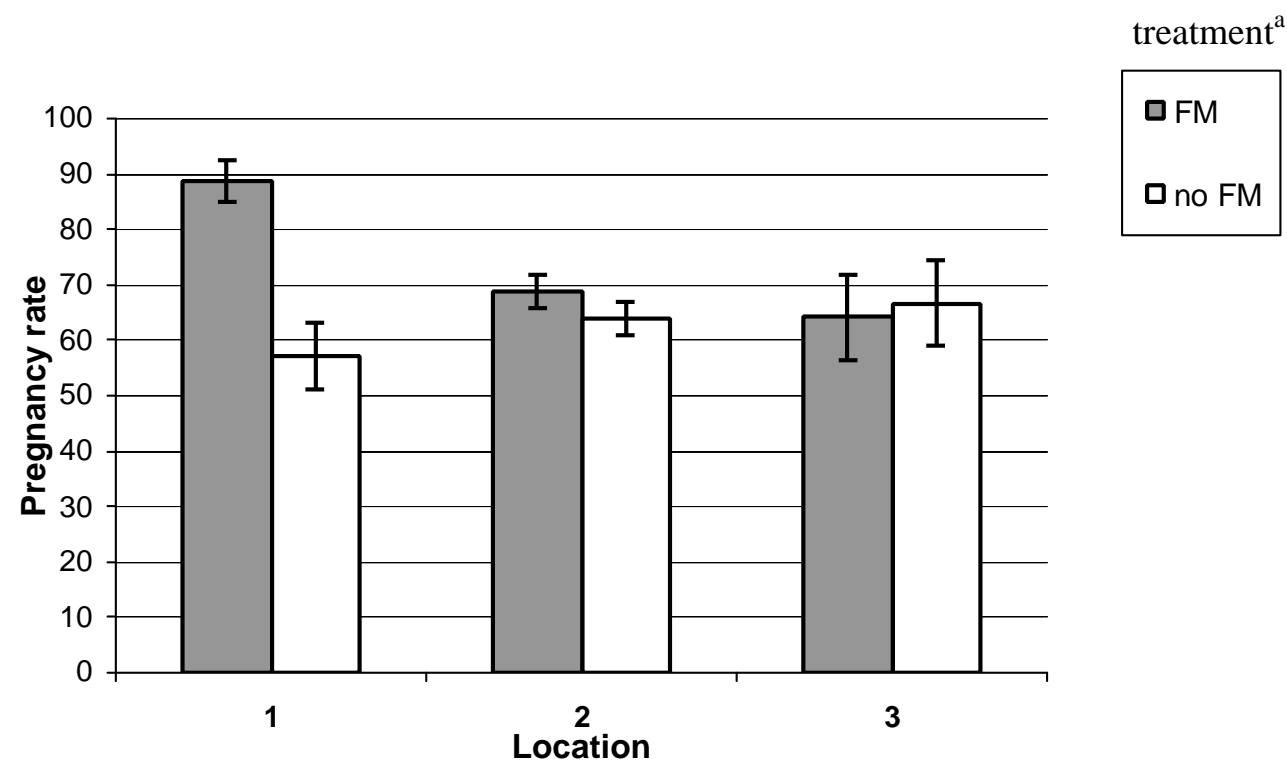

Figure 5.1a. Mean pregnancy rate \pm SEM of embryo recipients by FM treatment at each location. ${ }^{a} \mathrm{FM}$-treated recipients were administered $500 \mathrm{mg}$ flunixin meglumine at the time of ET.

The interaction between the effects of FM treatment and Location on pregnancy rate was significant $(P<0.01)$. 
Insertion of a CIDR immediately after ET tended to decrease pregnancy rate $(P=$ 0.11). Those animals that did not receive a CIDR were 1.3 times more likely to become pregnant than animals that received a CIDR. However, because this was not statistically significant, the $95 \%$ confidence interval for the odds ratio extended from 0.9 to 1.8 . The interaction between the effects of CIDR treatment and Location on pregnancy rate was not significant $(P=0.16$; Figure 5.1b). At Location 1, recipients fitted with a CIDR had a $16 \%$ lower pregnancy rate to the initial ET than recipients that did not receive a CIDR.

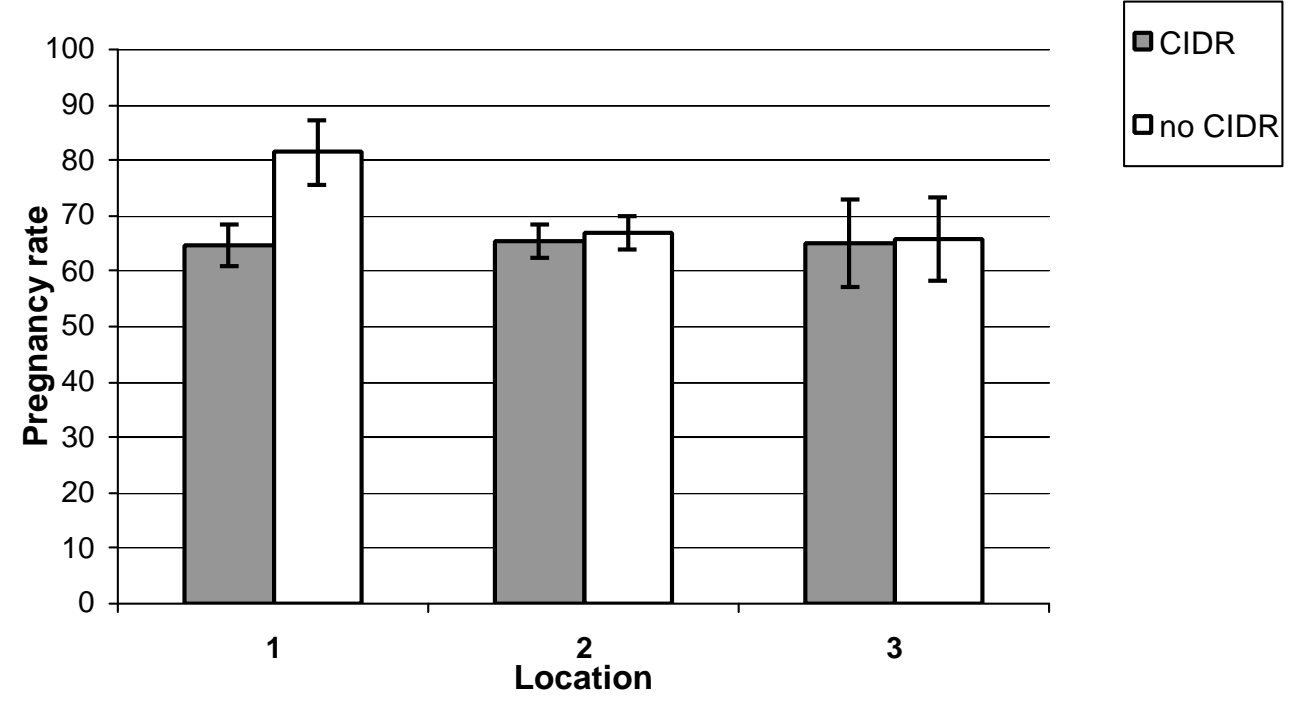

Figure 5.1b. Mean pregnancy rate \pm SEM of embryo recipients by CIDR treatment at each location. ${ }^{\mathrm{a}} \mathrm{CIDR}$-treated recipients were administered a CIDR containing $1.38 \mathrm{~g} \mathrm{P}_{4}$ at the time of ET for a $13 \mathrm{~d}$ period.

The interaction between the effects of CIDR treatment and Location on pregnancy rate was not significant $(P=0.16)$.

Data from Location 1 were most responsible for the overall negative effects of CIDR insertion on pregnancy rates. Note that at Location 2 and 3 pregnancy rates of those animals receiving a CIDR were only 2 and $1 \%$ lower than those of animals not receiving a CIDR, respectively.

Analysis of split embryos.

A total of 96 fresh embryos at Location 2 were split and 192 split embryos were transferred to synchronous recipients. The final model analyzing differences in pregnancy rate among recipients included Stage, Parity, CIDR treatment, FM treatment, and the CIDR x FM interaction. A summary of the steps used in the backward 
elimination of independent variables can be found in Appendix B. The pregnancy rates for recipients receiving split embryos that differed by stage of embryo development are presented in Table 5.5.

Table 5.5. Mean pregnancy rate of embryo recipients receiving split Stage 4 or 5 embryos.

\begin{tabular}{cccccccc}
\hline & & & & & & \multicolumn{3}{c}{$95 \% \mathrm{Cl} \mathrm{Limits}^{c}$} \\
\cline { 5 - 8 } Stage & No. of recipients Pregnancy rate (\%) & SEM $^{\mathbf{a}}$ & $\boldsymbol{P}_{\text {-value }}$ & odds ratio & lower & upper \\
\hline 4 & 162 & 50.3 & 3.9 & 0.01 & 1.0 & - & - \\
5 & 30 & 74.2 & 8.0 & 0.01 & 3.2 & 1.3 & 8.0 \\
\hline
\end{tabular}

${ }^{\mathrm{a}}$ Standard error of the mean

${ }^{\mathrm{b}}$ Odds ratio for the likelihood of the transfer of developmental stage 4 embryos resulting in pregnancy vs. the transfer of developmental stage 5 embryos resulting in a pregnancy

${ }^{c} 95 \%$ confidence interval for the pregnancy odds ratio $(\alpha=0.05)$ with upper and lower limits

Those recipients that received a split Stage 5 embryo were 3.2 times more likely to become pregnant than those recipients receiving a split Stage 4 embryo $(P<0.02,95 \%$ CI, 1.3 to 8.0$)$.

Parity of the recipient significantly influenced the pregnancy rates of animals receiving split embryos (Table 5.6). Those animals that were defined as parous were 3.4 times more likely to become pregnant than non-parous animals $(P<0.03 ; 95 \% \mathrm{CI} ; 1.1$ to 10.0).

Table 5.6. Mean pregnancy rate of embryo recipients receiving split embryos by parity.

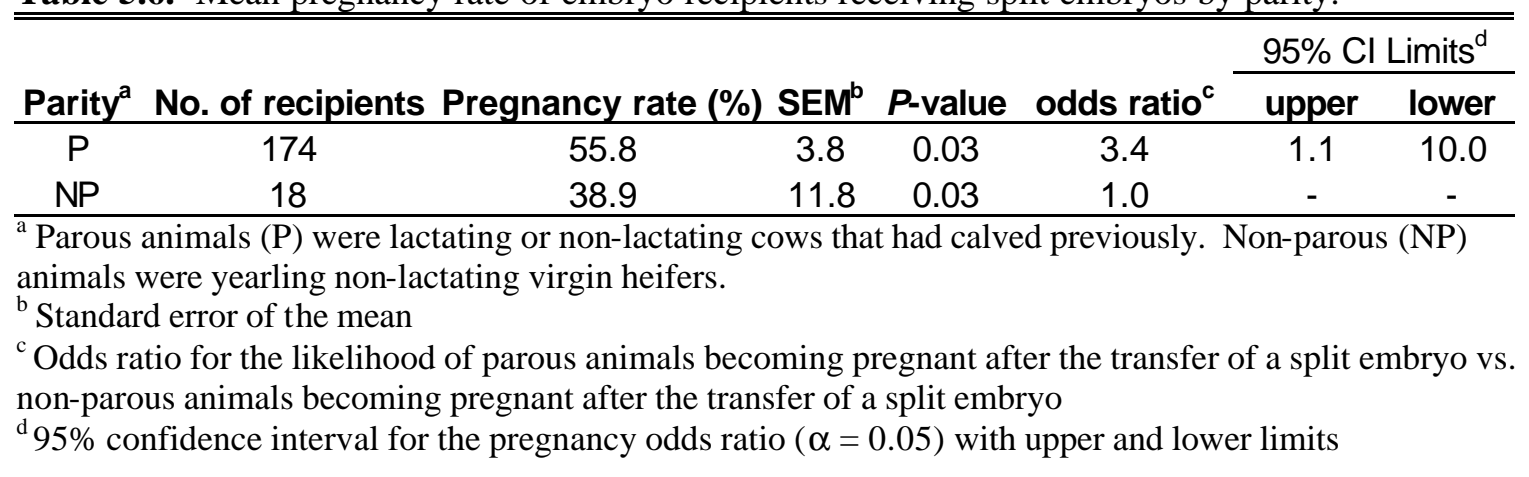

Injection of FM alone or insertion of a CIDR alone did not influence pregnancy rates of recipients receiving split embryos $(P=0.36$ and 0.50 , respectively). However, there was a significant interaction between the effects of FM and CIDR on pregnancy rate (CIDR x FM, $P<0.04$ ). Pregnancy rate of recipients assigned to each of the four treatment groups are shown in Figure 5.2. 


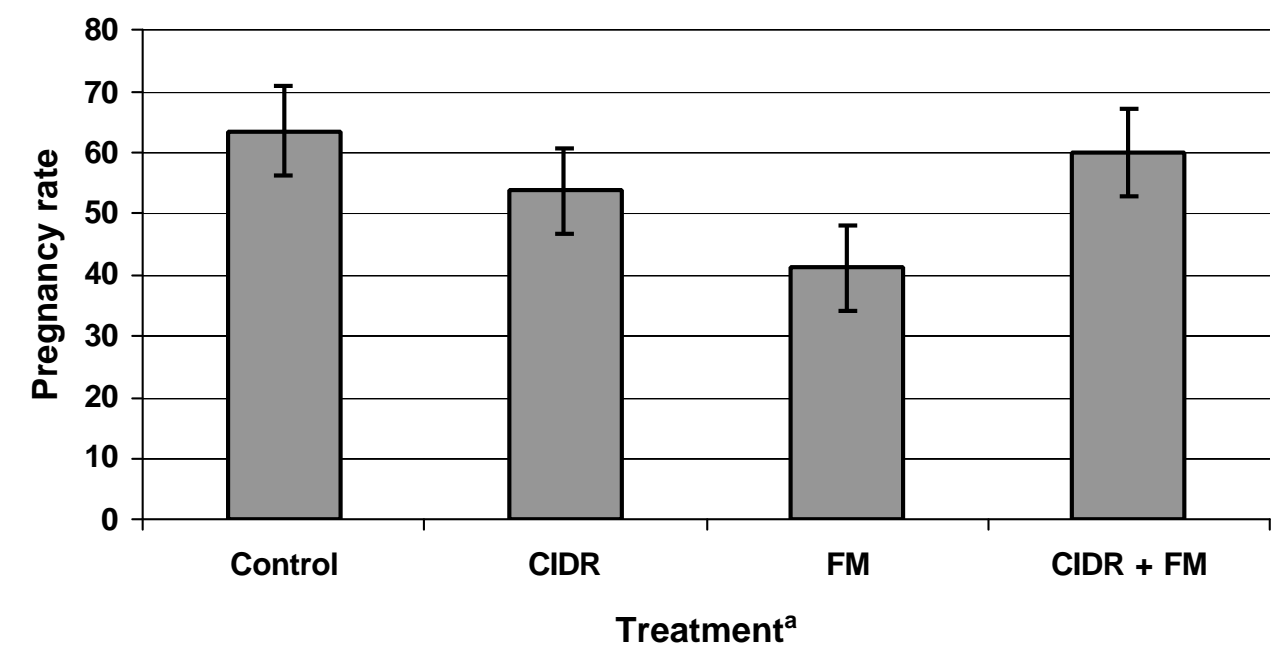

Figure 5.2. Mean pregnancy rate \pm SEM of embryo recipients by treatment for split embryos at Location 2.

${ }^{a}$ Recipients were assigned to one of four treatments:

Control recipients received no treatment,

CIDR-treated recipients were administered a CIDR containing $1.38 \mathrm{~g} \mathrm{P}_{4}$ at the time of ET for a $13 \mathrm{~d}$ period. FM-treated recipients were administered $500 \mathrm{mg}$ flunixin meglumine (FM) at the time of ET, CIDR + FM-treated recipients were administered both a CIDR and FM at the time of ET.

The interaction between the effects of CIDR and FM on pregnancy rate was significant $(P<0.04)$

The mean pregnancy rate of those animals receiving both an injection of FM and insertion of a CIDR was similar to that of untreated control animals $(60.0 \pm 7.2$ and 64.0 $\pm 7.3 \%$, respectively). However, the pregnancy rates of animals receiving FM only (41.2 $\pm 7.0 \%)$ or CIDR only $(53.9 \pm 7.0 \%)$ were numerically less than those recipients of the control or CIDR + FM treated groups.

Return to estrus: Resynchronization.

Animals returning to estrus after the initial ET at Location $2(n=205)$ were identified and either bred by AI approximately $12 \mathrm{~h}$ after detected estrus or assigned to receive an embryo approximately $7 \mathrm{~d}$ after detected return to estrus. The timing of the return estrus was less variable $(P<0.01)$ in those animals that had received a CIDR at the time of the initial ET than in those with no CIDR (Figure 5.3). 


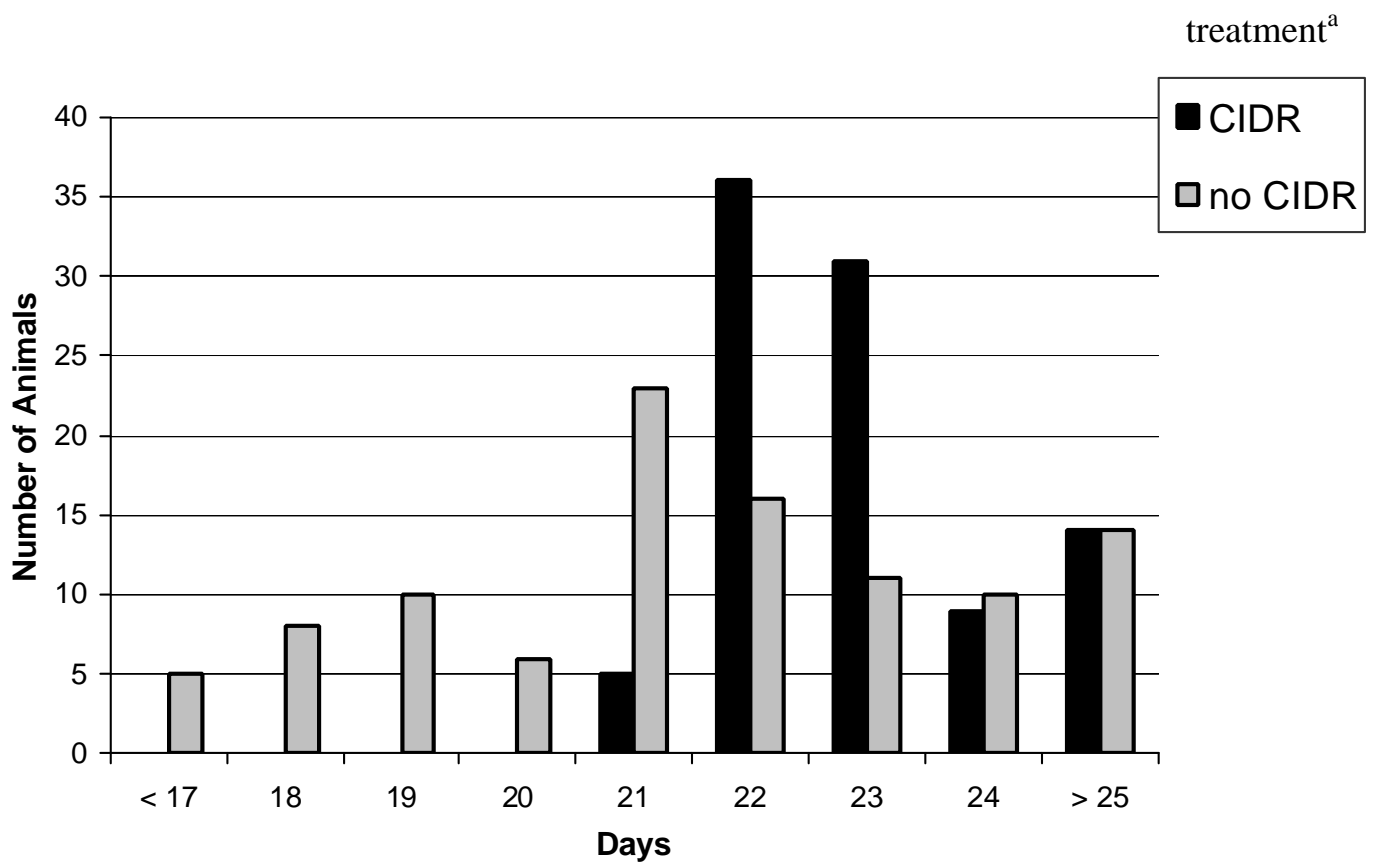

Figure 5.3. Time of the return to estrus of those animals that did not become pregnant to the initial ET. ${ }^{\mathrm{a}} \mathrm{CIDR}$-treated recipients received a CIDR containing $1.38 \mathrm{~g} \mathrm{P}_{4}$ at the time of ET for a $13 \mathrm{~d}$ period.

The variances for those animals that received a CIDR compared to those animals that did not receive a CIDR were 4.2 and $11.0 \mathrm{~d}$, respectively. In animals that had received a CIDR, 75\% were detected in estrus on d 21 to 23 after their initial estrus. Detection of return to estrus in the recipients that did not receive a CIDR was only $48.5 \%$ during the same time period. The median $d$ of return to estrus for those animals receiving a CIDR was d 23 while the median d of return to estrus for those animals that did not receive a CIDR was $d 21$. The $d$ of return to estrus ranged from $d 21$ to 34 in animals that had received a CIDR and from $\mathrm{d} 8$ to $\mathrm{d} 30$ in animals that had not received a CIDR.

Return to estrus: Pregnancy rate.

Pregnancy rates of animals bred after the return to estrus were analyzed using the LOGSITIC procedure of SAS with CIDR treatment, breeding method (AI or ET), Parity (Breeding method), Breeding method x CIDR, and Parity(Breeding method) x CIDR as main effects. Separate statistical analyses of animals bred by AI or ET following a return to estrus were also conducted to determine the effects of embryo characteristics (ET) or parity (AI) on the likelihood of recipients becoming pregnant.

Pregnancy rates of animals bred by AI or ET following a return to estrus were affected by Parity (Breeding method) $(P<0.02)$. Parity (Breeding method) was the only 
significant independent variable in that analysis. Animals that had previously calved (parous; $\mathrm{n}=161)$ had a greater pregnancy rate $(69.6 \pm 3.6 \%)$ than animals that had not calved previously (non-parous; $\mathrm{n}=44 ; 47.7 \pm 7.6 \%$ ). Treatment with a CIDR did not have a significant effect on pregnancy rate after the return to estrus $(P>0.13)$. The mean pregnancy rates of those animals that had received $(n=99)$ or did not received a CIDR ( $n$ $=106)$ to resynchronize the return to estrus were $67.7 \pm 4.7 \%$ and $61.7 \pm 4.8 \%$, respectively. The effect of method of breeding on pregnancy rate approached significance $(P=0.08)$. The mean pregnancy rates for those animals bred by AI $(\mathrm{n}=$ $114)$ or by ET $(\mathrm{n}=91)$ after a return to estrus were $59.7 \pm 4.6 \%$ and $70.7 \pm 4.8 \%$, respectively. However, because animals bred by AI were both parous $(\mathrm{n}=70)$ and nonparous $(n=44)$ the reduced pregnancy rate observed in animals bred by AI was disproportionally influenced by the non-parous animals in this group.

A separate analysis of animals that received an embryo following a return to estrus included CIDR treatment, embryo stage, embryo quality grade, CIDR x embryo stage, and CIDR x embryo quality grade as main effects. There were no significant effects of individual independent variables on pregnancy rate, however, the CIDR $x$ embryo grade interaction approached significance $(P=0.09)$. Low numbers of animals in the treatment groups prohibited this effect from being statistically significant, however, much of the interaction can be explained by differences in pregnancy rates of recipients receiving Grade 3 embryos (Figure 5.4). The pregnancy rate for those animals that received a Grade 3 embryo and were administered a CIDR for resynchronization $(n=8)$ was only $25.0 \pm 9.3 \%$. Conversely, the pregnancy rate for those animals receiving a Grade 3 embryo without CIDR administration $(n=7)$ was $71.4 \pm 18.4 \%$.

A separate analysis was conducted for those animals bred by AI. Treatment with a CIDR, parity, and CIDR x parity were included as main effects. Parity had an effect ( $P$ $<0.02$ ) on pregnancy rate of animals bred by AI after the return estrus (Table 5.7). Parous animals were 3.0 times more likely to become pregnant following AI $12 \mathrm{~h}$ after the return to estrus than non-parous animals bred by AI (95\% CI; 1.3 to 7.0$)$. 


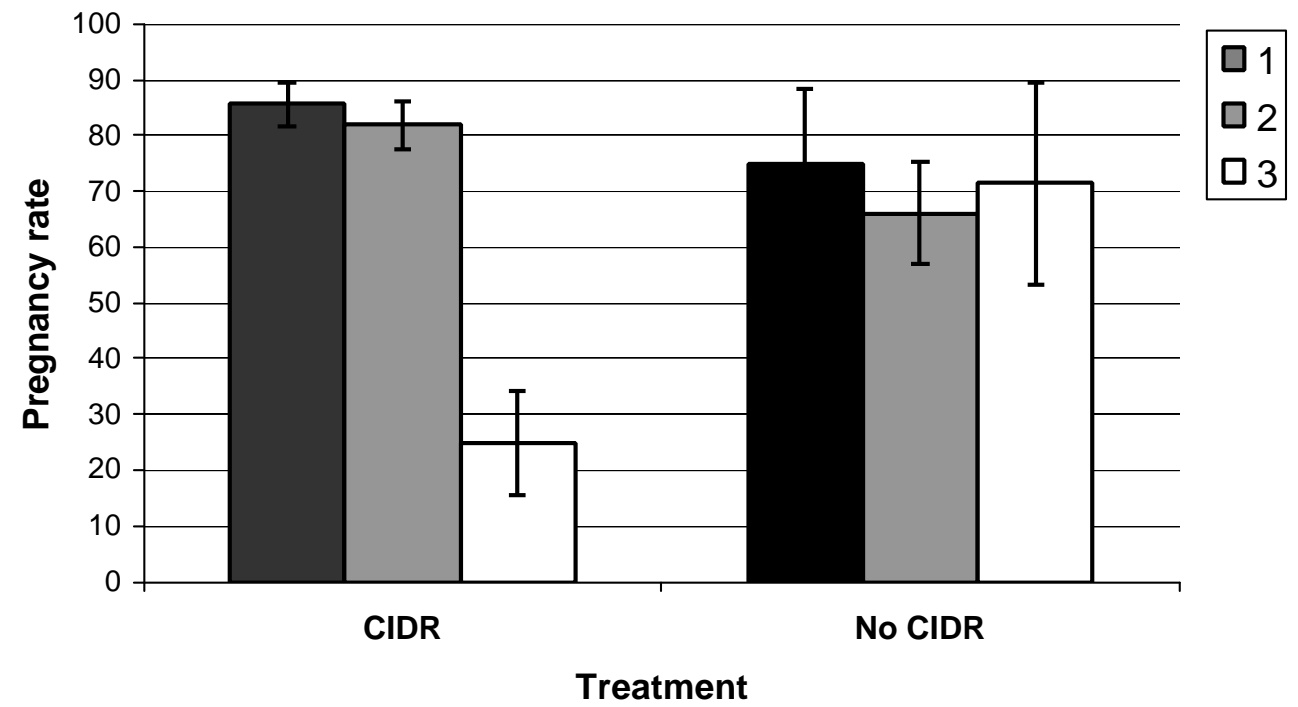

Figure 5.4. Mean pregnancy rate \pm SEM by CIDR treatment and embryo grade for those animals bred by ET after a return to estrus.

CIDR-treated animals received a CIDR containing $1.38 \mathrm{~g} \mathrm{P}_{4}$ at the time of ET.

The interaction between the effects of CIDR treatment and embryo quality grade on recipient pregnancy rate approached significance $(P<0.09)$.

Table 5.7. Mean pregnancy rate of parous (P) and non-parous (NP) animals bred by AI following a return to estrus by parity.

\begin{tabular}{ccccccccc}
\hline \hline & & & & & \multicolumn{2}{c}{$95 \%$ Cl Limits $^{d}$} \\
\cline { 4 - 8 } Parity $^{\mathrm{a}}$ & No. of animals & Pregnancy rate (\%) & SEM $^{\mathrm{b}}$ & $\boldsymbol{P}$-value & odds ratio & lower $^{\text {upper }}$ \\
\hline $\mathrm{P}$ & 70 & 68.1 & 5.7 & 0.02 & 3.0 & 1.3 & 7.0 \\
$\mathrm{NP}$ & 44 & 47.7 & 7.6 & 0.02 & 1.0 & - & - \\
\hline
\end{tabular}

${ }^{a}$ Parous animals $(\mathrm{P})$ were lactating or non-lactating cows that had calved previously. Non-parous (NP) animals were yearling non-lactating virgin heifers.

${ }^{\mathrm{b}}$ Standard error of the mean

${ }^{\mathrm{c}}$ Odds ratio for the likelihood of parous animals becoming pregnant to AI after a return to estrus vs. nonparous animals becoming pregnant to $\mathrm{AI}$ after a return to estrus

${ }_{\mathrm{d}}^{9} 95 \%$ confidence interval for the pregnancy odds ratio $(\alpha=0.05)$ with upper and lower limits

In animals bred by AI following a return to estrus, CIDR treatment did not have a statistically significant effect on pregnancy rate $(P=0.13)$. The pregnancy rates of those animals that had received a CIDR $(\mathrm{n}=55)$ for resynchronization of estrus and those animals was that had not received a CIDR $(n=59)$ were $63.6 \pm 6.5 \%$ and $56.0 \pm 6.5 \%$, respectively. 


\section{Chapter 6 Discussion}

The purpose of this experiment was twofold; first, to determine if injection of a prostaglandin inhibitor (flunixin meglumine) at the time of ET could improve pregnancy rates of embryo recipients, and second, to determine if administration of progesterone (CIDR) for a 13-d period at the time of embryo transfer would improve the synchrony of the return estrus in non-pregnant animals without having a negative effect on established pregnancies or the fertility following the return estrus. We hypothesized that the FM injection would prevent the release of $\mathrm{PGF}_{2 \alpha}$ that may have been caused by the manipulation of the uterus involved during the ET procedure. Furthermore, we hypothesized that the CIDR, inserted immediately after ET for a 13-d period, would decrease the variability in the timing of the return estrus in animals failing to conceive without having a negative effect on fertility.

\section{Flunixin meglumine treatment.}

There was no interaction between the effects of CIDR and FM treatments on the pregnancy rate following the initial embryo transfer, indicating that any effect observed in recipients due to one treatment was not influenced by the other. The mean pregnancy rates for all animals receiving a FM injection (FM and CIDR + FM) and those animals that did not receive FM (Control and CIDR) were 72.3 and 63.0\%, respectively. Although there was a significant interaction between the effects of location and treatment with FM on pregnancy rate, an injection of FM at the time of the initial ET made recipients 1.9 times more likely to become pregnant than those animals not receiving a FM injection at the time of ET (95\% CI; 1.2 to 3.0). Therefore, discussion of this effect in context of the variation among locations is warranted.

The effect of FM on pregnancy rate following ET in the present study is comparable with the results observed by Schrick et al. (2001). In the experiment reported by Schrick et al. (2001), beef cows injected with $500 \mathrm{mg}$ FM at the time of ET had a $12.7 \%$ greater pregnancy rate than untreated control cows. However, the pregnancy rates for FM-treated and control cows (63.8 and 51.5\%, respectively) were both less than the pregnancy rates observed in this experiment. There are many factors that could have caused this difference in pregnancy rate including the location and management of the recipients. However, differences in the ET technician are more easily examined. 
The same technician transferred all embryos in the current study, whereas in the experiment by Schrick et al. (2001) six technicians transferred the embryos. Although technician did not have a significant effect on pregnancy rate in that study and there was no technician $\mathrm{x}$ treatment interaction reported, the experience level of all six technicians could have been a factor causing the reduced pregnancy rates. Manipulation of the uterus can cause the release of $\mathrm{PGF}_{2 \alpha}$ (Ferguson, J.W.K., 1941). During the ET procedure the uterus must be manipulated to place the embryo in the uterine horn ipsilateral to the CL. Additional data presented by Schrick et al. (2003) indicated a significant decrease in pregnancy rate as transfer difficulty increased, which may have been due to increased $\mathrm{PGF}_{2 \alpha}$ release induced by prolonged uterine manipulation. A less experienced technician may have a more difficult time transferring an embryo. Therefore, the decreased overall pregnancy rates observed in the study by Schrick et al. (2001) and the enhanced effect of FM on pregnancy rate may be due to technician differences between that study and the experiment reported here.

Previous studies reported that in-vitro culture with $\mathrm{PGF}_{2 \alpha}$ reduced development of Stage 4-(morula) embryos (Schrick et al., 2003). In vivo, $\mathrm{PGF}_{2 \alpha}$ injections on d 5 to 8 after AI caused a reduction in pregnancy rate compared to cows injected with $\mathrm{PGF}_{2 \alpha}$ at a later time (d 10 to 13 or d 15 to 18) or to saline-treated control cows (Seals et al., 1998). Furthermore, injection of $1 \mathrm{~g}$ FM on d 5 to 8 after AI prevented a reduction in pregnancy rate caused by OT-induced $\mathrm{PGF}_{2 \alpha}$ release (Lemaster et al., 1999). The time of the greatest reduction in pregnancy rate (d 5 to 8 or Stage 4 ) coincides with the time embryos were transferred in this study as well as the stage of development of embryos used in this study. Therefore, it appears that if $\mathrm{PGF}_{2 \alpha}$ release had occurred during the ET procedure, its affect on pregnancy rate should have been apparent. Because of the large number of animals in this study $(\mathrm{n}=940)$ it was not possible to take blood samples to measure for PGFM to determine if FM injection was causing a reduction in $\mathrm{PGF}_{2 \alpha}$ release. However, the improved pregnancy rate of animals treated with FM, albeit variable across locations, indicates that this may have occurred.

There were significant treatment interactions reported by Schrick et al. (2001) that affected recipient pregnancy rate. They reported that the effect of FM treatment at the time of ET varied depending on the quality grade of the embryo. Flunixin meglumine 
treatment significantly improved the pregnancy rate of recipients receiving Grade 1 and 2 embryos, but not Grade 3 embryos. The same authors also reported an interaction between the effects of FM treatment and developmental stage of the embryo on the pregnancy rates of embryo recipients. However, in the present study there were no significant interactions between embryo developmental stage or quality grade and treatment with FM. In the study by Schrick et al. (2001) embryos transferred were either fresh, frozen in glycerol, or frozen in ethylene glycol. There was an interaction between the effect of FM injection and type of embryo transferred. Pregnancy rate was improved in FM-treated cows that received embryos frozen in ethylene glycol. Again, this is in contrast to this study. There were no significant interactions between the effects of type of embryo transferred and FM treatment on pregnancy rate.

\section{CIDR treatment.}

There was a trend $(P=0.11)$ for insertion of a CIDR to reduce the pregnancy rate of embryo recipients following the initial ET. The pregnancy rate of all animals receiving a CIDR (CIDR and CIDR + FM) was $65.3 \%$ and those animals that did not receive a CIDR (FM and Control) recorded a 69.6\% pregnancy rate following the initial ET. Recipients that did not receive a CIDR were an average of 1.3 times more likely to become pregnant. However, the $95 \%$ confidence interval for the odds ratio indicated that the true value could be from 0.9 times less likely to 1.8 times more likely. Like FM treatment, there were no significant interactions between the effects of the CIDR treatment and the effects due to the developmental stage or quality grade of the embryo transferred. Likewise, the effects of CIDR treatment on pregnancy rate did not depend on the type of embryo transferred (fresh or frozen).

Progesterone supplementation after breeding was hypothesized to serve two potential purposes; the synchronization of the return to estrus and as an aid in the establishment of pregnancy. Progesterone is an essential element in the maternal recognition of pregnancy (Mann et al., 1999). Insufficient maternal $\mathrm{P}_{4}$ production could lead to EM (Vanroose et al., 2000). Embryo development has been advanced by the supplementation of $\mathrm{P}_{4}$ (Garrett et al., 1988; Van Cleef et al., 1996). Therefore, $\mathrm{P}_{4}$ supplementation after breeding was tested as a potential method of improving pregnancy rates, as well as resynchronizing estrus. 
The CIDR treatment used in this experiment was applied to all animals, although their pregnancy status at the time was unknown. For the resynchronization to be successful, the improvement in estrus synchrony needed to be accomplished without affecting established pregnancies.

Several researchers have reported that the use of an intravaginal progesteronereleasing device either improved pregnancy rates or did not affect pregnancy rates to the initial breeding. An improvement in pregnancy rate was observed if insertion of the CIDR after AI occurred during the early- or mid-portion of the estrous cycle (MacMillan and Peterson, 1993; Robinson et al., 1989). No effect on pregnancy rate was observed when the supplemental $\mathrm{P}_{4}$ was administered after mid-cycle (MacMillan and Peterson 1993; Stevenson et al., 2003), or when supplied during both the early- and mid-cycle (Stevenson and Mee, 1991). Furthermore, in other studies where exogenous $\mathrm{P}_{4}$ was administered after AI or ET by means other than an intravaginal device, $\mathrm{P}_{4}$ supplementation had no effect on pregnancy rate (Smith et al., 1996; Favero et al., 1995).

In the study described in this thesis insertion of a CIDR at the time of ET (d 7) for a 13-d period tended to reduce pregnancy rates. The tendency for CIDR insertion to decrease pregnancy rates observed in this study is similar to that reported by Chenault et al. (2003). They administered a CIDR from d 14 to $21 \pm 1 \mathrm{~d}$ after AI in lactating dairy cows and noted reduced pregnancy rates in those cows receiving a CIDR than controls (32.7 and 36.7\%, respectively). Pregnancy rate was also reduced by CIDR treatment when the CIDR was administered earlier after breeding (Van Cleef et al., 1996). Treatment of dairy heifers with a new or used CIDR on $\mathrm{d} 1$ or 2 after AI for a $7 \mathrm{~d}$ period resulted in a lower pregnancy rate than in heifers treated with a used CIDR from d 17 to 22 after AI (18.2 and 46.5\%, respectively).

There does not appear to be a consistent time period during which $\mathrm{P}_{4}$ supplementation improves or does not affect pregnancy rates. In studies that administered $\mathrm{P}_{4}$ by a variety of methods after breeding, pregnancy rates were only reduced when $\mathrm{P}_{4}$ was administered through an intravaginal device. In this study the CIDR was inserted on $\mathrm{d} 7$ and left in place for a 13-d period. In other experiments, no effect on pregnancy rate was reported when a CIDR was inserted on d 13 to 17 after breeding for a 5- to 7-d period (Stevenson and Mee, 1991; Stevenson et al., 1993, Van 
Cleef et al., 1996). Could the longer treatment period used in this study be a factor that reduced pregnancy rates? Localized irritation and bacterial infection leading to vaginitis can occur if any foreign object is inserted into the vagina. This could be especially true if the object is left in the vagina for a prolonged period. Vaginitis could have a negative impact on pregnancy rates of cattle. Chenault et al. (2003) recorded a mucous score (1= no mucous observed; $5=$ red or brown mucous) of cows receiving CIDRs to assess the severity of a vaginal irritation. The authors reported significantly greater pregnancy rates of cows with mucous scores 1, 2, and 3 combined (35\%) compared to cows with scores 4 and $5(26 \%)$. Vaginal irritation, due to the prolonged CIDR insertion period (13 d) could have reduced pregnancy rates of animals receiving a CIDR at the initial ET.

Few experiments described above have been conducted in which a CIDR inserted after breeding was left in place for a 13 -d period. A shorter treatment period $(\approx 7 \mathrm{~d})$ was used in most other studies. The longer treatment period used here may have caused an unfavorable altered uterine environment. Peak $\mathrm{P}_{4}$ production by the $\mathrm{CL}$ occurs around $\mathrm{d}$ 10 to 15 in cattle (Senger, 1999). It has been suggested that elevated $\mathrm{P}_{4}$ levels induced by CIDR insertion earlier in the estrous cycle may lead to shortened cycles due to premature release of uterine $\mathrm{PGF}_{2 \alpha}$ (Van Cleef et al., 1996). Although $\mathrm{P}_{4}$ levels were not measured in this experiment, it can be assumed that they were elevated following insertion of the CIDR. Therefore, premature $\mathrm{PGF}_{2 \alpha}$ release is another possible cause for the reduced pregnancy rates of recipients that tended to occur in this study.

\section{Treatment $x$ Location interaction.}

The pregnancy rates of each treatment are presented in Table. 5.4. Injection of $500 \mathrm{mg}$ FM improved the overall pregnancy rate following the initial ET, however, the effect of FM varied among locations. The negative effect of CIDR insertion at the time of ET on pregnancy rate of recipients approached significance $(P=0.11)$. Unlike the effect of FM treatment, the interaction between the effects of the CIDR and location on pregnancy rate was not significant $(P=0.16)$.

The difference in pregnancy rates between FM-treated and untreated animals at Location 1 that was less dramatic at other locations appears to be the major influence behind the FM treatment $x$ location interaction (Figure 5.1a). No other significant interactions between location and any of the independent variables existed in this 
experiment. At Location 2 and 3 the pregnancy rates of recipients ranged from a high of $68.8 \%$ for FM treatment at Location 2 to a low of $64.5 \%$ for no FM treatment at Location 2. Pregnancy rates of animals treated with FM at Location 3 tended to be decreased by $3 \%$ compared to animals that did not receive FM. Conversely, at Location 1 mean pregnancy rates were 88.7 and $57.4 \%$ for recipients that did or did not receive FM prior to ET, respectively.

A larger difference in pregnancy rates after the initial ET between animals in the two CIDR treatment groups was also apparent at Location 1 (Figure 5.1b). At that location, pregnancy rates for recipients receiving or not receiving a CIDR were 64.8 and $81.4 \%$, respectively. Conversely, at Locations 2 and 3 pregnancy rates ranged from a high of $65.5 \%$ for recipients receiving a CIDR at Location 2 to a low of $65 \%$ for those not receiving a CIDR at Location 3. Location 1 contained only 19\% $(n=141)$ of the animals included in the analysis of pregnancy rate to the initial ET, while $81 \%(\mathrm{n}=571)$ of the animals were at Locations 2 and 3. Despite the smaller number of animals at Location 1, the marked differences in pregnancy rates due to FM treatment was great enough to result in overall interactions between the effects of FM treatment and location on pregnancy rate following the initial ET. The cause of the FM treatment $x$ location interactions is largely unexplained, however there are certain factors within the animal populations that were examined in an effort to explain the significant interaction between the effects of FM and location. These factors include breed, parity, postpartum interval, BCS, and donor-sire matings.

Effort was made to create equal experimental conditions at all locations. All four treatments were evenly distributed at each location (Figure 4.2) and the same technician transferred embryos at each location. Embryo developmental stage and grade, as well as type of transfer (fresh or frozen) were evenly distributed among recipients in each treatment at all locations. The two main effects analyzed in the data set that were nested within location (Breed and Parity) did not significantly influence pregnancy rates following the initial ET ( $P=0.47$ and 0.12 , respectively). Of those two effects, only Parity(location) approached significance. Parous animals tended to have a greater pregnancy rate $(68.7 \%)$ following ET than non-parous animals (58.9\%). However, all 
non-parous animals were at Location 2, a location that did not have large differences in pregnancy rate due to either treatment.

Lactating animals were present at all locations, and days post partum (DPP) could have influenced the fertility of the cow. In a recent review of the literature, the postpartum anestrus period in suckled beef cows was reported to be from 29 to $67 \mathrm{~d}$ (Yavas and Walton, 2000). The first estrous cycle following the post-partum anestrus period can be short and is associated reduced fertility (Bridges et al., 2000; Yavas and Walton, 2000). Moreover, the fertility of post-partum cows is increased in cows that have had one or more estrous cycles before breeding (Rhodes et al., 2003). In this experiment, the average DPP was longer than the post partum anestrus period reported in the study by Yavas and Walton (2000) and was similar among Locations 1, 2, and 3 (90, 81, and 80 DPP, respectively). Furthermore, each cow that received an embryo had been observed in estrus approximately $7 \mathrm{~d}$ before ET, indicating that all animals in the study were exhibiting estrous cycles.

The locations of recipients in this experiment were close geographically and animals were fed similar diets and maintained under similar management conditions. Body condition score (BCS: 1 = emaciated, 9 = obese), however, was not recorded. Cows with higher BCS at calving resume estrous cyclicity sooner after calving (Randel, 1990). Body condition score may also influence the fertility of beef cattle. In a study by DeRouen et al. (1994) primiparous cows with BCS 6 and 7 at calving had greater pregnancy rates $70 \mathrm{~d}$ ( 87.0 and $90.7 \%$, respectively) after breeding than those with BCS 4 and 5 (64.9 and 71.4\%, respectively). Spitzer et al. (1995) also reported greater pregnancy rates in cows with a BCS of 6 than in cows with a BCS of 4 or 5. In contrast, Ciccioli et al. (2003) reported that BCS at calving had no effect on estrus, ovarian function, or reproductive performance in primiparous beef cows. The authors reported that these reproductive traits were influenced more by specific factors such as leptin, insulin, glucose, NEFA, and thyroxine (Ciccioli et al., 2003). Hence, differences in BCS may have resulted in differences in pregnancy rates recorded at each location in this experiment. However, recipients were randomly assigned to treatments within each location and each recipient had exhibited estrus prior to the initial ET. Therefore, it is unlikely that differences among treatment groups in pregnancy rate following the initial 
ET or interactions between the effects of either treatment and location were due to undocumented differences in BCS of the animals.

The donor and sire used to create the embryo varied within locations. Donor and sire were distributed within each location and across Locations 1 and 3. However, because the embryo developmental stages and quality grades produced from each donorsire mating were randomly distributed at each location, it is unlikely that donor and sire had an effect on the location interaction.

In conclusion, there does not appear to be a "smoking gun" to explain the reason for the marked differences in treatment effects at the three locations. No other main effects had significant interactions with location. In addition, those main effects nested within location were not significant. Although Parity(Location) approached significance, the trend for reduced pregnancy rates of non-parous animals would only have had an influence at Location 2. Although we did not measure BCS, it is unlikely that this influenced the interactions because treatments were assigned randomly and distributed evenly across locations. Because of these reasons, it is unknown why injection of FM or insertion of a CIDR would have a different effect on the pregnancy rate of recipients at different locations.

Embryo characteristics: Stage, Grade, and Type.

Embryos transferred following the first detected estrus in this experiment were quality Grade 1 or 2 and were at Stage 4 or 5 of development. No differences in pregnancy rates in recipients were observed following the transfer of embryos of different developmental stages. These results agree with large retrospective analyses done at commercial ET companies and with studies conduced at large ranches (Hasler, 2001; Spell et al., 2001).

Grade 1 embryos were 1.5 times more likely to result in pregnancy in this experiment than Grade 2 embryos (95\% CI, 1.1 to 2.1). Similar results have been reported by others. In an analysis of transfers done at a commercial ET companies Hasler (2001) reported pregnancy rates of recipients following the transfer of Grade 1 embryos $(62.8 \%)$ were greater than those that received Grade 2 embryos (56.8\%). An earlier analysis also reported greater pregnancy rates of recipients associated with the transfer of Grade $1(64 \%)$ embryos compared to Grade 2 (45\%) embryos. 
Embryos transferred in this experiment were transferred fresh $(n=262)$ or after being frozen and thawed $(n=450)$. Ethylene glycol $(E G)$ was used as the cryoprotectant for frozen embryos in this experiment. Use of EG facilitates the direct transfer of embryos without the need for post-thaw washing steps required with other cryoprotectants, such as glycerol. Pregnancy rate associated with the transfer of fresh and frozen embryos were 70.6 and $65.8 \%$, respectively. The statistical analysis revealed that the transfer of fresh embryos was 1.4 times more likely to result in pregnancy than the transfer of frozen embryos (95\% CI, 1.0 to 2.0). This is similar to the results of Hasler (2001) and Spell et al. (2001) who reported that pregnancy rates following the transfer of fresh embryos were $9.9 \%$ and $13.8 \%$ greater, respectively, than following the transfer of frozen embryos.

Split embryos.

A subset of fresh embryos were split and transferred fresh at Location $2(n=194)$. The overall pregnancy rate resulting from the transfer of split embryos was $54.1 \%$. A retrospective analysis by Lopes et al. (2001) revealed that pregnancy rates for recipients receiving fresh split embryos were routinely between 50 and 60\%. Embryos split in this study were Stage 4 or 5 embryos, that corresponded to the compact-morula and earlyblastocyst stages of development, respectively (Table 4.1). Later in development, when the blastocoel cavity has enlarged, embryos are generally not split because of the inability of the blastocoel fluid to be distributed evenly between the two halves. However, the early blastocyst, like the Stage 5 embryos used in this study, have a small blastocoel cavity with little fluid. In this study, the transfer of split, Stage 5 embryos was 3.2 times more likely to result in pregnancy than the transfer of embryos that had not formed a blastocoel cavity prior to splitting (Stage 4; 95\% CI, 1.3 to 8.0). Other studies have not reported a difference in pregnancy rate between split embryos of different developmental stages. Gray et al. (1991) reported pregnancy rates following the transfer of developmental Stage 3, 4, 5, and 6 embryos were 48.6, 51.6, 50.0, and 52.5\%, respectively. The reason for the difference observed in this study is unknown.

There has been little research done on methods to improve the pregnancy rate of split embryos because it is a seldom used technology in the commercial industry Although CIDR $(P=0.50)$ or FM $(P=0.36)$ treatment alone did not have an effect on 
pregnancy rate following the transfer of split embryos, a CIDR x FM interaction was detected. Recipients receiving both CIDR and FM had pregnancy rates similar to control animals while pregnancy rates of recipients that received just a CIDR or just FM were reduced. This trend was not apparent in the larger data set derived from the transfer of whole embryos. The reason that the treatments would have different effects on recipients receiving split embryos compared to whole embryos is unexplained.

Return to estrus: Fertility and synchrony.

Insertion of a CIDR at the time of ET for $13 \mathrm{~d}$ significantly decreased the variability of the return estrus in those animals failing to become pregnant to the initial ET (Figure 4.3). In those animals that received a CIDR for resynchronization, no animal displayed estrus $<21 \mathrm{~d}$ after the initial estrus. In contrast, in those animals that did not receive a CIDR, 29 out of 103 returned to estrus $<21 \mathrm{~d}$ from the initial estrus. The synchrony of the return estrus was also improved in other experiments when a CIDR was administered after breeding to resynchronize the return estrus (Van Cleef et al., 1996; MacMillan and Peterson, 1993; Chenault et al., 2003; Stevenson et al., 2003). In this study $75 \%$ of the animals that had received a CIDR and did not conceive to the initial ET were in estrus within $2 \mathrm{~d}$ of CIDR removal. Stevenson et al. (2003) reported $76 \%$ of inseminated, non-pregnant animals treated with a CIDR from d 13 to 20 after AI were in estrus within d 2 after removal. This shortened time period of the return to estrus and the prevention of estrus before CIDR remo val eases management requirements and time needed for rebreeding.

Animals returning to estrus in this study were either bred by AI approximately 12 $\mathrm{h}$ following the observed estrus, or received a fresh embryo $7 \mathrm{~d}$ following the observed estrus. Animals bred by AI following a return to estrus tended to have decreased pregnancy rates compared to animals bred by ET following a return to estrus (59.7 and $70.7 \%$, respectively). However, type of breeding was nested within parity because no non-parous animal received an embryo, while animals bred by AI were both parous $(\mathrm{n}=$ 69) and non-parous $(n=44)$. Non-parous animals were significantly less likely to become pregnant following the return to estrus. Therefore, the reduced pregnancy rates of animals bred by AI is likely due to the non-parous animals in that breeding group. 
Pregnancy rate was not affected by CIDR treatment, nor was there an interaction between the effects of CIDR treatment or type of breeding on pregnancy rate. Pregnancy rates at the second breeding for those animals that received a CIDR or did not receive a CIDR were 67.7 and $61.7 \%$, respectively. This agrees with studies that reported no statistical differences in pregnancy rates between CIDR-treated and untreated animals following a resynchronized estrus (Van Cleef et al., 1996; MacMillan and Peterson, 1993; Chenault et al., 2003). However, the fertility of the return estrus was reduced in other studies following CIDR treatment. In cows treated with a CIDR from d 13 to 20 after AI, Stevenson et al. (2003) reported a 26.7\% decrease in pregnancy rates and ElZarkouny et al. (2001) reported a $15 \%$ decrease in pregnancy rates compared to untreated cows. Reasons presented for this reduced fertility have focused on the development of a persistent follicle that may have been produced due to the low levels of $\mathrm{P}_{4}$ being released from the CIDR. Ovulation of a persistent follicle may result in reduced pregnancy rates due to premature oocyte maturation (Borchert et al., 1999; Mihm et al., 1999).

Although the duration of treatment was shorter in the studies above ( 4 to $7 \mathrm{~d}$ ), the fertility of the resynchronized estrus was not affected by the longer treatment duration (13 d) used in this study. In this study the CIDR was administered at the time of ET (d 7). At this time a CL was present on the ovary, and that CL presumably remained present for at least $10 \mathrm{~d}$. Development of a persistent follicle has been reported to occur when exogenous $\mathrm{P}_{4}$ was administered under conditions of low luteal $\mathrm{P}_{4}$ levels (Savio et al., 1993b; Robinson et al., 1989; Sirois and Fortune, 1990). Because of the time of CIDR administration in this study, low levels of $\mathrm{P}_{4}$ should have only been occurring during the last 3 to $4 \mathrm{~d}$ of the CIDR treatment. Studies have indicated that for a persistent follicle to result in decreased fertility it must be persistent for $>4 \mathrm{~d}$ (Austin et al., 1999) or $>9 \mathrm{~d}$ Mihm et al. (1999) before ovulation. Therefore, the time period that exogenous $\mathrm{P}_{4}$ was administered in this experiment may have prevented the occurrence of a persistent follicle and subsequent reduced fertility.

In those animals bred by ET following resynchronization, there was an interaction between the effects of CIDR treatment and the effects of embryo quality grade on pregnancy rate that approached significance $(P=0.08)$. The pregnancy rate of those 
animals receiving a Grade 3 embryo and a CIDR was much less (25\%) than the pregnancy rate of those animals that did not receive a CIDR (71\%; Figure 5.4). The difference in pregnancy rates due to treatment with a CIDR in recipients that received Grade 1 or 2 embryos was much less (16.5\% and 17\%, respectively). Due to the low number of Grade 3 embryos ( $n=15$ ), caution is necessary in interpreting these results, even though there was a significant treatment $\mathrm{x}$ quality grade interaction.

Parity effects.

In this experiment non-parous animals were those animals $1 \mathrm{yr}$ of age and parous animals were any animal $>1 \mathrm{yr}$ of age. The effect of Parity (location) on pregnancy rate following the initial ET approached significance. In the analysis of pregnancy rates following the transfer of split embryos at Location 2, parity had a significant effect (Table 5.6). Likewise, in the analysis of the fertility of those animals bred by AI following a returning to estrus after the initial ET at Location 2, parity had a significant effect on pregnancy rate (Table 5.7). In all cases, non-parous animals had lower pregnancy rates than parous animals. By contrast, a retrospective analysis of a commercial ET company reported no differences in ET pregnancy rates between parous (59\%) and non-parous animals (58\%; Wright, 1981). A more recent analysis of a commercial ET company also reported no differences in ET pregnancy rates between beef cows and heifers (Hasler, 2001). Reduced conception rates in beef heifers compared to cows are generally attributed to some of the heifers being non-cycling at the time of breeding. The non-parous animals used in this experiment, however, were known to be cycling because behavioral estrus was observed approximately $7 \mathrm{~d}$ before the initial embryo transfer was performed. Therefore, the cause of the reduced pregnancy rates observed in non-parous animals in this experiment is unexplained. 


\section{Chapter 7 Implications}

In summary, administration of FM at the time of ET improved pregnancy rates, however, this improvement was location dependent. The insertion of a CIDR at the time of ET tended to depress pregnancy rates to the initial ET, however this was not statistically significant. The CIDR treatment did reduce the variation in the return estrus without affecting the fertility of that estrus.

Although there was an interaction with location, the overall trend was for FM treatment to improve pregnancy rates. Whether being performed by a single veterinarian or a large commercial company, the process of transferring the embryo will likely be performed at a variety of locations. In order to practically evaluate an ET program, a practitioner will analyze his or her success in the context of the entire group of animals he or she treats, not as separate groups at separate locations. Therefore, the practitioner must choose treatments and protocols that will improve the overall success of the ET program and not base decisions on results obtained from single locations. Because FM injection at the time of ET resulted in an improvement in overall recipient pregnancy rates in this study, it is likely that a practitioner with this information would apply the treatment to recipients of all clients at all locations.

To determine the "real-world" implications of this it is necessary to calculate the costs and benefits of using FM. For this example Location $2(n=522)$ will be used because the most information is available from this ranch. The cost to transfer one frozen embryo at this ranch ranged from $\$ 60$ to $\$ 100$ per embryo. This included the cost of drugs, semen, embryo freezing, and labor at collection and transfer. An average cost of $\$ 80.00$ was adopted for this example. The cost of a $250 \mathrm{~mL}$ bottle of FM is approximately $\$ 70.00$, equating to $\$ 2.80$ per $10 \mathrm{~mL}$ injection. Using this information, the cost to treat all recipients at Location 2 would have been $\$ 1,461.60$ (\$2.80 x 522). This equates to a $3.5 \%$ increase in the transfer cost per embryo $(\$ 2.80 / \$ 80.00)$.

The increase in overall pregnancy rate observed at Location 2 was 5\%. Assuming a baseline pregnancy rate of $60 \%$, the use of FM would result in a $65 \%$ pregnancy rate, or 339 pregnancies in a herd the size of that at Location $2(n=522)$. Conversely, with no FM the pregnancy rate would be $60 \%$, or 313 pregnancies. Assuming each pregnant cow carried the calf to term, FM treatment would increase the ET calf crop by 26 calves. For 
those 26 calves to cover the cost of treating all the recipients with FM $(\$ 1,461.60)$ each additional calf would only have to generate $\$ 56.22$ in net income, or 3.9\% of the cost of the FM treatment. This is a reasonable goal for any producer to obtain, particularly when considering the value of an ET calf. Thus far, there has only been one other study reporting the effects of FM administered at the time of ET, therefore, more research is necessary to clearly define the benefits of this treatment.

The use of CIDR at the time of ET proved to be beneficial. It resulted in a tighter synchrony of the return to estrus and did not adversely affect the fertility of those animals. The CIDR also prevented the occurrence of estrus before the CIDR was removed. Furthermore, the close synchrony of the return estrus may allow the use of timed AI to further reduce the time and labor necessary to produce pregnancies in as many animals as possible.

The cost and benefits of the CIDR treatment can also be calculated using Location 2 as an example, albeit not as objectively as in the analysis of the costs and benefits of FM treatment. Each CIDR insert costs approximately \$8.00, therefore, if a CIDR was administered to all recipients at Location 2 this would cost the producer $\$ 4,176.00(\$ 8.00$ $x$ 522). The benefits of the synchronous return to estrus that the CIDR treatment would provide are a reduction in the time and labor needed to detect estrus, and the ability to more easily breed the recipient by AI or to more easily schedule a second opportunity for ET, as opposed to breeding with a cleanup bull. Therefore, the convenience to the producer and the value of an AI or ET calf must offset the $\$ 4,176.00$ cost of administering the CIDR treatment.

Lastly, the administration of the CIDR occurred concurrently with the injection of FM and the transfer of the embryo. These two treatments, both easily provided to embryo recipients at the same time as ET are beneficial in terms of pregnancy rate and resynchronization of estrus, which is a great benefit to any cattle producer. 


\section{Literature Cited}

Adams, G. P. 1999. Comparative patterns of follicle development and selection in ruminants. J. Reprod. Fertil. Suppl. 54:17-32.

Ahmad, J., F. N. Schrick, R. L. Butcher and E. K. Inskeep. 1995. Effect of persistent follicles on early embryonic losses in beef cows. Biol. Reprod. 52:1129-1135.

Arosh, J. A., S. K. Banu, P. Chapdelaine, and M. A. Fortier. 2004a. Temporal and tissuespecific expression of prostaglandin receptors EP2, EP3, EP4, FP, and cyclooxygenases 1 and 2 in uterus and fetal membranes during bovine pregnancy. Endocrinology 145:407-417.

Arosh, J. A., S. K. Banu, P. Chapdelaine, E. Madore, J. Sirois, and M. A. Fortier. 2004b. Prostaglandin biosynthesis, transport, and signaling in corpus luteum: A basis for autoregulation of luteal function. Endocrinology 145:2551-2560.

Arosh, J. A., J. Parent, P. Chapdelaine, J. Sirois, and M. A. Fortier. 2002. Expression of cyclooxygenases 1 and 2 and prostaglandin $E$ synthase in bovine endometrial tissue during the estrous cycle. Biol. Reprod. 67:161-169.

Asselin, E., F. W. Bazer, and M. A. Fortier. 1997. Recombinant ovine and bovine interferons tau regulate prostaglandin production and oxytocin response in cultured bovine endometrial cells. Biol. Reprod. 56:402-408.

Austin, E. J., M. Mihm, M. P. Ryan, D. H. Williams, and J. F. Roche. 1999. Effect of duration of dominance of the ovulatory follicle on onset of estrus and fertility in heifers. J. Anim. Sci. 77:2219-2226.

Bartol, F. F., R. M. Roberts, F. W. Bazer, G. S. Lewis, J. D. Godkin, and W. W. Thatcher. 1985. Characterization of proteins produced in vitro by periattachment bovine conceptuses. Biol. Reprod. 32:681-693.

Bigelow, K. L., and J. E. Fortune. 1998. Characteristics of prolonged dominant versus control follicles: follicle cell numbers, steroidogenic capabilities, and messenger ribonucleic acid for steroidogenic enzymes. Biol. Reprod. 58:1241-1249.

Binelli, M., W.F W. Thatcher, R. Mattos, and P. S. Baruselli. 2001. Antiluteolytic strategies to improve fertility in cattle. Theriogenology 56:1451-1463.

Borchert, K. M., C. E. Farin, and S. P. Washburn. 1999. Effect of synchronization with norgestomet on the integrity of oocytes from persistent follicles in beef cattle. J. Anim. Sci. 77:2742-2748.

Breuel, K. F., A. Fukuda, and F. N. Schrick. 1993. Effect of prostaglandin $F_{2 \alpha}$ on development of 8-cell rat embryos in vitro. Biol. Reprod. (Suppl.) 48:173. 
Bridges, P. J., R. Taft, P. E. Lewis, W. R. Wagner, and E. K. Inskeep. 2000. Effect of the previously gravid uterine horn and postpartum interval on follicular diameter and conception rate in beef cows treated with estradiol benzoate and progesterone. $\mathrm{J}$. Anim. Sci. 78:2172-2176.

Chenault, J. R., J. F. Boucher, K. J. Dame, J. A. Meyer, and S. L. Woods-Follis. 2003. Intravaginal progesterone insert to synchronize return to estrus of previously inseminated dairy cows. J. Dairy Sci. 86:2039-2049.

Ciccioli, N. H., R. P. Wettemann, L. J. Spicer, C. A. Lents, F. J. White, and D. H. Keisler. 2003. Influence of body condition at calving and postpartum nutrition on endocrine function and reproductive performance of primiparous beef cows. J. Anim. Sci. 81:3107-3120.

Clark, B. J., J. Wells, S. R. King, and D. M. Stocco. 1994. The purification, cloning, and expression of a novel luteinizing horomone-induced mitochondrial protein in MA-10 mouse Leydig tumor cells. Characterization of the steroidogenic acute regulatory protein (StAR). J. Biol. Chem. 269:28314-28322.

DeRouen, S. M., D. E. Franke, D. G. Morrison, W. E. Wyatt, D. F. Coombs, T. W. White, P. E. Humes, and B. B. Greene. 1994. Prepartum body condition and weight influences on reproductive performance of first-calf beef cows. J. Anim. Sci. 72:1119-1125.

El-Zarkouny, S. Z., J. A. Cartmill, A. M. Richardson, M. A. Medina-Britos, B. A. Hensley, and J. S. Stevenson. 2001. Presynchronization of estrous cycles in lactating dairy cows with Ovsynch + CIDR and resynchronization of repeat estrus using the CIDR. J. Dairy Sci. Suppl. 84:249 (Abstr.)

Garrett, J. E., R. D. Geisert, M. T. Zavy, and G. L. Morgan. 1988. Evidence for maternal regulation of early conceptus growth and development in beef cattle. J. Reprod. Fertil. 84:437-446.

Greenspan, F. S. and D. G. Gardner. 2001. Basic and Clinical Endocrinology. 6th Edition. Lange Medical Books/McGraw Hill, New York, NY.

Farin, P. W., and C. T. Estill. 1993. Infertility due to abnormalities of the ovaries in cattle. Vet. Clin. North Am. Food Anim. Pract. 9:291-308.

Favero, R. J., D. B. Faulkner, and D. J. Kesler. 1993. Norgestomet implants synchronize estrus and enhance fertility in beef heifers subsequent to a timed artificial insemination. J. Anim. Sci. 71:2594-2600.

Favero, R. J., D. B. Faulkner, T. G. Nash, and D. J. Kesler. 1995. Effect of norgestomet treatment after insemination on the calving rate of postpartum suckled beef cows. J. Anim. Sci. 73:3230-3234. 
Ferguson, J. K. W. 1941. A study of the motility of intact uterus at term. Surg. Gynecol. Obstet. 73:359-366.

Gray, K. R., K. R. Bondioli, and C. L. Betts. The commercial application of embryo splitting in beef cattle. Theriogenology 35:37-44.

Hanzen, C.H., P.V. Drion, O. Lourtie, C. Depierreux, and E. Christians. 1999. La mortalite embryonnaire. Aspect cliniques et facteurs etiologiques dans l' espece bovine. Ann. Med. Vet. 143: 91-118.

Hansen, P.J. 2002. Embryonic mortality in cattle from the embryo's perspective. J. Anim. Sci. 80 (Suppl. 2):33-44.

Hasler, J. F. 2001. Factors affecting frozen and fresh embryo transfer pregnancy rates in cattle. Theriogenology 56:1401-1415.

Hasler, J. F. 2003. The current status and future of commercial embryo transfer in cattle. Anim. Reprod. Sci. 79:245-264.

Heape, W. 1891. Preliminary note on the transplantation and growth of mammalian ova within a uterine foster mother. Proc. Roy. Soc. Lond. 48:457-458.

Hixon, J., and W. Hansel. 1974. Preferential transfer of prostaglandin $\mathrm{F}_{2 \alpha}$ to the ipsilateral ovarian artery following intrauterine administration in cattle. Biol. Reprod. 11:543-552.

Kim, I., and D. S. Yeoun. 1983. Effect of prostaglandin $\mathrm{F}_{2 \alpha}$ on Na-K-ATPase activity in luteal membranes. Biol. Reprod. 29:48-55.

Lamming, G. E., A. O. Darwash, and H. L. Back. 1989. Corpus luteum function in dairy cows and embryo mortality. J. Reprod. Fertil. Suppl. 37:245-252.

Lamming, G. E., and G. E. Mann. 1995. Control of endometrial oxytocin receptors and prostaglandin $\mathrm{F}_{2 \alpha}$ production in cows by progesterone and oestradiol. J. Reprod. Fertil. 103:69-73.

Lee, J., S. W. Kim, T. K. Jung, Y. Oh, C. S. Park, S. K. Ma, N. H. Kim, and K. C. Choi. 2004. Indomethacin decreases particulate guanylyl cyclase activity in the rat kidney. Clin. Exp. Pharmacol. Physiol. 31:207-211.

Lemaster, J. W., R. C. Seals, F. M. Hopkins, and F. N. Schrick. 1999. Effects of administration of oxytocin on embryonic survival in progestogen supplemented cattle. Prostaglandins 57:259-268. 
Lewis, G. S., D. W. Caldwell, C. E. Rexroad, H. H. Dowlen, and J. R. Owen. 1990. Effects of gonadotropin-releasing hormone and human chorionic gonadotropin on pregnancy rates in dairy cattle. J. Dairy Sci. 73:66-72.

Lopes, R. F. F., P. Forell, A. T. D. Oliveira, and J. L. Rodrigues. 2001. Splitting and biopsy for bovine embryo sexing under field conditions. Theriogenology 56:13831392.

Lopez-Gatius, F., J. Labernia, P. Santolaria, M. Lopez-Bejar, and J. Rutllant. 1996. Effect of reproductive disorders previous to conception on pregnancy attrition in dairy cows. Theriogenology 46:643-648.

Macmillan, K. L., and A. J. Peterson. 1993. A new intravaginal progesterone releasing device for cattle (CIDR-B) for oestrous synchronisation, increasing pregnancy rates, and the treatment of post-partum anoestrous. Anim. Reprod. Sci. 33:1-25.

MacPhee, D. J., D. H. Jones, K. J. Barr, D. H. Betts, A. J. Watson, and G. M. Kidder. 2000. Differential involvement of $\mathrm{Na}^{+}, \mathrm{K}^{+}$, -ATPase isozymes in preimplantation development of the mouse. Dev. Biol. 222:486-498.

Mann, G. E., G. E. Lamming, R. S. Robinson, and D. C. Wathes. 1999. The regulation of interferon tau production and uterine receptors during early pregnancy. J. Reprod. Fertil. (Suppl.) 54:317-328.

Mattos, R., A. Guzelogu, and W. W. Thatcher. 2001. Effect of polyunsaturated fatty acids $\mathrm{n}$ secretion of $\mathrm{PGF}_{2 \alpha}$ from bovine endometrial (BEND) cells stimulated with phorbol 12 13, dibutyrate (Pbdu). Theriogenology 55:326 (Abstr.)

Mattos, R., C. R. Staples, J. Williams, A. Amorocho, M. A. McGuire, and W. W. Thatcher. 2002. Uterine, ovarian, and production responses of lactating dairy cows to increasing dietary concentrations of Menhaden fish meal. J. Dairy Sci. 85:755-764.

Maurer, P. R., and H. M. Beier. 1976. Uterine proteins and development in vitro of rabbit preimplantation embryos. J. Reprod. Fertil. 48:33-41.

McCracken, J. A., D. T. Baird, and J. R. Goding. 1971. Factors affecting the secretion of steroids from the transplanted ovary in the sheep. rec. Prog. Horm. Res. 27:537582.

McCracken, J. A., B. Barcikowski, J. C. Carlson, K. Green, and B. Samuelsson. 1973. The physiological role of prostaglandin $\mathrm{F}_{2 \alpha}$ in corpus luteum regression. Adv. Biosci. 9:599-624. 
McCracken, J. A., J. C. Carlson, M. E. Glew, J. R. Goding, D. T. Baird, K. Green, and B. Samuelsson. 1972. Prostaglandin $\mathrm{F}_{2 \alpha}$ identified as a luteolytic hormone in sheep. Nature New Biol. 238:129-134.

McCracken, J. A., E. E. Custer, and J. C. Lamsa. 1999. Luteolysis: A neuroendocrinemediated event. Physiol. Rev. 79:263-323.

Mihm, M., A. Baguisi, M. P. Boland, and J. F. Roche. 1994. Association between the duration of dominance of the ovulatory follicle and pregnancy rate in beef heifers. J. Reprod. Fertil. 102:123-130.

Mihm, M., N. Curran, P. Hyttel, P. G. Knight, M. P. Boland, and J. F. Roche. 1999. Effect of dominant follicle persistence on follicular fluid oestradiol and inhibin and on oocyte maturation in heifers. J. Reprod. Fertil. 116:293-304.

Niswender, G. D., J. L. Juengel, P. J. Silva, M. K. Rollyson, and E. W. McIntush. 2000. Mechanisms controlling the function and life span of the corpus luteum. Physiol. Rev. 80:1-29.

Nutrient Requirements for Beef Cattle, $7^{\text {th }}$ Ed. 2000. National Academies Press. Washington, D. C.

Odensvik, K., M. Duchens, and H. Gustafsson. 1993. Does mechanical manipulation of the reproductive organs cause a prostaglandin release in the heifer during embryo transfer? Acta vet. scand. 34:219-221.

Odensvik, K. and G. Fredriksson. 1993. The effect of intensive flunixin treatment during the postpartum period in the bovine. Zentralbl. Veterinarmed A. 40:561568 .

Odensvik, K. Gustafsson, H., and H. Kindahl. 1998 The effect on luteolysis by intensive oral administration of flunixin granules in heifers. Anim. Reprod. Sci. 50: $35-44$.

Oldick, B. S., C. R. Staples, W. W. Thatcher, and P. Gyawu. 1997. Abomasal infusions of glucose and fat effect on digestion, production, and ovarian and uterine functions of cows. J. Dairy Sci. 80:1315-1328.

Ozil, J. P. 1983. Production of identical twins by bisection of blastocysts in the cow. J. Reprod. Fertil. 69:463-468.

Randel, R. D. 1990. Nutrition and postpartum rebreeding in cattle. J. Anim. Sci. 68:853862.

Revah, I., and W. R. Butler. 1996. Prolonged dominance of follicles and reduced viability of bovine oocytes. Reprod. Fertil. 106:39-47. 
Rathbone, M. J., C. R. Bunt, C. R. Ogle, S. Burggraaf, K. L. Macmillan, C. R. Burke, and K. L. Pickering. 2002. Reengineering of a commercially available bovine intravaginal insert (CIDR insert) containing progesterone. J. Contr. Rel. 85:105115.

Rhodes, F. M., S. McDougall, C. R. Burke, G. A. Verkerk, and K. L. Macmillan. 2003. Invited review: Treatment of cows with an extended postpartum anestrous interval. J. Dairy Sci. 86:1876-1894.

Robinson, N. A., K. E. Leslie, and J. S. Walton. 1989. Effect of treatment with progesterone on pregnancy rate and plasma concentrations of progesterone in Holstein cows. J. Dairy Sci. 72:202-207.

Santos, J. E. P., W. W. Thatcher, L. Pool, and M. W. Overton. 2001. Effect of human chorionic gonadotropin on luteal function and reproductive performance of high producing lactating Holstein dairy cows. J. Anim. Sci. 79:2881-2894.

Savio, J. D., W. W. Thatcher, L. Badinga, R. L. de la Sota, and D. Wolfenson. 1993a. Regulation of dominant follicle turnover during the oestrous cycle in cows. J. Reprod. Fertil. 97:197-203.

Savio, J. D., W. W. Thatcher, G. R. Morris, K. Entwistle, M. Drost, and M. R. Mattiacci. 1993b. Effects of induction of low plasma progesterone concentrations with a progesterone-releasing intravaginal device on follicular turnover and fertility in cattle. J. Reprod. Fertil. 98:77-84.

Schallenberger, E., D. Schams, and H. H. D. Meyer. 1989. Sequences of pituitary, ovarian, and uterine hormone secretion during the first 5 weeks of pregnancy in dairy cattle. J. Reprod. Fertil. (Suppl.) 37:277-286.

Schrick, F. N., M. E. Hockett, T. M. Towns, A. M. Saxton, N.E. Wert, and M. E. Wehrman. 2001. Administration of a prostaglandin inhibitor immediately prior to embryo transfer improves pregnancy rates in cattle. Theriogenology (Suppl.) 55: 370.

Schrick, F. N., M. E. Hockett, S. C. Wilkinson, N. R. Rohrbach, J. L. Edwards, and M. E. Wehrman. 1999. Prostaglandin $F_{2 \alpha}$ appears to directly influence early embryonic survival in cattle: Should this be a concern? Pages 10-21 in Proc. of AETA Annu. Conv. Colorado Springs, CO.

Schrick, F. N., F. N. Scenna, J. L. Edwards, M. E. Hockett, and A. M. Saxton. 2003. More evidence for a direct interaction between prostaglandin $\mathrm{F}_{2 \alpha}$ and development of bovine embryos. Pages 43-52 in Proc. of CETA and AETA Joint Annu. Conv. Calgary, Alberta. 
Seals, R. C. 2000. Prostaglandins modulate the uterine response to infectious bacteria in postpartum and estrous cyclic ewes. Ph.D. Diss., Virginia Tech, Blacksburg.

Seals, R. C., J. W. Lemaster, F. M. Hopkins, and F. N. Schrick. 1998. Effects of elevated concentrations of prostaglandin $\mathrm{F}_{2 \alpha}$ on pregnancy rates in progestogen supplemented cattle. Prostaglandins 56:377-389.

Seidel, G. E., Jr. 1986. Principles of cryopreservation of mammalian embryos. Pages 612 in Techniques For Freeezing Mammalian Embryos: 1986 Short Course Proc. Fort Collins, CO.

Senger, P. L. 1999. Pathways to Pregnancy and Parturition. $1^{\text {st }}$ revised ed. Mack Printing Group-Sciences Press, Ephrata, PA.

Sirois, J., and J. E. Fortune. 1990. Lengthening the bovine estrous cycle with low levels of exogenous progesterone: A model for studying ovarian follicular dominance. Endocrinology 127:916-924.

Smith, A. K., P. J. Broadbent, D. F. Dolman, S. P. Grimmer, D. A. Davies, and H. Dobson. 1996. Norgestomet implants, plasma progesterone concentrations, and embryo transfer pregnancy rates in cattle. Vet. Rec. 139:187-191.

Smith, W. L., D. L. DeWitt, and R. Garavito. 2000. Cyclooxygenases: Structural, cellular, and molecular biology. Annu. Rev. Biochem. 69:145-182.

Spell, A. R., W. E. Beal, L. R. Corah, and G. G. Lamb. 2001. Evaluating recipient and embryo factors that affect pregnancy rates of embryo transfer in beef cattle. Theriogenology 56:287-297.

Spencer, T. E., and F. W. Bazer. 2002. Biology of progesterone action during pregnancy recognition and maintenance of pregnancy. Front Biosci. 7:1879-1898.

Spitzer, J. C., D. G. Morrison, R. P. Wettemann, and L. C. Faulkner. 1995. Reproductive responses and calf birth and weaning weights as affected by body condition at parturition and postpartum weight gain in primiparous cows. J. Anim. Sci. 73:1251-1257.

Sreenan, J. M., and M. G. Diskin. 1983. Early embryonic mortality in the cow: its relationship with progesterone concentration. Vet. Rec. 112:517-521.

Steel, R. G. D., and J. H. Torrie. 1960. Principles and Procedures of Statistics. McGrawHill, New York, NY.

Stevenson, J. S., S. K. Johnson, M. A. Medina-Britos, A. M. Richardson-Adams, and G. C. Lamb. 2003. Resynchronization of estrus in cattle of unknown pregnancy status using estrogen, pregesterone, or both. J. Anim. Sci. 81:1681-1692. 
Stevenson, J. S., and M. O. Mee. 1991. Pregnancy rates of Holstein cows after postinsemination treatment with a progesterone-releasing intravaginal device. J. Dairy Sci. 74:3849-3856.

Thatcher, W. W., M. Binelli, J. Burke, C. R. Staples, J. D. Ambrose, and S. Coelho. 1997. Antiluteolytic signals between the conceptus and endometrium. Theriogenology 47:131-140.

Thatcher, W. W., A. Guzeloglu, R. Mattos, M. Binelli, T. R. Hansen, and J. K. Pru. 2001a. Uterine-conceptus interactions and reproductive failure in cattle. Theriogenology 56:1435-1450.

Thatcher, W. W., F. Moreira, J. E. P. Santos, R. C. Mattos, F. L. Lopes, S. M. Pancarci, and C. A. Risco. 2001b. Effects of hormonal treatments on reproductive performance and embryo production. Theriogenology 55:75-89.

Thatcher, W. W., C. R. Staples, G. Danet-Desnoyers, B. Oldick, and E. P. Schmitt. 1994. Embryo health and mortality in sheep and cattle. J. Anim. Sci. 72:16-30.

Van Cleeff, J., K. L. Macmillan, M. Drost, M. C. Lucy, and W. W. Thatcher. 1996. Effects of administering progesterone at selected intervals after insemination of synchronized heifers on pregnancy rates and resynchronization of returns to service. Theriogenology 46:1117-1130.

Vane, J. R., and R. M. Botting. 1998. Mechanism of action of nonsteroidal antiinflammatory drugs. Am. J. Med. 104(3A):2S-8S.

Vanroose, G., A. de Kruif, and A. Van Soom. 2000. Embryonic mortality and embryopathogen interactions. Anim. Reprod. Sci. 60-61:131-143.

Yavas, Y. and J. S. Walton. 2000. Postpartum acyclicity in suckled beef cows: A review. Theriogenology 54:25-55.

Walton, J. S., G. W. Halbert, N. A. Robinson, and K. E. Leslie. 1990. Effects of progesterone and human chorionic gonadotropin administration five days postinsemination on plasma and milk concentrations of progesterone and pregnancy rates of normal and repeat breeder dairy cows. Can. J. Vet. Res. 54:305-308.

Warfield, S. J., G. E. Seidel, Jr., and R. P. Elsden. 1987. Transfer of bovine demi embryos with and without the zona pellucida. J. Anim. Sci. 65:756-761.

Wann, R. A., and R. D. Randel. 1990. Effect of uterine manipulation 35 days after parturition on plasma concentrations of 13, 14-dihydro-15-keto prostaglandin $\mathrm{F}_{2 \alpha}$ in multiparous and primiparous Brahman cows. J. Anim. Sci. 68:1389-1394. 
Willet, E. L., W. G. Black, L. E. Casida, W. H. Stone, and P. J. Buckner. 1951. Successful transplantation of a fertilized bovine ovum. Science 113:247.

Wilmut, I. and L. E. A. Rowson. 1973. Experiments on the low-temperature preservation of cow embryos. Vet. Rec. 92:686-690.

Wright, F. M. 1981. Non-surgical embryo transfer in cattle: embryo-recipient interactions. Theriogenology 15:43-56.

Zavy, M.T., and R.D. Geisert. 1994. Embryonic Mortality in Domestic Species. CRC Press, Boca Raton, FL. 


\section{Appendices}

Appendix A. Main effects and interactions removed during the backward elimination process in the analysis of pregnancy rate following the initial ET.

\begin{tabular}{|c|c|c|c|c|}
\hline Step & Effect Removed & DF & Wald Chi-Square & Pr $>$ Chi-Square \\
\hline 1 & Stage x CIDR & 1 & 0.0663 & 0.7969 \\
2 & CIDR x FM & 1 & 0.1459 & 0.7025 \\
3 & Synchrony & 5 & 3.9518 & 0.6832 \\
4 & Grade x FM & 1 & 0.3232 & 0.5697 \\
5 & Breed (Location) & 2 & 1.5023 & 0.4718 \\
6 & CL quality & 1 & 1.0443 & 0.3068 \\
7 & Grade x CIDR & 1 & 1.1677 & 0.2799 \\
8 & Stage x FM & 1 & 1.5801 & 0.2087 \\
9 & Stage & 1 & 0.0158 & 0.9000 \\
10 & Location x CIDR & 2 & 3.6657 & 0.1600 \\
11 & Parity (Location) & 1 & 2.3936 & 0.1218 \\
\hline
\end{tabular}

Appendix B. Main effects and interactions removed during the backward elimination process in the analysis of pregnancy rates following the transfer of split embryos at Location 2.

\begin{tabular}{|c|c|c|c|c|}
\hline Step & Effect Removed & DF & Wald Chi-Square & Pr > Chi-Square \\
\hline 1 & Grade x FM & 1 & 0.0082 & 0.9279 \\
2 & Synchrony & 5 & 2.7079 & 0.7449 \\
3 & Stage x CIDR & 1 & 0.2166 & 0.6417 \\
4 & Parity x CIDR & 1 & 0.4971 & 0.4808 \\
5 & Parity x FM & 1 & 0.5097 & 0.4753 \\
6 & CL quality & 1 & 0.7576 & 0.3841 \\
7 & Grade x CIDR & 1 & 0.7668 & 0.3812 \\
8 & Grade & 1 & 0.2079 & 0.6484 \\
9 & Stage x FM & 1 & 1.7501 & 0.1859 \\
\hline
\end{tabular}




\section{Vita}

Scott Hudson Purcell, son of John and Jacqueline Purcell was born April 2, 1980 in Richmond, VA. He graduated from Midlothian High School in May of 1998. Scott began his Freshman year at Virginia Tech in August of 1998, majoring in Animal and Poultry Sciences. The Spring semester of his Sophomore year Scott left Virginia Tech to study abroad at the University of the Orange Free State in Bloemfontein, South Africa. He returned to Virginia Tech the Spring of 2001.

In the Fall of 2002 he began his graduate work in Physiology of Reproduction under the direction of Dr. Bill Beal in the Animal and Poultry Sciences department at Virginia Tech. Scott was awarded a Graduate Teaching Assistantship during his two years of graduate study. He is an active member of the American Society of Animal Science. In the Fall of 2004 he plans to continue his studies and pursue a Ph.D. in Physiology of Reproduction under the direction of Dr. G. E. Seidel, Jr. at Colorado State University. 